University of Louisville

ThinkIR: The University of Louisville's Institutional Repository

Electronic Theses and Dissertations

$8-2020$

\title{
The sidewalk less traveled: evaluating change in community and police perception.
}

Jennifer Lee Hall

University of Louisville

Follow this and additional works at: https://ir.library.louisville.edu/etd

Part of the Criminology Commons

\section{Recommended Citation}

Hall, Jennifer Lee, "The sidewalk less traveled: evaluating change in community and police perception." (2020). Electronic Theses and Dissertations. Paper 3522.

https://doi.org/10.18297/etd/3522

This Doctoral Dissertation is brought to you for free and open access by ThinkIR: The University of Louisville's Institutional Repository. It has been accepted for inclusion in Electronic Theses and Dissertations by an authorized administrator of ThinkIR: The University of Louisville's Institutional Repository. This title appears here courtesy of the author, who has retained all other copyrights. For more information, please contact thinkir@louisville.edu. 
THE SIDEWALK LESS TRAVELED:

\title{
EVALUATING CHANGE IN COMMUNITY AND POLICE PERCEPTION
}

\author{
By \\ Jennifer Lee Hall \\ M.A., University of Louisville, 2015 \\ B.S., Eastern Kentucky University, 2005

\begin{abstract}
A Dissertation
Submitted to the Faculty of

College of Arts and Sciences of the University of Louisville

In Partial Fulfillment of the Requirements

For the Degree of
\end{abstract} \\ Doctor of Philosophy \\ in Applied Sociology \\ Department of Sociology \\ University of Louisville
}

August 2020 
(C) Copyright 2020 by Jennifer Lee Hall

All rights reserved 

THE SIDEWALK LAST TRAVELED:

EVALUATING CHANGE IN COMMUNITY AND POLICE PERCEPTION

\author{
By \\ Jennifer Lee Hall \\ M.A., University of Louisville, 2015 \\ B.S., Eastern Kentucky University, 2005
}

A Dissertation Approved on

August 5, 2020

by the following Dissertation Committee:

Lauren Heberle, PhD, Dissertation Committee Chair

Mark Austin, PhD, Committee Member

Ryan Schroeder, PhD, Committee Member

Benjamin Fisher, PhD, Committee Member

James Itschner, MS, Committee Member 


\section{DEDICATION}

This dissertation is dedicated to my father, Brian Lee, who even in death is a continuous motivator, encourager, and dream builder.

"The place to improve the world is first in one's own heart and head and hands, and then work outward from there."

-Robert M. Pirsig 


\section{ACKNOWLEDGEMENTS}

I want to start by thanking Dr. Lauren Heberle for her support, patience, and confidence in me, not only during this project, but throughout my entire graduate school experience. Taking on a subject outside your area of expertise, learning the material with me, and consistently providing direction and input was extremely appreciated and did not go unnoticed.

To my husband, Dave Hall, your patience with late night study sessions and scheduling conflicts has been amazing. The stress this brought into our home was tremendous, but you took it in stride. You made sure that the family still operated normally and our home didn’t implode! Thank you for loving me unconditionally and offering continuous support, encouragement, and advice. You make me a better person. I can always count on you to make me "take a knee and drink water."

To my children, thanks for supporting me and loving me, even when I wasn't being the most fun and patient mom. I hope that one day you have the opportunity and desire to follow all the wild goals you set for yourself. I also pray that you have a support system as good as mine, pushing you to the finish line.

To my entire family, thank you for your love, support, and the occasional sassiness. You give me the courage to try new adventures.

Thanks to all my coworkers that were my "whiteboard" for all the crazy and constant ideas surrounding this study. Especially, Sergeant John Bradley, who trusted me 
with this project and offered up direction, advice, ideas, and encouragement throughout this dissertation, but also throughout my career. Thank you for your mentoring and friendship.

I want to thank my cohorts Jessica Newton and Adam Sizemore. Adam, thanks for the FaceTime, text, and email help. You were always available for all of my questions and nervous rants. I appreciate your advice, support, and friendship. Jessica, you are the person that convinced me to start the PhD program. Saying I would not be here without you is the absolute truth. Many late nights, procrastination, deaths, births, laughter, and tears followed that agreement I made with you. Thank you for getting me through the last push and convincing me to sign up for this mixture of torture and enjoyment. 


\section{ABSTRACT \\ THE SIDEWALK LESS TRAVELED: EVALUATING CHANGE IN COMMUNITY AND POLICE PERCEPTION}

Jennifer Lee Hall

July 13, 2020

For a police department to provide efficient and effective services to the community, they must obtain the support of the public, continuously cultivating and maintaining positive perceptions from the citizens being served. Various methods, such as walking patrols, have been implemented to increase public support and trust in police, which, in turn, contributes to a cooperative relationship between community and law enforcement. When opinions of law enforcement are precarious or police departments fall out of favor with the surrounding community, police officers can feel isolated if their work is unsupported. This often leads to the development of a strong bond or police culture between law enforcement officers based on shared experiences, attitudes, and interactions with others. The symbiotic relationship between police and the public is at the core of community policing, which has the aim of reforming cultural norms and decision-making practices within law enforcement. While a substantial amount of literature exists on both the relationship between public perception of law enforcement and community relations as well as police culture, there is limited research on the intersection of these areas. 
This case study examines the efficacy of the Louisville Metro Police Department (LMPD) walking patrol initiative in Louisville, Kentucky, which was piloted between April and September 2019. The LMPD walking patrol initiative focuses on the interconnectivity between public perception of law enforcement and the police perception of public opinion as well as how this affects community policing efforts. It sought to increase police visibility, informal contacts between police and community members, and overall communications with the public. The desired outcomes were to improve perception of crime, produce better trained officers, and grow citizen satisfaction with the overall goal of improved community relations. This research is important for assisting the LMPD in evaluating this initiative, determining whether or not the effort and manpower should be continued, and how it impacted community relationships.

To adequately address the complexities of this topic, this research employed a mixed methods approach, utilizing both quantitative and qualitative methods to address several hypotheses. A survey was distributed, and the data were analyzed using ordinal logistic regression, multinomial linear regression, and negative binomial regression. Qualitative methods included participant observation, focus groups, and semi-structured interviews and the data were analyzed using Dedoose coding software. This research hypothesized the following: perceptions of the police, personal safety, and crime will improve for community members within the walking patrol area; foot patrol officers will have a more positive perception of community opinions of law enforcement than vehicle patrol officers; and police officers with more informal law enforcement interactions will have higher job satisfaction. As data were analyzed, unexpected yet important themes 
related to police culture emerged. Using a grounded theoretical approach, information related to this topic were incorporated into the results and contributions of this research.

Although the LMPD walking patrol initiative did not have a significant change on crime rates in the area, it did have significant findings in relation to community members' perception of crime and disorder, fear of crime, and police legitimacy. It was found to have positive effects on community members' perception of police characteristics and activities. The walking patrol officers were found to have a more positive perception of public opinion and an increased level of community engagement. This research also found the walking patrol officers lacked a connection to the current police culture, which is critical information for departments seeking ways to redevelop social learning in law enforcement. Although a walking patrol is not the singular response to establish cooperative community relations between law enforcement and citizens or improve police cultural norms, this research shows it can influence community engagement, increase legitimacy, decrease the fear of crime, and impact police culture. This case study provided significant contributions to the literature, specifically on community policing and patrol techniques, and has provided valuable information regarding training, communication, and officer and community perceptions. 
TABLE OF CONTENTS

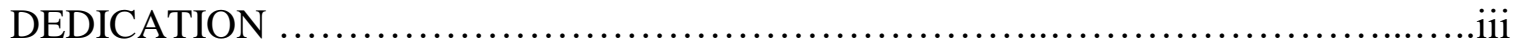

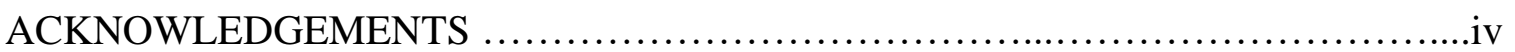

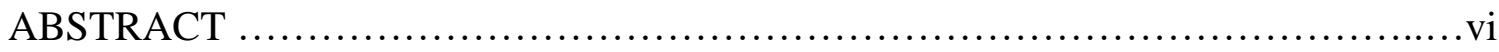

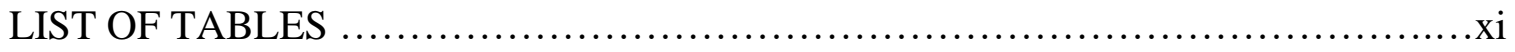

LIST OF FIGURES................................................................

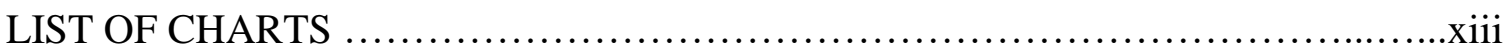

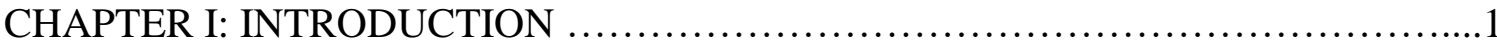

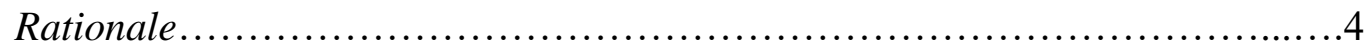

Research Aims .........................................................

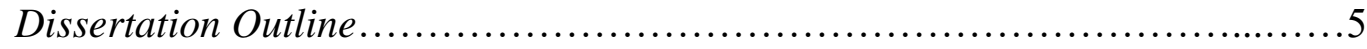

CHAPTER II: LITERATURE REVIEW/THEORETICAL FRAMEWORK ....................7

Community Policing ...................................................... 8

Walking Patrol......................................................... 15

Perception-Community and Policing.........................................21

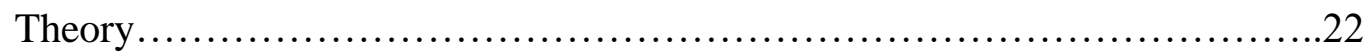

Rational Choice/Routine Activities...........................................23

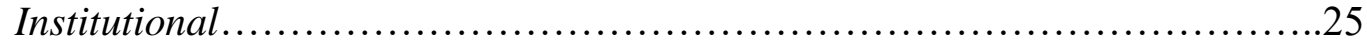

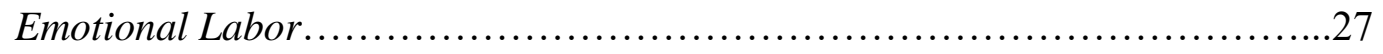

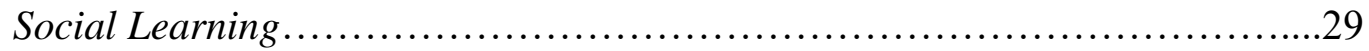

Perception ................................................................ 33

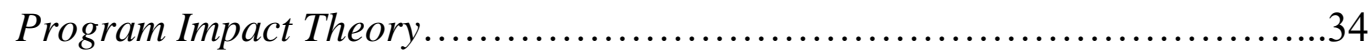

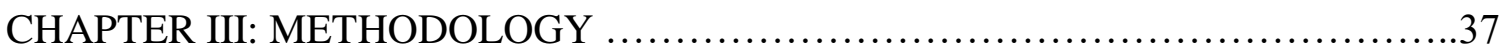

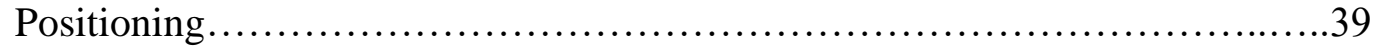

Program Design ................................................................ 40

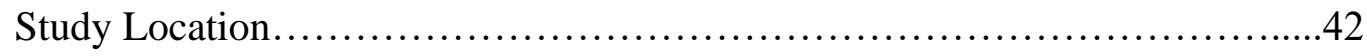

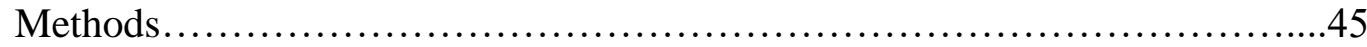

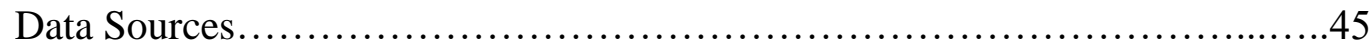


Participant Observation.............................................................

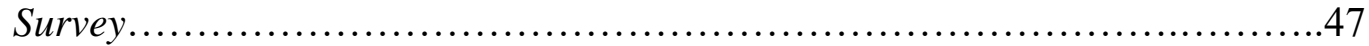

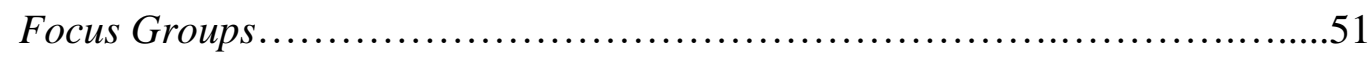

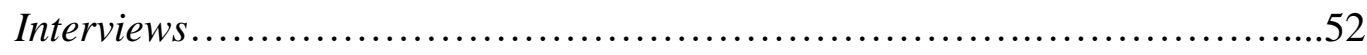

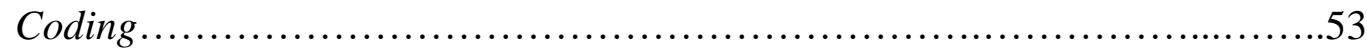

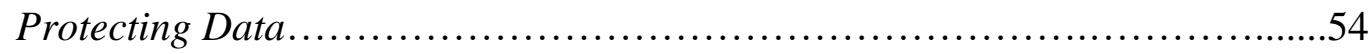

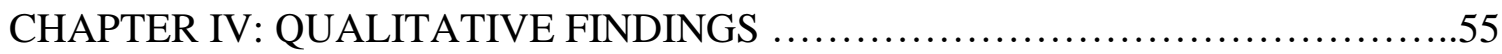

Participant Observations.................................................55

Interviews and Focus Groups...........................................67

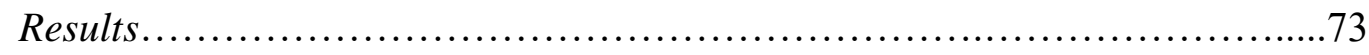

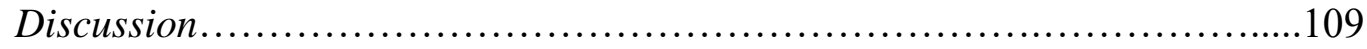

Methodological Strengths and Weaknesses................................115

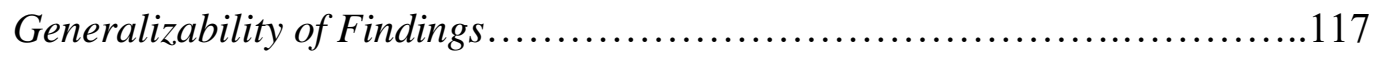

CHAPTER V: QUANTITATIVE FINDINGS …............................. 118

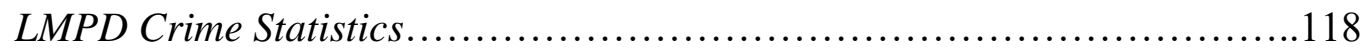

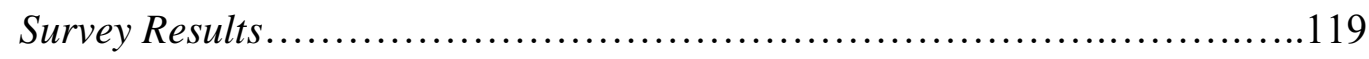

Perception of Crime ........................................................120

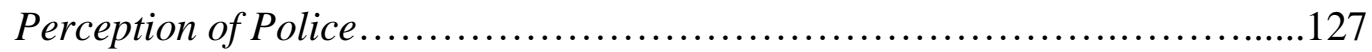

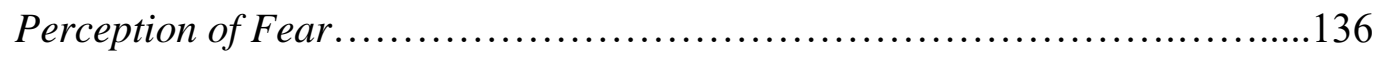

Crime Statistics....................................................... 141

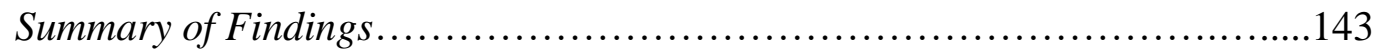

CHAPTER IV: DISCUSSION AND CONCLUSION ...............................146

Future Research ....................................................... 153

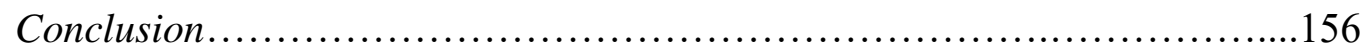

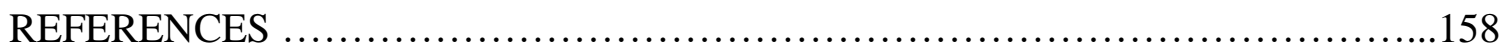

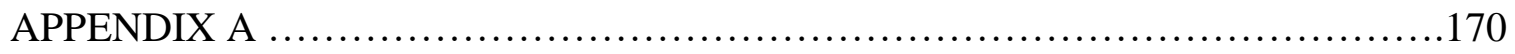

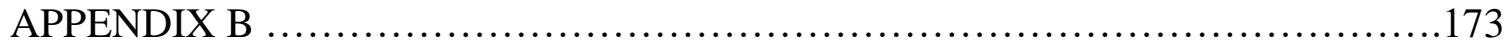

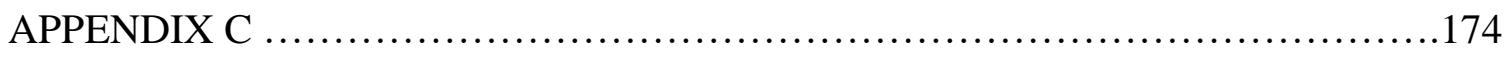

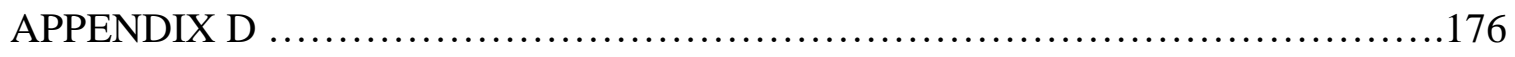

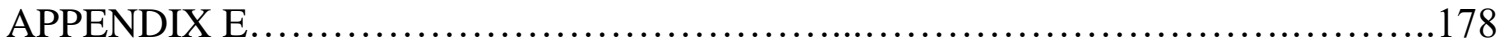

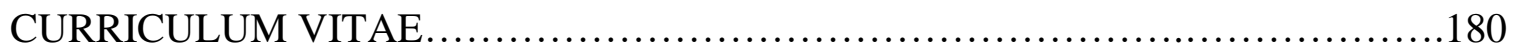




\section{LIST OF TABLES}

\section{TABLE}

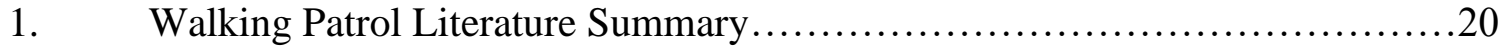

2. CSPS Survey Outreach.............................................50

3. Demographic Information of LMPD Study Participant.......................69

4. Louisville Metro 2015-2019 Crime Rates....................................118

5. Variable List for Perception of Crime.................................. 121

6. Pearson's Chi-Square Goodness of Fit Test Results........................123

7. Pseudo-R2 Variables for the Dependent Variables...........................124

8. Perception of Crime Model Parameters..................................125

9. Variable List for Perception of Police Characteristics........................128

10. Variable List for Perception of Police Activity.............................129

11. Perception of Police Characteristics Correlation Matrix ........................131

12. Perception of Police Activity Correlation Matrix..........................131

13. Linear Regression Coefficients for Perception of Police Characteristics.........132

14. Linear Regression Coefficients for Perception of Police Activity..............133

15. Descriptive Statistics for Independent Variables ............................134

16. Logistic Regression for Perception of Police Characteristics.................135

17. Logistic Regression for Perception of Police Activity......................136

18. Variable List for Perception of Police Characteristics......................138

19. Fear of Crime Correlation Matrix ..................................... 139

20. Linear Regression Coefficients for Fear of Crime.........................140

21. Multiple Linear Regression Results for Fear of Crime Variable...............141 


\section{LIST OF FIGURES}

\section{FIGURE}

1. Cycle of Officer Perception............................................... 13

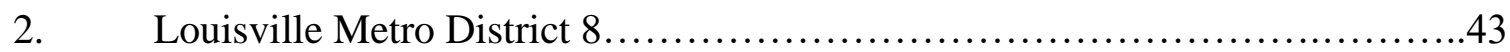

3. LMPD Fifth Division ..............................................43

4. Walking Patrol Initiative Area and Displacement Boundaries...................44

5. Residential Zones for CSPS..........................................49

6. Qualitative Data Category Classification ..................................110 


\section{LIST OF CHARTS}

\section{CHART}

1. Program Impact Theory Model......................................... 35

2. Crime Statistics Pre and Post Walking Patrol Initiative.......................142 


\section{CHAPTER I: \\ INTRODUCTION}

For a police department to provide efficient and effective services to the community, they must obtain the support of the public. To be considered a legitimate and professional agency, law enforcement must continuously cultivate and maintain positive perceptions from the citizens being served. Carter (2002) explained the vital nexus between police and public perception and discussed the ideal of "policing by consent," meaning that police cannot achieve their goals and objectives unless they have the public's support and full cooperation. Law enforcement agencies introduced community policing efforts to highlight the need to examine the link between public support and opinions of the police concerning the outcome of a department's efforts in maintaining order, legitimacy, and cooperation. Substantial empirical evidence shows the importance of legitimacy in securing law-abiding behavior and cooperation from citizens (Tankebe 2013).

When considering how to conceptualize the dimensions of legitimacy in police work, Bottoms and Tankebe (2012) relies on the work of Beetham (1991), who outlined effectiveness, distributive fairness, procedural fairness, and lawfulness as the main components. Their findings suggest that these components that are typically used as predictors of legitimacy are instead essential parts and carry different levels of importance based on the respondent's values, experiences, and demographics. There are many recommendations available to communities and police departments on ways to 
increase legitimacy and public support, with most attempting to achieve at least one of the components. Research shows that there is no simple solution, but Maguire, et al. (2016) confirms that interactions between the police and the public is foundational to community relations and simply put, "how police officers talk to people matters" (367). Their results showed that the role of police in gaining trust, improving legal compliance, and increasing cooperation depended upon the encounters with citizens in the community. When police officers do their work fairly, respectfully, and make decisions free from bias, the community is more trusting of those law enforcement officials. In turn, the citizen becomes more compliant during future interactions and become more willing to assist police during their duties (Maguire, et al. 2016: 368).

Although gaining legitimacy and a positive perception for the police department seems direct and straight forward, there are other variables at play. Police departments are organizational structures with deep-rooted culture embedded in them at every level and most changes are criticized and cause tension from personnel. Departmental expectations, internal and external operations, and social norms are factors that impact legitimacy and community relations. In addition to public perception of law enforcement and legitimacy, another factor is police officer's perception of their occupation, their role in the community, and the community they serve.

Police officers often view the public as resistant to their efforts and unsupportive of their work, spending most of their careers believing that they are perceived less favorably by the public (Smith 1979; Yim and Schafer 2009). This tends to isolate police socially from those outside of their department and simultaneously builds a social bond between coworkers. A culture among the officers forms through the shared interactions, 
experiences and attitudes occurring during their law enforcement career. The police culture is strengthened and shared with the next generation of officers and continues cyclically.

The police culture and public perception can influence an officer's attitude, the way they perform their duties, interact with the public, and how they perceive their job. Policing programs and methods intend to generate change within a police organization to enhance and promote community relations need systematic, ongoing evaluation. Examining the relationship between public perceptions of law enforcement and police officers' perceptions of public opinion reveals a complex and contingent relationship. This case study adds to our knowledge of perceptions held by both groups and begins to deconstruct police culture and improve communication between police and the public they serve.

There are large bodies of literature that have looked at the public's perception of law enforcement and how that affects community relations. Police culture is another area that has significant amounts of research available. It is the intersection between the two that need further examination. The symbiotic relationship between police and community is at the core of community policing. Therefore, deconstructing its elements will fill a gap in the literature and better inform those programs and/or policies intended to improve policing efforts by including community policing into their organizational practices.

In review, the main issues that law enforcement agencies and communities find are that police cannot achieve their goals unless they have the support and cooperation of the community they serve. This is a complex problem, because several variables factor into this legitimation needed by law enforcement officers. Second, police often feel 
resistance from the public, perceiving that they are not favored by their community. This perception is problematic in any efforts to build rapport and trust because officers are now isolating themselves within their organization. Lastly, community policing efforts do not always focus on changing community and police perceptions. Although the initiative may successfully decrease crime or decrease police response time, the focus of the work is not focused on building police and community relations.

\section{Rationale}

This dissertation examines the interconnectivity between public perception of law enforcement and police perception of the public's opinion and how that affects community policing efforts. A walking patrol has the potential to increase visibility, improve perception of crime, and enhance communication with the public. It can also change the officer's perception of policing, improve their communication skills, and enhance their problem-solving skills. These are all variables that can affect the success of a community policing program. The research evaluates the efficacy of the LMPD walking patrol initiative in Louisville, Kentucky.

Specifically, this study assesses if the goals of the pilot program introduced between the dates of April 15, 2019, and September 8, 2019, were met and what, if any, adjustments should be made. I used a multi-method research approach to evaluate the walking patrol through qualitative and quantitative techniques. This included participant observation, focus groups, interviews, a community survey, and local crime statistics. The methodologies used informed future strategies when working with law enforcement officers and contributed details regarding participant recruitment. Although the research provides information regarding a specific program with LMPD, the results can be 
generalizable to other departments and communities and enhance the literature regarding community perceptions and police perceptions. It expands the literature surrounding community policing, police and community perceptions, and specific walking patrol parameters. The results also contribute to the theoretical frameworks used to inform this case study, specifically looking at police practice, police culture, and the process of learned police behavior. The research results summarize recommendations for the walking patrol initiative and provide future recommendations and research possibilities.

\section{Research Aims}

More importantly, in relation to this case study are the overall hypotheses that the research addressed directly throughout the data collection, analysis, and interpretation of the results. Although the research did produce additional frameworks through a grounded theoretical approach, the following are what shaped the research project.

1. Perception of the police, personal safety, and crime will improve for community members within the walking patrol area.

2. Foot patrol officers will have a more positive perception of community opinions of law enforcement than vehicle patrol officers.

3. Police officers with more informal law enforcement interactions will have higher job satisfaction.

\section{Dissertation Outline}

Following the introduction, this dissertation contains five additional chapters, including the literature review and theoretical framework, methodology, qualitative findings, quantitative findings, and discussion and conclusion. Chapter 2 introduces three 
main literature topics in relation to the case study. First, community policing is defined and the research difficulties surrounding the topic are introduced. Then the literature is narrowed to foot patrol and discusses the effects of this patrol technique in other law enforcement agencies. There is also a brief introduction to the topic of perception and how police interactions with the community can determine future contacts. Also, several theoretical frameworks are introduced, including rational choice and routine activities theories, institutional theory, social learning theory, and emotional labor theory. Chapter 3 describes the methods used to complete the research. Chapter 4 introduces the findings from the qualitative work and discusses presenting themes. Discussed in Chapter 5 were the quantitative findings from the ordinal logistic, multinomial, and negative binomial regressions. Lastly, chapter 6 concludes the research by relating the results to the theoretical perspectives, addresses the gaps in and contributions to the literature, program recommendations, and ideas for future research. The dissertation concludes with references, appendices, and my curriculum vitae. 


\section{CHAPTER II: \\ LITERATURE REVIEW AND THEORETICAL FRAMEWORKS}

The literature that surrounds community policing, walking patrol, and perception is extensive and essential in ensuring identification of previous studies, their conflicts, gaps, and similarities. The knowledge gained through the critical evaluation of other research informed the case study and determined what results would be contributions, but also what would conflict with previous findings. It is important to consider all the literature and provide a comprehensive overview surrounding the topic of study to limit duplication and inconsistencies.

Community policing literature was abundant, but lacked in consistency when looking at the success or failure of specific programs. This was due to insufficient data, lack of pre-established goals, and the inability to measure the results. This is why it was important to have LMPD establish the direction and framework of the program prior to its introduction. A unidirectional framing for departmental goals was initially presented and guided the focus for this case study. It was critical to acknowledge what other departments and agencies had done in relation to specific community policing initiatives, focusing on walking patrol units.

This investigation led to information surrounding officers working on foot and how that affected crime, fear of crime, and the community's perception of law enforcement. There was a gap in the literature when investigating how patrolling on foot changed officer perception of the public and how they viewed the community perception 
of law enforcement. This case study informed that area of the literature and incorporated a focus on that during the qualitative work.

The literature surrounding community perception in relation to law enforcement officers is an important aspect of measurement within community policing efforts. The literature looks at informal and formal police contacts and how those interactions can impact future contact with community members. Previous research framed several questions used for the quantitative portion of this case study and provided contributions to the established literature.

\section{Community Policing}

The approach to contemporary policing changed drastically, with police agencies around the world focusing less on incident-driven policing, random vehicle patrol, and reactive response and investigations. Law enforcement personnel are now encouraged by their departments to create proactive partnerships with the community to develop problem-oriented policing and intelligence-led strategies to reduce crime and disorder. Community policing in the U.S. has become more common and receives federal government support through the Office of Community Oriented Policing Services (COPS Office). The history of its introduction is difficult to trace. Scholars have not identified a single person, agency, or organization to whom they can attribute its initiation into law enforcement (Gayadeen and Phillips 2014; Oliver 2000).

The 1960s and 1970s brought civil rights and anti-war protests, along with televised instances of police brutality, which caused widespread perceptions of law enforcement to lower or lose legitimacy and identified them as ineffectual or contributing to the large spikes in crime (Crank 2003). A bridge of communication between the 
community and the police was needed for police to and to regain and maintain legitimacy throughout the nation. The 1980s took a conservative swing, and crime-fighting along with order control was pushed by government agencies and accepted by the public, which again changed the community policing initiatives (Crank 1994). Political, economic, and cultural shifts trickled down to law enforcement efforts and consistently affected law enforcement efforts.

Along with the tracing of its history, community policing is also difficult to define. The characteristics are different within each policing agency. Community policing involves reforming cultural norms and decision-making practices within law enforcement. Therefore, it is not just a focused tactical plan and can look different in every city based on community input regarding prioritizing and addressing crime problems (Gill, et al. 2014; Skogan 1995). Trojanowicz, et al. (1998) explained that community policing is not something that solves a single problem and can be abandoned after achieving the goal. Gill et al. (2014:421) added that it should involve a long-term, multi-stage process. The COPS Office describes community-oriented policing (COP) as a philosophy consisting of three elements: community partnerships, organizational transformation, and problem-solving (Office of Community Oriented Policing Services 2012).

Many strategies have developed since the initiative for community-oriented approaches. Examples include neighborhood watch groups and partnerships between government agencies and community organizations. Transparency and communication between law enforcement and the public about crime statistics, departmental strategies, and investigations involving officers became more available (Watson, Stone, and DeLuca 
1998). New training techniques were implemented to assist new officers in adapting to the new approaches to policing and enhancing their problem-solving skills. With these skills, the officers participated in developing and implementing solutions for complex problems in the community they serve, thus, reducing crime, disorder, and fear (Goldstein 1990; Weisburd and Eck 2004). Law enforcement also assigned officers to specific areas within the community boundaries instead of the previous approach of rotating them on a regular basis. This shift ensured familiarity of an area and the specific patrol strategies that worked best to maintain order and safety in a defined location, or what is termed a patrol beat, and increased accountability to the community. Stemming from this initiative were new patrol techniques, including foot and bicycle patrol. Kelling (1996) discussed the frustration felt by minority citizens who saw police and their administration as an insulated organization unwilling to receive input and from their neighborhoods. The constant concern with the violation of human rights and the isolation of police in their patrol cars makes the attempts to create an outlet or bridge for communication an important and motivating factor for community policing (Trojanowicz 1998).

By focusing on community-based prevention, Skogan (2011) suggested that partnerships with the community have increased benefits to society and that alternatives to enforcement are becoming increasingly represented. In Weisburd and Eck's (2004) systematic review of research on police effectiveness, they found that the studies looking at community policing and their effects were weak and could not provide consistent evidence that these strategies decreased crime or disorder. They did find that fear of crime decreases when policing strategies involve direct contact between police and 
citizens, and when police gain legitimacy among the community members and offenders. There is also a reduction in the likelihood of delinquency (Tyler 1990; Weisburd and Eck 2004). Although Gill et al. (2014) found that there were limited effects on crime and fear of crime following community-oriented policing strategies. They did have positive impacts on citizen satisfaction, police legitimacy, and perception of disorder. After a review of evidence in relation to community policing initiatives, Skogan (1995) found mixed results. Implementation was the most difficult challenge that resulted in poor results; this included disbanding the efforts due to a rise in calls for service and changes in the command structure. The most consistent finding was the community's assessment of police officers improved even when local crime had not reduced. Similarly, Hauser and Kleck (2016) found no evidence that increasing arrest productivity increased community members' confidence in the police or decreased their fear of crime.

Co-production was introduced to policing practice in the late 1970s and acknowledges that citizens participate with police in establishing community security and safety, instead of their previous role as a bystander. For instance, community members facilitate police in identifying criminal activity by providing information and calling for service requests. The police maintain their role as the controlling agent, but citizens are complicit in the exchange of information and assistance (Friedman 1992). Determining the optimal level of citizen participation is a fundamental concern of a community. It could lead to undesirable outcomes with too much involvement, including intrusion of privacy and loss of trust among community members. Grabosky (1992) contends that coproduction among citizens should intrude as little as possible on the liberties of others and should enhance social cohesion, rather than community division (Brewer and 
Grabosky 2014). This idea of a beneficial partnership assumed that citizens are generally more knowledgeable about the activity occurring in the environments where they reside and work. Community members can fill information gaps where law enforcement officers may be lacking, specifically involving crime information that cannot be provided through existing intelligence sources.

The joint efforts between citizens and police officers can potentially increase safety and decrease crime, but regulating the level of citizen policing powers has proven to be a difficult task. For example, the well-known shooting of Trayvon Martin opened up the conversation surrounding co-production and the problems that could follow. The 17-year-old black male was walking through a Florida gated community while staying there with family when an altercation occurred between him and the neighborhood watch commander, George Zimmerman. Although Zimmerman was found not guilty, the legitimacy of civilian safety officials and the amount of discretion citizens should have, began to be questioned. The ability to monitor and regulate citizen behavior when involving them in enforcement can be contested. This does not invalidate the importance of community involvement and partnership with law enforcement, but more so, questions who should regulate these relationships.

Community policing efforts are an important part of ensuring improved communication and the deconstruction of police culture, but the broad direction of police efforts often makes evaluation difficult. Community policing directives can provide positive working experiences, expanding on officer's abilities to problem solve and work with citizens. They also have the potential to extend to other officers, not participating, 
through observation and vicarious experience, but the largest effects are expected to be seen with the officers having direct experience (Paoline, et al. 2000: 582).

Community policing may benefit the community and improve their perception of the police, but it also influences the perception of the officers and therefore has the potential to change police culture. Figure 1 shows the cycle of how perception can affect both groups even when they are not interacting directly.

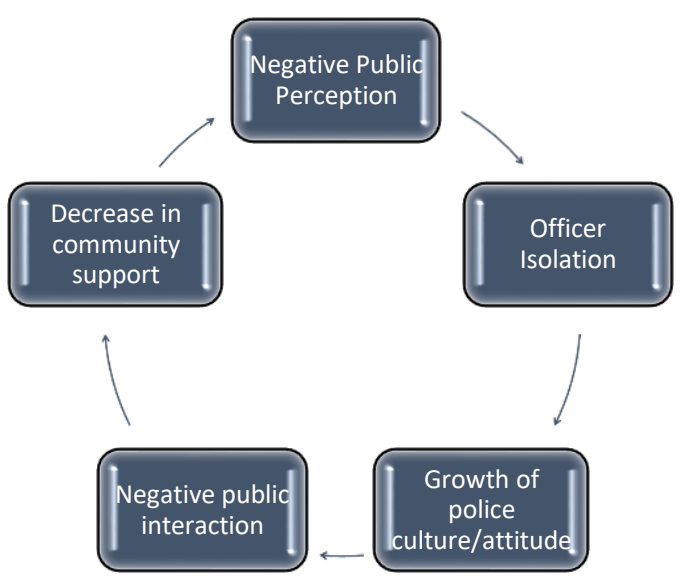

Figure 1. Cycle of Officer Perception

Patrol strategies and the implementation of new initiatives can have internal effects on department staff. Officers are an integral part of ensuring that the policing efforts are maintained and correctly established; therefore their belief in the system and their job satisfaction is crucial to the success of an initiative. Skogan (1995) found that the foot patrol policing efforts in Madison, Wisconsin, had more positive internal effects. Officers showed an increased level of job satisfaction, felt like they had more autonomy, believed in being customer-oriented, and became more trusting of the public. In Kelling's (1996) study, officers' frustration with the negative responses to traditional policing methods motivated changes and their acceptance of community policing. 
LMPD has adopted COP strategies enacting a variety of policies, programs, units, training, and meetings in an attempt to enhance community relations.

Organizational and structural changes intended to enhance relationships between officers and citizens, include assigning patrol men and women to a specific beat in a police division. The goal is to not only increase the officer's awareness of the specific people and crime in the area, but also provide the community access to an officer they know and with whom they are familiar. LMPD fostered several units to foster COP principles. The Community Policing Unit was established to link the department with members of the community through outreach programs, such as Neighborhood Watch and the Citizen's Police Academy. School Resource Officers are assigned to particular middle and high schools in the Louisville Metro area based on the amount of calls for service for that particular school and/or neighborhood. Not only have they addressed criminal issues, but several SROs have created specific programs to address bullying, violence, at-risk youth, social media, and texting safety issues. Another example is the change in departmental policies to enhance transparency involving police activity and crime statistics, making all information accessible through the LMPD webpage or a formal request.

There is limited systematic research and evaluation of which new programs and policies LMPD implements succeeds in reaching established goals. This case study evaluates elements of LMPD's recent walking patrol initiative. Findings will contribute to determining whether or not the efforts and manpower are continued by documenting the impact on community relationships. The results will also be valuable to other departments who are considering different methods of community policing. The purpose of community-oriented policing is to not only to enhance the relationship between the 
police and the citizens, but to change the culture of law enforcement. Establishing a framework and objectives for a program provides the ability for evaluation and future recommendations. Understanding the components of a community-oriented policing initiative is critical for measuring effects and overall goal attainment. Studying the different police initiatives and community projects will assist in providing reliable information for future generations to establish well-rounded and culturally sound policing organizations.

\section{Walking Patrol}

Law enforcement involves strategizing and implementing the most successful form of patrol to reach departmental goals and community safety. Foot patrol, the cornerstone of policing, was an early model used and established a way to maintain a vigil throughout an area and deter crime and disorder. Law enforcement evolved and began to limit or end walking patrols replacing it with motorized strategies. In the 1930s, police in the U.S. started to deploy more officers in motor vehicles with two-way radios (Police Foundation 1981). The new technology was initially issued to supervisors to oversee officers in response to increased allegations of police corruption. As vehicles became more available, officers were assigned to cars more often, and the advantages seemed to be enormous. Vehicle patrol decreased response time, increased the ability to pursue criminals, widened the range of patrol, allowed for the use of more equipment and supplies, and made completing runs more efficient. It also made radio contact with headquarters accessible during a patrol shift and made closer supervision of officers a possibility (Kelling and Coles 1996). 
The introduction of motor patrol was supposed to maintain the original foot patrol strategy, using the vehicle to move from one beat to another, thus expanding the foot patrol areas. That evolved into vehicle patrol being the primary policing strategy. It is assumed that the change in patrol routine was due to departmental analysis and statistics, but it was also due to the public and their positive response to vehicle patrols (Police Foundation 1981). O.W. Wilson (1953) advocated for motor vehicle patrol, with officers continuing to interact with citizens throughout their shifts and maintaining a community presence. He argued that the quick response and the unpredictable movement of police vehicles within a particular area would make citizens perceive law enforcement as omnipresent within the community, and serve as a deterrent due to the increased potential of being caught committing a crime (Donnermeyer and O'Block 1991; Kelling and Coles 1996; Police Foundation 1981).

As the public and police relations began to deteriorate in the 1960s, especially within minority communities, researchers and police administrators began to question the impact that vehicle patrol was having on public perception, crime deterrence, and community relations. Police appeared to have minimal contact with citizens and were “isolated in their rolling fortresses" (Police Foundation 1981:25). The American Bar Association (1972) documented that there was little evidence showing vehicle patrols deterred crime. Research by Schnelle, et al. (1977) found that where vehicle patrol increased, statistically reliable decreases in crime only occurred during night hours and did not include all types of criminal activity. This research questioned the cost/benefit of saturation patrolling crime prevention techniques. Kelling, et al. (1974) concluded that the amount of crime, number of arrests, fear of crime, community attitude toward police, 
and the attitude of officers did not change due to the amount and/or type of patrol initiated. They also discussed community confidence, showing that increasing police visibility did not have a positive effect on the dynamic of police-citizen encounters. However, Winkel (1986) found that higher levels of visibility decreased fear of crime and recommended that police departments that allow for more "opportunities for police officers to make face-to-face contacts with residents in a positive context that is not primarily aimed at crime detection" (Winkel 1986: 395). Winkel proposed that walking patrol strategies could meet these recommendations. More recently, Groff, et al. (2013:135) researched the benefits of foot patrol, describing it as "boots on the ground" policing that better addresses disorder policing and builds proactive community contacts that result in valuable intelligence. The limited ability to respond quickly to emergency calls for service does increase response time and often causes community satisfaction with the law enforcement agency to decrease.

Research on the impacts of walking patrols has had mixed results. Early studies showed that walking patrols did not reduce criminal victimizations or disorder, but did reduce the fear of crime from the citizens in the patrol area (Bowers and Hirsch 1987; Police Foundation 1981). Some recent studies produced similar results, with Groff, et al. (2015) finding that foot patrol efforts do not change overall crime rates. While others found that foot patrols are successful in reducing crime when directed at hot spots, areas with higher crime rates (Braga, et al. 2014; Piza 2018; Ratliffe, et al. 2011; Weisburd and Eck 2004). Although the studies show crime prevention, the tactics utilized for each location varies, which can be related to the police strategy for that area or the varying decisions made by the individual officers due to the discretion that is allowed in the 
position (Lipsky 2010; Piza 2018). The ability to choose how certain police interactions will be handled and whether any legal action will ensue makes the results difficult to determine whether enforcement actions (i.e., arrests, citations, summonses, field interrogations) or guardian actions (i.e., citizen contacts, community presentations, business checks, bus stop patrols) affected the crime rates. Piza (2018) focused the study on different police actions during patrol activities and found that guardian actions impacted crime more than enforcement actions.

Simpson (2017) found that police patrolling on foot or bicycle were perceived as more approachable, respectful, and accountable by the community than when utilizing a police vehicle. This may also influence public impressions of the police by changing the traditional contact between citizens and law enforcement. Vehicle patrol appears to be more focused on responding to emergency calls and is associated with red and blue lights and sirens. Often the contact is initiated by the citizen and the patrol officer responds in his/her vehicle to handle the issue. Therefore, the first impression is of the officer and the traditional vehicular response. The study concluded that the public perceived the foot patrol officers as significantly friendlier and less aggressive.

Groff, et al. (2013) use the concept of "co-production" to better understand the impacts of foot patrol. Co-production is a partnership between police and the community they serve. It can arise from various law enforcement strategies, such as broken windows policing, hot spot policing, and community-oriented policing, but reflects the interaction between police and other entities, such as community members, business owners, city officials, and other city agencies (Groff, et al. 2013; Innes and Roberts 2008; Taylor 2006). Groff, et al. (2013) also found that the relationship between vehicle and foot 
patrols overlap to create the best community safety results, further contributing to the coproduction model. It is important to use the most efficient and effective method during the development of those strategies, but it is also critical to understand how one initiative may impact another

\begin{tabular}{|c|c|c|c|}
\hline Author(s) & Location & Method(s) & Findings \\
\hline $\begin{array}{l}\text { Kelling, et al. } \\
\text { (1974) }\end{array}$ & $\begin{array}{l}\text { Kansas City } \\
\text { Police } \\
\text { Department }\end{array}$ & $\begin{array}{l}\text { Officers assigned to control } \\
\text { beat/proactive beat. Results } \\
\text { measured by crime statistics and } \\
\text { community surveys. }\end{array}$ & $\begin{array}{l}\text { Increased officer } \\
\text { visibility did not have } \\
\text { positive effect on } \\
\text { community/law } \\
\text { enforcement } \\
\text { encounters. }\end{array}$ \\
\hline $\begin{array}{l}\text { Police } \\
\text { Foundation } \\
\text { (1981) }\end{array}$ & $\begin{array}{l}\text { Newark } \\
\text { Police } \\
\text { Department }\end{array}$ & $\begin{array}{l}\text { Control area (vehicle patrol) and } \\
\text { experiment area (walking patrol) } \\
\text { evaluated by reported crime, } \\
\text { arrests, victimization, and } \\
\text { community pre-post surveys. }\end{array}$ & $\begin{array}{l}\text { Walking patrol did not } \\
\text { decrease crime. } \\
\text { Community perception } \\
\text { of crime in the } \\
\text { experiment area had a } \\
\text { decreased fear of } \\
\text { crime and the } \\
\text { perception of crime } \\
\text { rates lowered. }\end{array}$ \\
\hline $\begin{array}{l}\text { Winkel } \\
\text { (1986) }\end{array}$ & $\begin{array}{l}\text { Zaanstad, } \\
\text { Netherlands }\end{array}$ & $\begin{array}{l}\text { Community survey given to } \\
\text { control group (officer not } \\
\text { present) and experiment group } \\
\text { (officer present). }\end{array}$ & $\begin{array}{l}\text { Increased police } \\
\text { visibility decreased } \\
\text { fear of crime. } \\
\text { More positive } \\
\text { response from citizens } \\
\text { in experiment group. }\end{array}$ \\
\hline $\begin{array}{l}\text { Bowers and } \\
\text { Hirsch } \\
\text { (1987). }\end{array}$ & $\begin{array}{l}\text { Boston Police } \\
\text { Department }\end{array}$ & Computer-aided dispatch data. & $\begin{array}{l}\text { Walking patrol did not } \\
\text { decrease crime. }\end{array}$ \\
\hline $\begin{array}{l}\text { Ratcliffe, et } \\
\text { al. (2011) }\end{array}$ & \multirow{2}{*}{$\begin{array}{l}\text { Philadelphia } \\
\text { Police } \\
\text { Department }\end{array}$} & \multirow{2}{*}{$\begin{array}{l}\text { New officers assigned to walking } \\
\text { patrol in crime hotspots in two } \\
\text { phases-March-September } 2009 \\
\text { and July-September } 2009 .\end{array}$} & $\begin{array}{l}\text { Decrease in violent } \\
\text { crime in walking } \\
\text { patrol areas. }\end{array}$ \\
\hline $\begin{array}{l}\text { Sorg, et al. } \\
\text { (2013) }\end{array}$ & & & $\begin{array}{l}\text { First phase had a } \\
\text { decaying deterrent } \\
\text { effect on crime as } \\
\text { opposed to the second } \\
\text { phase. }\end{array}$ \\
\hline
\end{tabular}




\begin{tabular}{|l|l|l|l|}
\hline $\begin{array}{l}\text { Groff, et al. } \\
\text { (2015) }\end{array}$ & $\begin{array}{l}\text { Philadelphia } \\
\text { Police } \\
\text { Department }\end{array}$ & $\begin{array}{l}\text { Veteran officers assigned to } \\
\text { walking patrols June-August } \\
\text { 2010 in hot spot areas and 7 } \\
\text { control groups (vehicle patrol) } \\
\text { were measured through crime } \\
\text { statistics. }\end{array}$ & $\begin{array}{l}\text { No change in crime in } \\
\text { walking patrol } \\
\text { locations. }\end{array}$ \\
\hline $\begin{array}{l}\text { Simpson } \\
(2017)\end{array}$ & Unknown & $\begin{array}{l}\text { Participants looked at images of } \\
\text { officers in different uniform } \\
\text { attire based on their assignment } \\
\text { (e.g. bike, detective, vehicle, } \\
\text { walking). }\end{array}$ & $\begin{array}{l}\text { Walking patrol } \\
\text { officers were viewed } \\
\text { as more approachable, } \\
\text { friendlier, and less } \\
\text { aggressive. }\end{array}$ \\
\hline Piza (2018) & $\begin{array}{l}\text { Newark } \\
\text { Police } \\
\text { Department }\end{array}$ & $\begin{array}{l}\text { Walking patrol area and control } \\
\text { area (vehicle patrol) measured } \\
\text { for guardian action and } \\
\text { enforcement action. }\end{array}$ & $\begin{array}{l}\text { Guardian actions } \\
\text { decreased crime more } \\
\text { than enforcement } \\
\text { actions. }\end{array}$ \\
\hline
\end{tabular}

Table 1. Walking Patrol Literature Summary

The research shows mixed results when studying walking patrol (see Table 1), but there were often large differences in the goals of the programs. Due to officer discretion, there will always be limitations to generalizability. The positive results regarding public perception of the police officers in their community are promising, and walking patrols ensure that citizens have more contact than those relating to enforcement actions. This is found to be important for not only crime rates, but also perceptions of safety. Developing and enhancing community relations is an important part of policing, and there have been strategies that have been successful for departments. As the research shows, success can have different measurements. Just because crime did not decrease, the public may feel safer; therefore, departments need to establish goals for policy or program changes and/or initiatives. Although reducing crime and taking enforcement action are important aspects of policing, it is considered a traditional method of measurement. Determining how a community perceives crime and measuring the effects of guardian actions is just as important, if not even more, according to Piza (2018). There is also limited research on how police officers' perceptions change following walking 
patrol assignments and whether their decision-making, problem-solving, and communication skills change.

\section{Perception-Community and Police}

Most people will not have direct or routine interaction with police; therefore they rely on the media, neighbors, or family and friends to develop their opinion (Langan et al. 2001; Schafer et al. 2003). This heightens the importance of each contact with the public, whether formal or informal. Schafer et al. (2003) examined factors predicting community perception of police services and found that citizens' satisfaction (or lack thereof) with their contacts with law enforcement was a significant predictor of their broader perceptions of police services (460). When participants reported dissatisfaction with voluntary and/or involuntary police interactions, their overall perception of the police was less positive. The research also showed that community culture and neighborhood assessments also affected the perceptions toward law enforcement. If a person had a positive perception of their community culture and their neighborhood, a more positive perception of community policing efforts was expressed. This demonstrates that several factors, including individual encounters and the overall perception of neighborhood issues, can influence police relations and community opinion.

Police contact with the public in a non-enforcement capacity. Communicating through informal methods has a positive impact on perception. Maxson et al. (2003) surveyed residents regarding their opinions of the police and concluded that attending community meetings, increasing visibility in neighborhoods, and talking with citizens increased the public's positive opinion about officers' job performance. Even when the public perceived higher crime and disorder in their neighborhood, the informal contacts 
positively impacted their approval ratings for local law enforcement. It also countered the negative response from formal contacts, such as an arrest, citation, or traffic stop. Community members that had both interactions had higher approval ratings than those only reporting formal exchanges. Approval and positive opinions from the public are essential in gaining legitimacy.

Yim and Schafer (2009) completed a study that produced three key findings: "first, police officers believed they were generally perceived less than favorably by the community than other professions. Second, officers' perceptions of the community's views of them positively affected their job satisfaction during non-enforcement situations. Third, among officers' demographic and social variables, officers' rank and years of service were significantly related to officers' perceptions" (26). Specifically, officers that had less time on and less rank on the department perceived that they were viewed by the public less favorably. Effectively performing in their law enforcement capacity could be difficult because of the perceived negativity from the public. This can directly affect job satisfaction among police and in turn, their work attitudes; however, it is a complex issue, as police officers come from varying backgrounds and perspectives (i.e., rank, years of service), all of which directly influence their perceptions of the job (Fosam et al. 1998; Greene 1989). Very little research has been completed looking specifically at how officers perceive that their jobs as viewed by the community and how that affects work-related attitudes.

\section{Theory}

To thoroughly explore this case study and its complexities, several theoretical frameworks are introduced and used to inform the research. Traditional forms of 
measuring police success and legitimacy generally involve crime statistics and focus on determent through focused policing efforts. The first group of theoretical perspectives are representative of this and includes rational choice theory and routine activities theory.

These two inform the research in relation to people who commit crime and posit different explanations behind fluctuating statistics. These are based on individual circumstances, but also systemic issues within a community that create opportunities for criminal activity. These two theories are embedded within the second group of theoretical frameworks that focus on the relationships between police practice, culture, and perceptions between the public and law enforcement. These perspectives are institutional theory, social learning theory, emotional labor theory, and social network theory. These frameworks contributed to the understanding of community engagement and provided a direction for the research when developing, conducting, and analyzing the results. Because of the complexity of this research, I utilized several different theories to fully envelop the multiple methodologies used and large amounts of data gathered. These perspectives created a framework for the researcher, allowing the narrowing of variables through relevancy during data collection, analysis, and interpretation of the results. These theoretical frameworks informed the research, but the results also contributed to the theories.

\section{Rational Choice/Routine Activities}

When evaluating crime and the statistics that surround them, this research will utilize two theoretical approaches: routine activities and rational choice theory. First, rational choice theory, which is an expansion of deterrence theory, has played a key role in the U.S. criminal justice system. This approach assumes that crime is a purposive 
behavior to meet the needs of the offender (Clarke 1997). It claims that an offender evaluates the expected reward for committing a crime against the other risks and costs that may be associated with criminal activity. When the utility of rewards outweighs the costs of crime, the offender is motivated and makes the rational choice to move forward with the delinquent behavior (Akers 2012; Reid 2009). A criminal often has no other choice or cannot perceive any other options, which is significant when analyzing the education, assistance, and determent programs that are available to these groups. Reiman (2004) explains that without options that deter him/her, the individual does not have reason enough to avoid criminal activity and feels that they have little to no options for success in the future. Therefore, the decision to participate in delinquency becomes much easier. When law enforcement agencies focus on deterring crime, it can increase the perceived risk of apprehension by the offender, which can lead to discouragement related to an increase in the perceived effort required to complete the criminal act (Clarke and Weisburd 1994). Similar to the efforts from LMPD through the foot patrol initiative, the increase in officer presence in a specific area could deter the criminal from participating in delinquent activity because the perceived risk outweighs the reward.

The second perspective is routine activities theory developed by Cohen and Felson (1979) suggests that crime is a normal activity if the opportunity is available. It is a subfield of rational choice theory. The rate of delinquency can increase when certain elements are present, including an available target(s), a motivated offender, and a lack of guardian(s) or authority figures to prevent the crime from occurring. Often people become comfortable in an area, making them more knowledgeable about who may be a suitable target and the times that they would be the most successful at committing a 
criminal act. Independent of offender motivation, a crime often must take place in a particular location, at a specific time, and against an available target. Basing police strategy on this theory is where several police initiatives take shape, including the foot patrol initiative in Louisville, but also other locations in the U.S. Through directed patrol, the presence of authority figures increases in specific areas. Decreasing the presence of available targets through educating the public also changes the crime opportunities. Motivated offenders may choose another location to participate in criminal activities or be deterred from being involved at all.

\section{Institutional}

Police departments are complex organizations within the government structure and, although intraorganizational components are involved, the overarching influence consists of environmental factors. These external transactions, exchanges, interactions, and influences can internally change the operations of an agency and have a powerful influence on their behavior and their organizational direction (Jaffee 2001). Meyer and Rowan (1977) distinguish that these types of organizations turn their focus to outward constituencies and the values they represent are considered institutional. Unlike organizations that are solely utilitarian directed, seeking economic reward and efficient production, institutional models must operate under the prevailing rules and requirements within their social environment to receive support and legitimacy (Jaffee 2001). The actions taken daily by law enforcement officials do not have an economic worth that can be attached and are not measured in standard production numbers. For example, when a police officer responds to an opioid overdose, distributes medication to the person to counteract the drug, calls for emergency medical services to respond, and the person 
lives, the ability to measure this becomes complicated. It is easy to place a value on the medication, the EMS response, and the hourly rate of the officer. Evaluating the efficiency in response times, the distribution of the medication, and the completion of paperwork can all be easily assessed. But attaching a price tag to the life saved becomes more difficult. Organizations that operate in an institutional environment are characterized by work that is valued by the members and the constituencies (Crank 2003). As Jaffee (2001:243) explains, the goal-directed economic image of an organization is replaced with human institutions characterized by routines and traditions that are driven by "myths, symbols, and the desire for social legitimacy." The foundation of a police department is built and sustained by the powerful external influence of the public and the legitimacy gained through this involvement. Crank and Langworthy (1992:342) refer to these powerful actors as "sovereigns" and explain that these institutional forces can affect the fundamental well-being of the organization. Police departments are similar to large businesses; if the consumers do not support the product that is sold, the company will likely fail unless they adjust their strategy. Crank (1994) uses the Kerner and Crime Commission reports as an example of this influence on the institutional organization. The reports began to delegitimize and question the professionalism of police officers nationwide during the 1960s. Media outlets were airing images of police brutality, and communities were questioning their local police. Constituents began to demand change to standard operating procedures and the overall direction that police departments were placing their focus. The institutional environment forced departments to implement activities that would rebuild legitimacy, confidence, and decrease conflict. Then following the community policing initiatives leading to new 
practices for departments to follow, a more community-directed structure to regain professionalism.

Meyer and Rowan (1977) refer to these institutionally enforced practices and procedures as "rationalized myths." The researchers explain that they are rational because the members of an organization and external participants believe the efforts to be the most appropriate means to achieve a particular goal. The attachment and support for these procedures come from tradition, culture, and societal conformity, not empirical evidence. Therefore, it is also considered a myth. In the example of community policing, the efforts were rational. They seemed appropriate in regaining community trust and respect, but it was implemented without the support of related research into that initiative. It found that the more an organizational structure considers institutionalized myths, the higher the chance it will maintain internal and external votes of confidence, satisfaction, and legitimacy (Jaffee 2001; Meyer and Rowan 1977; Thornton, et al. 2012).

\section{Emotional Labor}

Sociologist Arlie Hochschild studied human emotion and its connection with socialization. Her emotional labor theory developed from this concept, which is the regulation of emotions that creates visible signs of expression, whether verbal or nonverbal, in the workplace. Certain places of employment require an employee to display a particular type of emotion to the public during the work shift, no matter how they may feel during a particular situation. Hochschild used this theory to research the effects that consistent contradictory emotions had on a worker. She described the internal conflict between a person's internal standards and the opposing expressed response as emotive dissonance (Bakker, 2006). The introduction of the topic of emotions involved in the 
workplace has increased substantially, which has involved many different service professions (Schaible, 2010). Police consistently encounter incidents that can vary greatly, but they must handle each one with the same level of attention and concern. This theory describes how some careers require neutral feelings during interactions with the public and require the skill to subdue any internal contradictions. For example, it is a requirement of police detectives to interrogate suspects that have committed crimes that test the detective's capability to "downplay" the offense, or concur with the suspect's perception that the crime was necessary. Sitting down next to a person that committed sexual acts on a child, murdered their spouse, or shot a clerk at the liquor store and saying that you understand how easy it would be to act that way or that you can relate to their situation is not an easy response. Yet, at times, that is what it takes to get a confession. Erving Goffman introduced the concept of deep acting and surface acting, which links with the emotive dissonance discussed by Hochschild. Individuals involve themselves in deep acting during an attempt to relate artificially and put themselves in a altered state that for the organizational expectations of the employer (Goffman, 1959; Schaible, 2010). This is with or without the internal agreement from the individual that is taking action. Law enforcement is not exempt from this concept, where it can be seen clearly on a daily basis. Another concept by Goffman (1959) is impression management, a process where people attempt to influence the perceptions of others by controlling information during a social interaction.

The police department is a career path that entails constant interaction with the public. It is a unique profession, because of the type of assistance they are to offer, but also that the officer continuously operates as an officer, even when off-duty. For 
example, an airline attendant must meet the needs of the passengers on board the flight, but when the shift is over, the attendant does not have to continue his/her assistance. It is the expectation of a law enforcement officer to respond, protect, and serve the community when something happens. An officer does not put away their badge during their off-time.

When police are interacting with the public, it is in an uncontrolled environment. Whether it be a response to a residence, a business, a highway, or a hospital, police do not have the luxury of choosing the venue to complete their work. Police officers also deal with people from all walks of life, making it necessary to identify these differences and be able to communicate accordingly (Steinberg, 1999). Most interactions police have with the public are during some type of conflict, and people are at their worst, whether they have been victimized, injured, or violated a law (Martin, 1999; Brown, 1981). Making an effort to understand and empathize with the situation the citizen has encountered and why they are responding in a certain way is the officer's job. Still, they are also in a state of hypervigilance. Not only does the officer have to assess their own emotions and those of the citizen, but also maintain the safety of all involved. Since the job of an officer carries into the time when they are off duty, this hypervigilance continues throughout all their interactions and activities. Many professions that perform emotional labor will not have to consider the aspect of continuous service.

\section{Social Learning}

Organizational culture is the overarching behavior and belief system that contributes to the social environment of a business or organization that influences the way they interact, handle changes, and share knowledge. These shared patterns of 
behavior are taught to incoming members, teaching them how to perceive, think, and feel in relation to other members and outside clients (Ravasi and Schultz 2006). There can be written and unwritten procedures concerning the development of members' perspectives within the workplace, and the communication of these can be accomplished through different methods. Traditional approaches involve establishing culture through objective things, including stories, rituals, and symbols, but an interpretivist approach can reflect cultural values and norms through the network sharing of subjective meanings applied by current and/or previous members of the organization (Modaff, et. al 2011).

For law enforcement, the training academy is the beginning of the policing journey for officers, and it is also the start of procedural, tactical, and customary learning. The recruits usually participate in militaristic traditions, such as hierarchical roles, uniformity, language, and physical strain. They tell them that their main objective is to "go home at the end of every shift," and the importance is reiterated through stories of heroism, sacrifice, and service to a hostile world (Fielden 2009; Stoughton 2014). The constant barrage of information surrounding recruits depicts that their survival is always in question and that one mistake can lead to death (Stoughton 2014). This occurs during their formal training and continues into the informal settings with veteran officers, who share "war stories" of violent encounters and other extreme events they have dealt with on-duty. A collective understanding begins to form as recruits develop a common language, demeanor, and even uniforms that set them apart from society at large (Peak 2015).

Jerome Skolnick (1994) discussed that these characteristics from a collective understanding lead to camaraderie and solidarity in the workforce, which he labels work 
personality. This is a theory on the way police tend to look at the world, because of the constant perception of potential threats. This tends to isolate police socially and build a social bond between coworkers, a culture among the officers formed through the similar interactions and attitudes that occur during their law enforcement career.

Police culture is strengthened and shared with the next generation of officers and continues cyclically. There is an unwritten loyalty that work cohorts develop into friendships that meet outside of work hours. The police culture is nurtured and continued to the next generation of police; therefore the cycle continues. The attitudes the officers hold regarding the public become shared, and an interaction that an officer has with a community member may be retold to another officer. Coping strategies, policing 'commonsense,' an understanding about how to view their external environment, and how policing is done becomes engrained in the officer through these frames of reference provided by training officers and cohorts (Bacon 2014: 104). If that interaction was described negatively, it becomes a communal experience and can change the officer's perception of the public. This can constrain future communication with the public, based on an officer's past personal experiences or those of others within the police agency. Lack of communication is one of the causes of citizens' dissatisfaction with law enforcement, because there is a misunderstanding by the officer of what the public needs and/or wants from the agency (Fosam et al. 1998).

Organizational culture for law enforcement officers is learned through the process of exposure and repetition, from the beginning of the academy until the end of their career (Rose \& Unnithan 2015). Most literature focuses on the elements surrounding police misconduct and deviance due to law enforcement action in relation to differential 
association. The association with peers leads to mirroring behavior, attitude, and perceptions to maintain acceptance in the group or organization (Chappell and Piquero 2004). The research suggests that the presence of police culture can lead an officer to make decisions and respond in a particular way based on the learned behavior from the organization. Akers (2011) reminds researchers that conforming behavior is just as relevant as deviant behavior and learned in the same way. Social learning theory was first introduced by Edwin Sutherland as differential association theory of crime and further developed by Akers by identifying various learning mechanisms (Agnew and Brezina 2015). This theory teaches that the exposure and associations develop the engagement in delinquency or conformity with others who participate in the same. A culture of behavior will develop. When specifically looking at law enforcement organizations, officers become their own community. The "us versus them" attitude grows and can affect decision-making, attitude, and the ability to adapt to change (Terrill et al. 2016).

Further, the behavior is reinforced, looked at favorably, and provides behaviors for other officers to imitate. Social learning can lead to conforming behavior and an acceptance into the culture, which is one of the most influential forces in the actions of an officer (Maskaly and Donner 2015). Within the context of conforming behavior, it is often overlooked when considering how and why police make decisions that cause an escalation in citizen animosity toward officers. Some researchers believe influence from the culture is one of the most powerful forces in officers' actions (Maskaly \& Donner, 2015). This cultural transmission can make change difficult. Adapting to new policies and initiatives can be met with resistance, minimal support, and backlash among officers (Cordner 2014). The participation or lack thereof is taught by the remarks and/or actions 
of others in the group, therefore requiring a change in social learning to bring success of program introduction or changes (Burgess \& Akers, 1966). Robert Adlam (2002) explained that the police culture is immune to the provisions toward change by police leadership, rarely changing the behavior or dispositions of police officers. Therefore, changing policy or training requirements may have a superficial effect on police rhetoric, but the impact on the internal aspects of police culture may be minimal. The complexities of how police culture successfully controls the perception of officers regarding performance and professionalism is difficult to capture. Police reform is largely unsuccessful at overriding these perceptions, which leads to insufficient approaches. Cockcroft (2014) found that organizational culture and reform are deeply intertwined, and changing an officer's language or behavior is insufficient if it does not change the way they think.

\section{Perception}

Social perception uses knowledge of others to identify and use cues, norms, and interactions to judge relationships, roles, and characteristics of others (Aronson et al. 2010). This perception can then be shared with others and develop a unified judgement or subjective look at a topic, event, or person. When specifically looking at perception of crime there are five theories regarding insecurity and fear of crime (Vilalta 2013). They are incivility, victimization, physical vulnerability, social vulnerability, and social networks. Incivility attributes fear of crime or perceptions of high levels of delinquency based on signs of social disorder or physical dilapidation (Shaw and McKay 1942). The victimization theory describes a victim of a previous crime feeling less safe than those that had not been victimized (Skogan 1990). Physical vulnerability results in a higher fear 
of crime for a person who cannot defend themselves. Social vulnerability describes the theoretical perspective that, if a crime were to occur, an individual would not be able to recover, possibly due to their socioeconomic standing. Social network theory proposes that increased social involvement can provide feelings of greater security and resources to prevent crime (Ferguson and Mindel 2007). Although all of these theories within the context of "perception of crime" are important factors to consider when attempting to understand responses from the community, this research will focus more on the social network theory. Vilalta (2013:15) explains it in more detail that individuals who are more informed and participate in community events will likely be more realistic regarding law enforcement expectations and criminal activity in their neighborhoods. The results of this lead to higher levels of "collective effectiveness, confidence in other citizens, confidence in the local police, and a feeling of greater security."

\section{Program Impact Theory}

The development of a program's direction and goals is essential to determine if the efforts were successful for the organization and worth the manpower and funding in the future. I attended several meetings with the LMPD command staff to discuss the direction of the program. They established a framework for the program to assist in understanding the overall impact of the walking patrol initiative. The creation of the unidirectional impact diagram visually informed the specific components of the framework. Chart 1 shows the model specified for the LMPD. This is the overall approach LMPD used to understand how they might improve community relations. Increasing visibility according to rational choice and routine activities theory deters crime by increasing the person's risk of being caught by law enforcement and decreasing the 
amount of targets available. Increasing community contacts can positively impact an officer's perception of the community and decrease their feelings of isolation. This could reduce emotional labor for an officer and, as the theory describes, can have effects on their attitude and involvement in police culture. Walking patrols increase opportunities for communication with the public, especially the location selected for this initiative. This can have several implications on policing, including the collection of crime intelligence, increasing informal police contacts, and change police perceptions of the community.

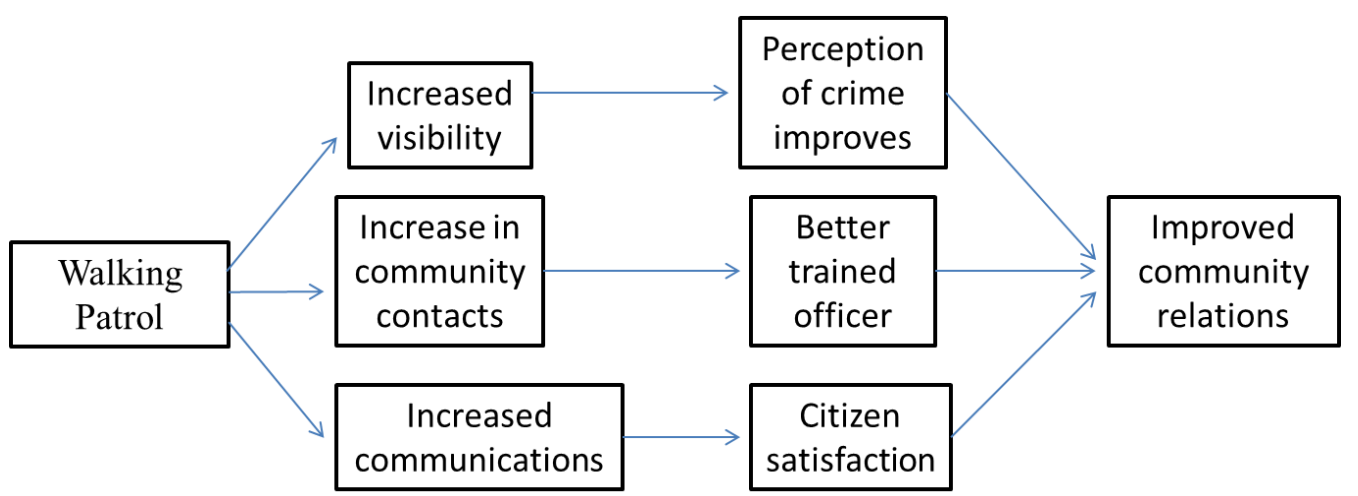

Chart 1. Program Impact Theory Model.

The discussions with the commanding officers and stakeholders involved in the design and implementation of the program established these goals:

1. Produce officers who are better equipped in recognizing and addressing problems inherent to the beat they are assigned.

2. Improve officers' inter-personal communication skills and relationships with community stakeholders in order to provide precision policing-based services.

3. Develop officer's problem/incident solving skills alternative to enforcement while addressing quality of life issues.

4. Improve citizens' perceptions of crime in the areas that they reside and/or work.

5. Improve citizens' perceptions of local law enforcement, specifically LMPD, and increase officer visibility and approachability. 
6. Evaluate the impact on crime statistics and displacement in the walking patrol area.

These goals are interconnected with the theoretical frameworks informing this case study.

Evaluating the initiative and providing program recommendations will be framed by these perspectives. 


\section{CHAPTER III: METHODOLOGY}

Defining community policing is difficult and the literature shows how it has been implemented differently based on what a police department considers essential.

Evaluating these programs is even more challenging, because determining if something was successful without defining the overall measurements can become ambiguous. Looking at the literature, the goal is for law enforcement to develop a proactive partnership with the community and to reduce social disorder and crime. Discovering how to progress that into a continuous relationship with positive perceptions and cooperation is where the questions arise. It is unlikely that there will be a single solution to decreased crime and increased community relations, but departments can implement programs and policies that focus on specific goals that have been successful. Determining what variables impact the community and police officers can assist in focusing the efforts of community policing initiatives. It can also legitimate if the distribution of time and manpower to this area of law enforcement is an important start to deconstructing the concepts of community policing.

The need for consistent program evaluation of community policing efforts is fundamental in determining whether the outcomes are sustainable or to answer why the initiative may have failed. Without this, there is the danger of repeating the same curriculum even if it was deemed ineffective by prior departments or communities. Through this case study of the LMPD walking patrol initiative, the literature regarding 
perception and its effect on community relationships expanded, and the conceptual understanding of community policing has the potential to improve.

This research hypothesized the following: perceptions of the police, personal safety, and crime will improve for community members within the walking patrol area; foot patrol officers will have a more positive perception of community opinions of law enforcement than vehicle patrol officers, and police officers with more informal law enforcement interactions will have higher job satisfaction. As data were analyzed, unexpected, yet important themes related to police culture emerged. When using a grounded theoretical approach, the incorporation of the results and information related to this topic contributes to the research.

For the research analysis, I used a mixed methods approach, which provided comprehensive results and expanded the breadth, depth, and range of inquiry. It included statistical analysis of crime data and participant observation of the walking patrol officers. A cross-sectional community survey assessing citizen's perceptions of crime and local police was created for District 8 residents and/or employees. I used a quasiexperimental design comparing two groups, walking patrol and non-walking patrol residents and/or employees. Although the groups were not randomly assigned, I attempted to use a control group that would be as similar as possible to the experimental group when looking at demographics, population, and crime statistics. Survey data were analyzed using ordinal logistic regression, multinomial linear regression, and negative binomial regression. Focus groups and follow-up semi-structured interviews were completed with walking patrol and vehicle patrol officers from Metro Academy Class 42 to assess their experiences and perceptions with LMPD. This delivered a broad look at 
the walking patrol initiative and expanded on previous literature. I also consistently used an inductive analytic approach throughout my data analysis, which included reviewing my notes, recordings, and data. Exploring concepts through constant comparison and using grounded theory to conduct qualitative research can lead to additional categories and potential themes that emerge from the data (Charmaz 2009; Glaser and Strauss 1967).

\section{Positioning}

I completed this research and evaluation as a doctoral student at the University of Louisville, but I am also employed as an officer with the LMPD. This position has given me a unique opportunity to gain entrée with the commanding officers and also the probationary officers participating in the study. My knowledge of the language, structure, and services provided is extensive and assisted in analyzing participant responses and observations. I also have a unique understanding of police culture, attitude, hierarchy, and training, which contributed to my ability to evaluate all variables involved in the program. As a researcher, I had to involve reflexivity during the entire case study and recognize the different "selves" that I assumed during the study, which had the potential to influence my conceptualization of the results (Attia and Edge 2016).

My position within LMPD was helpful throughout the research, because of my knowledge of the job, but it did not help as much during recruitment of participants. Although I am considered a complete member, fully immersed and employed within the research setting, I was merely a peripheral member to the vehicle patrol officers (Adler and Adler 1987). I only had gained rapport with the walking patrol officers, so the interviews and focus groups were very productive at the beginning and throughout the 
interactions. The vehicle patrol was not as receptive initially and building a certain level of comfort and casual conversation was more difficult. It took much longer for the vehicle patrol officers to become more talkative and open up with stories. I concluded that my previous involvement with the walking patrol officers, including meetings, roll calls, community events, and conversations during my participant observations, led to a more relaxed environment when they participated in the interviews and focus groups. If I was to conduct this research again, it would be prudent for me to attend roll calls and shifts of other eligible participants, not only to introduce myself, but also to gain their trust. Although the interactions were productive during my research, this introduction could have furthered the information I was able to obtain during focus groups and interviews.

Again, throughout the research, it was important to recognize the on-going process to acknowledge and reflect on my subjectivity distorting the results. I was constantly adjusting my role in the research due to my actual position with LMPD and as a researcher. It was challenging, but the availability of such robust information, specifically during the qualitative parts of the research, was instrumental in informing the current literature. I acknowledge that even with great effort and reflexivity, subjectivity remains. However, the results still give meaningful information regarding community policing efforts, public and police perceptions, and police culture.

\section{Program Design}

The relationship between community members and law enforcement is a consistent challenge for police departments nationwide, which leads to innumerable initiatives to assist in rebuilding communication, trust, legitimacy, and cooperation. 
Louisville Metro Police are no exception in the national effort and have implemented several different policies, programs, and initiatives to improve community relations. LMPD began discussions about the walking patrol pilot program in October 2018. It was introduced to the Chief of Police by the Deputy Chief and his Executive Officer, with a Major from the research site later attending the meetings. Planning ensued in developing the program guidelines, directives, staff, and location. They decided that the unit would be staffed with probationary officers, with the potential for it to becoming an extension of the final training phase. The initial number of requested participants was 12, but due to budget and manpower concerns, the group decreased to 8 officers and one sergeant. The walking patrol was assigned to the Chief's Office to alleviate any concerns about the redistribution of officers to other locations due to call volume or hot spots. If assigned to a specific Division, the group could be calculated as platoon members and could potentially be removed from their duties on walking patrol and be assigned to a beat if several other vehicle patrol officers were in training, out on injury, or vacation. This could have become an issue when evaluating the study, due to the decreased amount of time that the walking patrol unit would be visible and communicating with the public.

There were eight uniformed probationary officers assigned to the area working in two-person 10-hour shifts. One sergeant supervised them and operated on the $5^{\text {th }}$ Division patrol channel. During foot patrols, officers were instructed to identify and address criminal activity, including quality of life crimes, but also communicate with pedestrians, business owners, and residents throughout the shift. Calls for service were limited to emergent issues or when all patrol cars assigned to the beat were unavailable. This was due to the officer's slower response without a vehicle, and it maintained the goals of the 
initiative for the majority of their shift. The walking patrol unit uniform was the Class C uniform, consisting of navy blue pants with cargo pockets, a navy blue polo with police insignia, and black tennis shoes. The use of exterior vests was prohibited, with the goal of making the officer more approachable, but interior vests were approved (Kraska and Kappeler 1997). Vehicles were provided for the officers during their shift for driving to and from assigned patrol areas and for any transports that were necessary during their shift. Body cameras were also assigned to each officer and worn during the entirety of their shift.

\section{Study Location}

Louisville is the largest city in the state of Kentucky, with a population of approximately 620,000 and separated into 26 council districts and eight police Divisions (U.S. Census Bureau 2017). District 8, with a population of approximately 30,000, was selected for the research study by the command staff from LMPD. It consists of commercial and residential zoning, which includes the neighborhoods of Belknap, Bonnycastle, Bowman, Cherokee Seneca, Cherokee Triangle, Deer Park, Gardiner Lane, Hawthorne, Hayfield Dundee, Highlands Douglass, (Original) Highlands, and Tyler Park (See Figure 2). LMPD $5^{\text {th }}$ Division patrols District 8 on Beats 2,3 , and 4 . It ranks $6^{\text {th }}-7^{\text {th }}$ in criminal activity and reports in comparison to the other police Divisions (See Figure $3)$. 


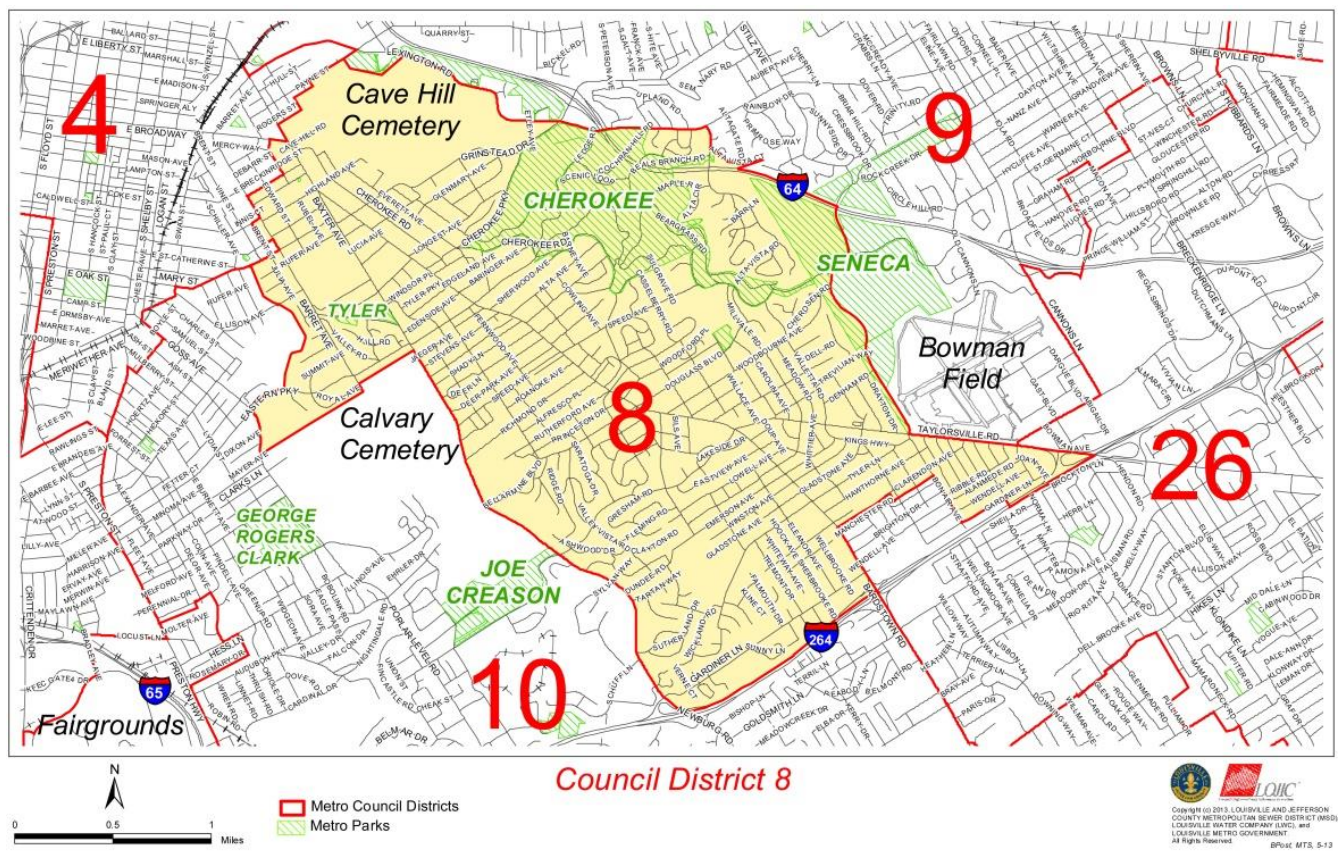

Figure 2. Louisville Metro District 8.

Fifth Division

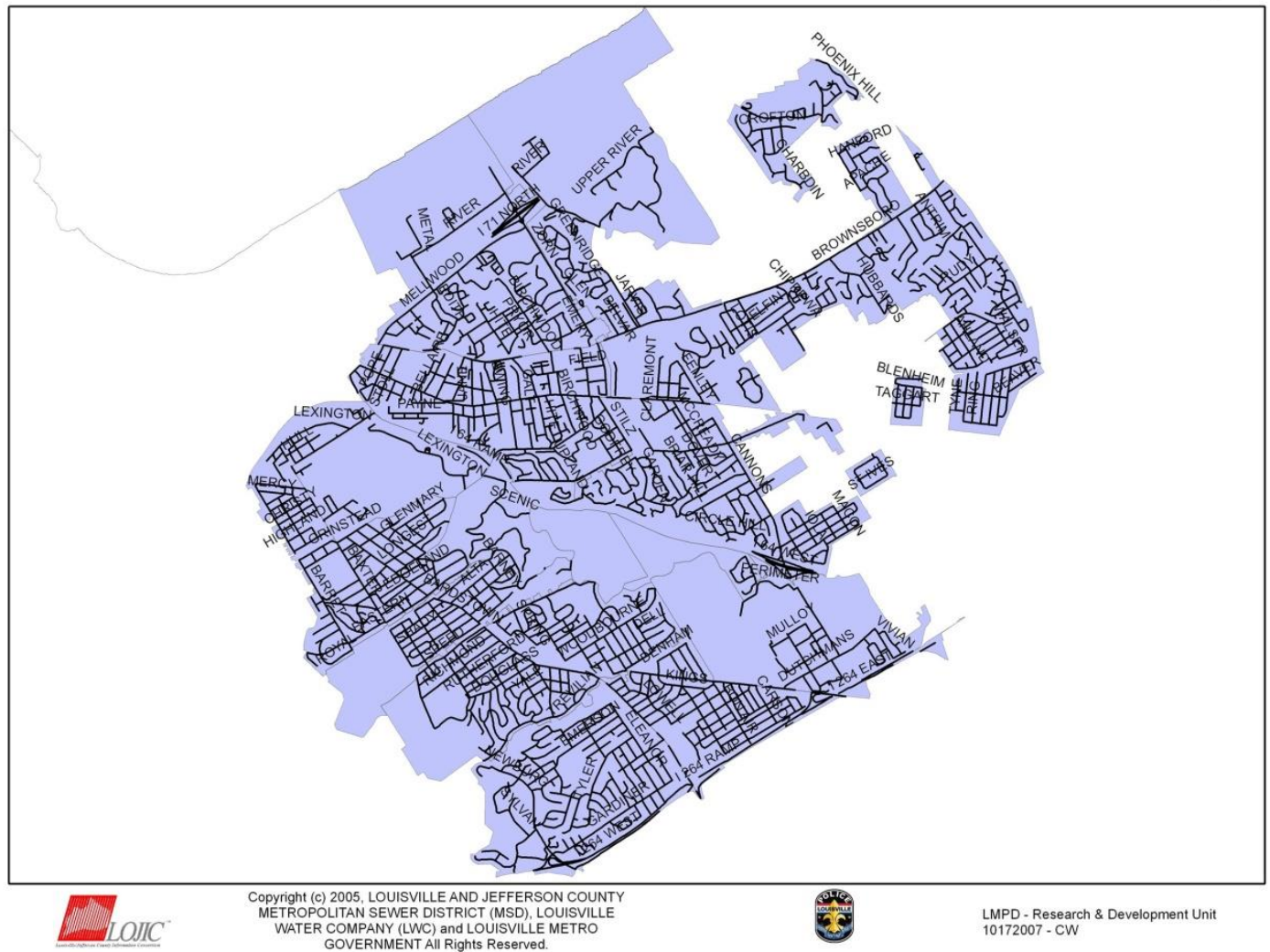

Figure 3. LMPD Fifth Division. 
The target area for the walking patrol initiative includes a section of the Tyler Park and Cherokee Triangle neighborhoods (See Figure 4). The police Division selected for the project was based on the business district and residential distribution in relation to walking availability, visibility, and safety. Personnel needs were also considered, along with the requests from community leaders and members. The public was not alerted to the initiative. I was not involved in selecting the district, but did assist in determining specific boundaries for data collection and analysis.

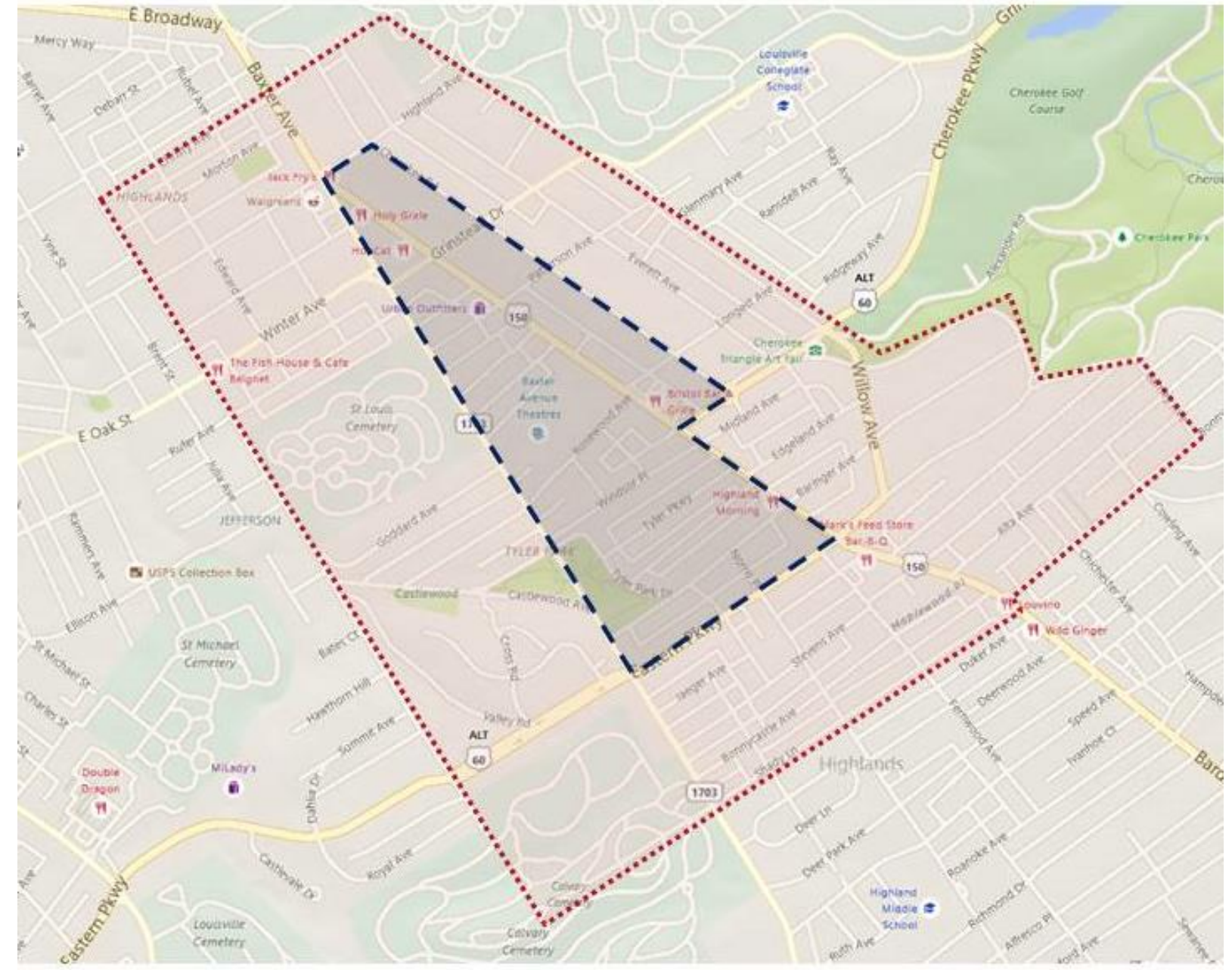

Figure 4. Walking Patrol Initiative Area and Displacement Boundaries. 
Basic training recruits were educated about the new assignment but not notified of who would go to foot patrol. The command staff presented information about the initiative to the recruits several months prior to their graduation and were told to email if they were interested in the new program. I was not informed about how many officers showed an interest in participating. Officers were selected following completion of their field training to participate in the walking patrol initiative and assigned by the command staff to that location from April $15^{\text {th }}, 2020$ until September $8^{\text {th }}, 2020$.

\section{Methods}

To adequately address the complexities involved in this case study, I used a multi-method approach. It was important to gain inclusive results for future programs and to attain information regarding policing and community relations, providing comprehensive results to other departments and/or policymakers. For this reason, I used both qualitative and quantitative data to obtain a thorough look at the initiative and the results that developed. This helps counter the argument against qualitative methods due to poor reliability and validity that may result if only a single method is applied. I also consistently used an analytic inductive approach throughout my data analysis. Sensitizing concepts through constant comparison, and using grounded theory to conduct qualitative research did lead to additional categories and themes to emerge from the data. The stakeholders, which includes LMPD command staff, also requested a comprehensive evaluation that monitored all aspects of the initiative.

\section{Data Sources}

Crime incident data and police contacts through proactive policing and calls for service are documented in the Records Management System (RMS) and through 
Computer Aided Dispatch (CAD). I used both measure the crime statistics in the walking patrol initiative area and the displacement area. These systems were also used to conduct a comparative analysis of the current initiative and the data from the same timeframe in 2018. This included quality of life issues, calls for service, criminal activity by type and severity, field interrogations, arrests, and documented police contacts. By utilizing this traditional measurement of policing for this project, I could monitor the community crime rates. More importantly, the department needed to ensure that the displacement areas were not being affected during the initiative. This is a phenomenon that can occur when police initiatives focus on a specific space for enforcement or engagement and redistribute the criminal activity to the surrounding areas. Neighboring communities to the focused patrol area will often see a rise in criminal activity; therefore, it is important to monitor adjoining locations to prevent potential displacement.

I recognized that crime data could change due to unrelated circumstances, and that the research data would be limited to crimes that were reported or noted from proactive police work resulting in an arrest and/or citation. Police activity and criminal reports were monitored in the walking patrol area and the displacement zone. This is the area surrounding the walking patrol boundaries, where displacement of crime could potentially occur during the initiative. This information was already being collected and provided to the public through the Mayor's Open Data Executive Order (2013) for all Louisville Metro Government agencies. Therefore, it was provided to the researcher without additional access requests.

The stakeholders specifically requested that the crime data assist in determining what effect the walking patrol had on crime in the target area. It was important also to 
monitor the displacement area and ensure that the walking officers were not simply

pushing issues into other areas. The data was also valuable in understanding if the perception of crime from the survey respondents was consistent with the crime reported in the area they resided and/or worked.

\section{Participant Observation}

The method of participant observation allows a researcher to view actual behavior, interactions, and comments in the natural environment of those being observed (Jorgensen, 1989). My participant observations were opportunity-based sampling, due to my access as an officer. I observed several meetings concerning the implementation, the roll calls of participants, patrol shifts, and community gatherings during the program. This provided an in-depth assessment of the officers' behavior and reactions along with the community response to police walking in their neighborhood. Participant observation allowed me to observe many things that I would have otherwise missed in other data collection methods. In observing the walking patrols, I was able to observe not only the quantity but also the quality of the interactions the officers had with the public.

Observing the daily activities and interactions of the walking patrol provided greater insight into the inner workings of this initiative.

\section{Survey}

To measure community perception of crime, safety, and law enforcement, the study used a quasi-experimental approach through a comparative design survey. It sought to obtain information from the respondents regarding their perceptions of crime, the police, and safety in their neighborhoods. The information gathered gave direct information regarding the perceptions of the walking patrol, but also evaluated how the 
initiative affected the overall perception of LMPD and their level of legitimacy, professionalism, and community involvement. The respondents were also prompted to provide personal information, including age, race, education, and income. As the literature shows, demographic variability could have a significant influence on an individual's perception of law enforcement. Although I did not use this information for this research project, its use in future research about police and community involvement may be considered.

The survey I conducted was through an online database, SurveyMonkey, with the target population consisting of all residents and business owners within the intervention area (experimental group) and outside the initiative boundary, but within District 8 (control group). Both groups received the same survey questions, which were drafted by reviewing existing literature within the established conceptual framework. They specifically addressed the perception that the individual respondent has of their police department based on their interactions directly or indirectly with patrol officers. The respondents did not know what group they fell into and were only identified upon designating what "zone" they resided and/or worked in. While completing the survey, participants were prompted to look at a color-coded map identifying several zones in the area and indicate within which zone they reside (See Figure 5). The walking patrol zone was labeled purple and served as the experimental group. Zones that served as control groups were labeled various other colors (green, brown, etc.). 


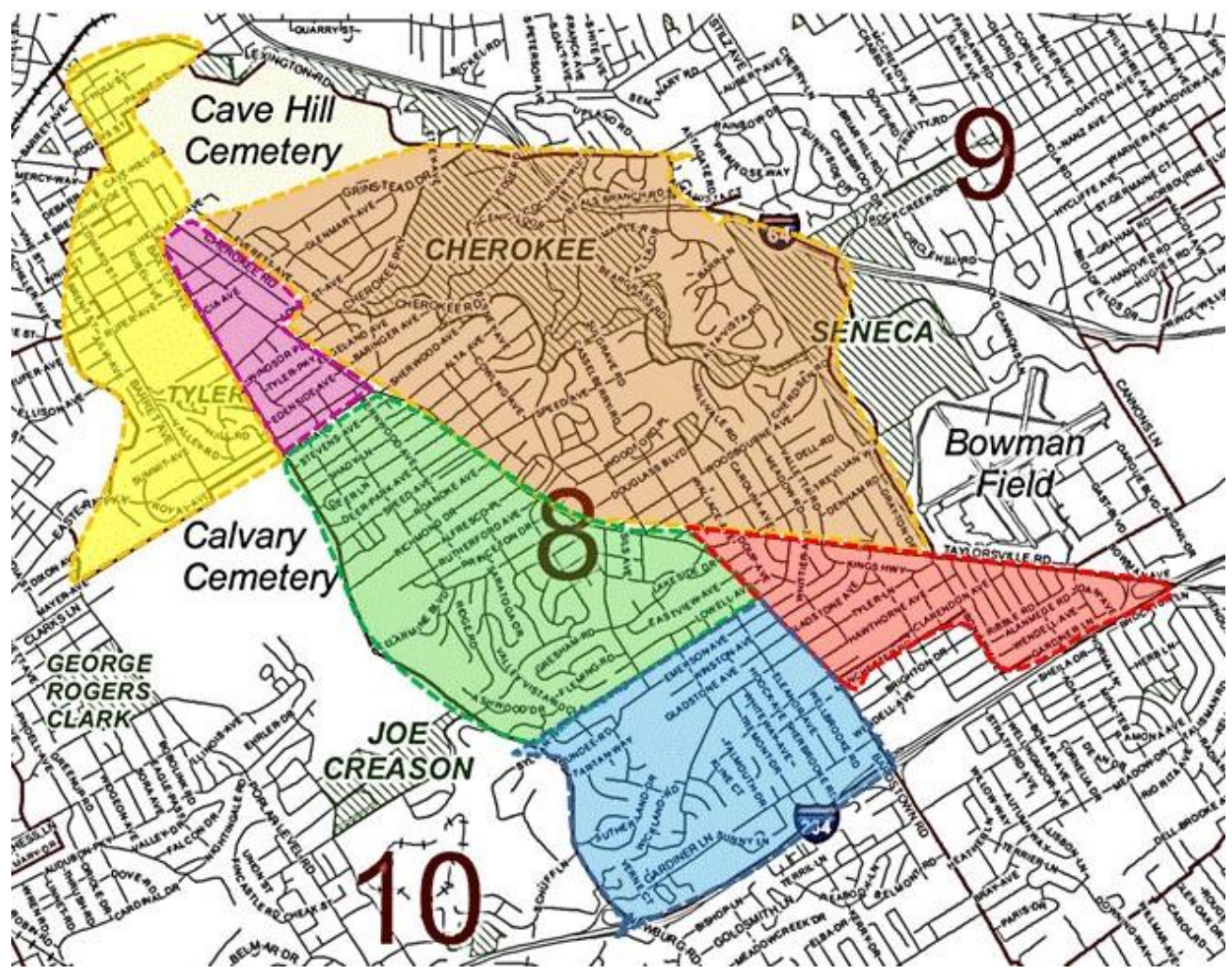

Figure 5. Residential Zones for CSPS

The survey was accessible on the Metro Council District 8 website through a link on the site's homepage. I distributed the survey link through residential door-to-door, business-to-business interactions, community events and meetings, and flyers displayed in public areas and businesses. Approximately 250 small handouts and 30 flyers were handed out to community members. In total, spent approximately 24 hours disseminating printed materials encouraging survey participation. I also sent emails to all the neighborhood association presidents, along with several follow-up phone calls. This resulted in third-party social media updates, emails to residents, and announcements at neighborhood meetings. Table 2 shows details regarding survey outreach for this case study. 


\begin{tabular}{|c|c|c|}
\hline \multicolumn{3}{|l|}{ Survey Outreach } \\
\hline & $\#$ & Hours Spent \\
\hline Handouts & 250 & 10 \\
\hline Flyers & 30 & 4 \\
\hline Community Outings & 1 & 2.5 \\
\hline Community Meetings & 2 & 4 \\
\hline Neighborhood Associations & 12 & 3.5 \\
\hline & & Total $=\mathbf{2 4}$ \\
\hline
\end{tabular}

Table 2. CSPS Survey Outreach

Information was provided to the respondents with adequate details about what was involved in participation and a voluntary informed consent had to be completed. The agreement to participate was voluntary and they did have the opportunity to withdraw at any time. Due to the survey format, this was simply done by the respondent exiting the survey application.

The questions are focused on the participants' perceptions of crime and law enforcement officials. This information can assist police in developing policies and practices that are successful at increasing community-police cooperation (Ashcroft et al, 2003). Standardized measurements that assess the quality of service industry employees have been used to attempt to measure police performance (Donnelly et al., 2006). Although there are aspects that coincide since it involves customer service, how police complete their work involves additional challenges and not all interactions are with willing participants. The government aslo sanctions police involvement and does not rely on patronage or sales. Several studies have been completed to test specific measures of police performance through public opinion surveys, including testing against theories and consulting policing stakeholders (Maguire and Johnson 2010). By identifying the conceptual definitions of trust and legitimacy, questions were created and tested through several stages, such as cognitive interviews, review of the questions by a multi- 
disciplinary panel of experts, and the use of the validity software called Survey Quality

Predictor Program (Maslov 2015). These stages were repeated and two pilot surveys were administered, measuring for non-response items, the extent of scalability, and correlations and then final revisions were made. (Maslov 2015). The questions about community perceptions of police performance and crime used for this survey were pulled from this research and are considered valid and reliable measures. The questions used for the survey are found in Appendix A.

\section{Focus Groups}

To obtain qualitative data from the law enforcement officers, a focus group method was used, which allowed several officers to systematically and simultaneously be interviewed. Focus groups allow researchers to see differences and commonalities arise through conversation (Barbour, 2007). This method was appropriate for this study because it offered the ability to observe interactions based on directed topics of conversation. This also led to an open and honest conversation that offered insight into what were important topics for the participants. The focus group approach was the selected method due to the police culture literature that describes the strong social group that formed through the camaraderie that exists between police officers. This method built on the understanding that each of them might have regarding police culture and then alleviated the potential difficulty in expressing information to an "outsider." The discussion questions asked the participants to pull material spanning a large amount of time, which could include several instances of formal and informal community interactions. The group setting assisted in recalling events, interactions, and encouraged anecdotal narratives that would otherwise have been forgotten or discounted. The 
questions guided the officers to discuss topics relating to perception of the job, the community they serve, and specifically about walking patrols. These answers developed themes and helped contribute to the overall evaluation of the results of community policing efforts from the officers' perspectives and how this contributed to their work attitude.

Officers who participated in the foot patrol were divided into two focus groups, with four participants per session. The other two groups consisted of four and three officers who were assigned primarily to vehicle patrol. This method was selected to bring out aspects of the topic that would not have been otherwise introduced by the researcher through individual interviews (Babbie 2010). The guided discussion was based on questions listed in Appendix B, but were occasionally altered during the session to get more details from an officer's comment or to direct the discussion back to the original topics. I recorded the sessions in their entirety and the I copied the audio files to a computer file that was password protected and then deleted from the recording device. The recordings were transcribed, imported into the Dedoose database, and coded. Overall, focus groups allowed for deeper insight into police culture, providing a space where officers could describe details of similar experiences and perspectives, often jogging each other's memories to provide greater detail. The inclusion of focus groups as a method allowed for richer data and a more thorough picture of the officer's experiences on patrol.

\section{Interviews}

Semi-structured interviews were completed and allowed for an increased understanding and more thorough examination of the topics that were observed or 
brought out in focus groups (Gillham, 2000). Trust and confidence are important to establish early when doing interviews, which leads to more open responses. For this research, using this method was beneficial to me, because I had already established a rapport and trust with the participants. "It is, in fact, remarkable what people will disclose if they feel you are a person they can talk to" (Gillham, 2000: 16). These interviews allowed me to discuss the topics with the walking patrol officers in more detail following the focus groups, allowing for more personalized experiences and/or clarification from focus group responses. The interviews provided an opportunity for officers to share information or opinions they were possibly unwilling to share with others during a focus group, such as views that countered the majority consensus or more private details and experiences. It was also a chance to talk to vehicle patrol officers that were unavailable for the focus groups. The goals of these interviews were to both expand on topics identified as points of interest in focus group and to provide a space for individuals to share more candidly or privately in a one-on-one setting. The guided discussion was based on questions listed in Appendix C, but was occasionally altered during the interviews to get more details or descriptions. The sessions were recorded in their entirety and the audio files were copied to a computer file that was password protected and then deleted from the recording device. The recordings were transcribed, imported into the Dedoose database, and coded.

\section{Coding}

I completed a line-by-line process in the Dedoose program using the focus groups and interview transcripts. I assigned broad categories, then narrowed them into sub-codes. I also separated the responses based on the officer's assignment, walking or 
vehicle patrol. These codes and sub-codes I reviewed thoroughly to determine if any additional themes developed from the research. Since this case study indicated additional codes, I went back through all the transcriptions and did shared coding for the additions. This process allowed me to quickly analyze the responses and determine differences and similarities based on the patrol assignment.

\section{Protecting Data}

The survey required the identification of a respondent's residential "zone," which were visually represented on a color-coded map (see Figure 5). This information was necessary to determine if they were within the boundaries of the foot patrol initiative. The focus groups and interviews could potentially allow for individual identification. A pseudonym was given to each participant and only minimal demographic information was provided for the research project to limit the possibility of other officers, command staff, or community members identifying any participant. Data files for the survey and the focus group protected respondent identity and ensured confidentiality. Electronic files from the survey data were password protected and the storage device or network had a password requirement. Focus group recordings were accessible only by the principal investigator. Once the information was received and processed, the data files containing any identifiable information were deleted and/or destroyed. Information during analysis was distributed only to the principal investigator to minimize a potential breach in confidentiality. At no point will the sponsoring organization receive information regarding identifiable information from the survey data. 


\section{CHAPTER IV: \\ QUALITATIVE FINDINGS}

I completed approximately 560 hours of participant observation during this case study, where I attended roll calls regularly, walked the patrol area with and without walking patrol officers, and observing police/citizen interactions throughout the shifts. I spoke with business owners, residents, and the walking patrol participants. Operating in

dual roles, researcher and police officer, during this study provided me with an incredible amount of insight into the walking patrol initiative, the community response, and the officer's daily activities. I recognize the limitations that result in operating in an official capacity during the research, but it also allowed me to observe, converse, and interact in ways that would not have occurred otherwise. I also walked some shifts in plain clothes to add a different lens to my observations, which made me less noticeable by the public and the walking patrol officers. This allotted the opportunity to watch undetected and ensure that the interactions were not affected by my presence.

\section{Participant Observations}

Although I am very familiar with policing and public response to law enforcement, I included participant observation in my research because I have never participated in a walking patrol as my primary assignment. To gain a full understanding of this program and its implementation, this was an important research method to utilize. I not only had access to observe the officers while patrolling their assigned beat, but also 
their roll calls at the beginning of the shift. I also got to view the public response to the foot patrol officers on the sidewalk, in businesses, and at community events. I did observations in plain clothes, a police uniform, and from my unmarked police vehicle, as to encompass all the different responses that may be received based on my presence or lack thereof.

My first participant observation was at the introductory meeting that included the foot patrol sergeant and the officers that had been detailed to his unit. Since they were all from the same basic academy class, there were no introductions, except the sergeant. He did a brief overview of the locations of the foot patrol boundaries and proceeded to explain the expectations. The meeting was opened- up for questions and the first one was, "So, no exterior vests?" The sergeant immediately responded with a no and explained that "We want to be approachable." The question became a uniform conversation. The officer's wanted comfort, but affordability. They had just become probationary officers and did not have an abundance of uniforms. There were concerns about wearing combat boots instead of tennis shoes while walking. The discussion was tabled by the sergeant and he advised them to report to their first roll call in their Class A uniform, or formal attire. Several weeks and miles later, the sergeant allowed them to wear their Class C uniform, which was a polo with tactical pants and tennis shoes.

Roll calls occurred at the LMPD $5^{\text {th }}$ Division, and although the times were different from the vehicle patrol officers, they would often cross paths getting equipment, docking body cameras, using the restroom, eating lunch, or turning in paperwork. The body camera docking station was small with white labels above each row to identify where different shifts were supposed to upload their videos and charge their devices 
while they were off duty. The $5^{\text {th }}$ Division made a label for the walking patrol, designating their spots. On several occasions, there would be handwritten notes taped over the "walking patrol" label. One label read "coffee and snow-cone patrol," and another read, "enjoy your popsicles and coffee." The sergeant removed the small, jaggededged paper and responded by writing "we will" and taped it to the roll call door. It stayed there until the last day of the walking patrol assignment and is possibly still there. I could tell that the new officers were not amused by the comments made in a passively aggressive way, but they also did not retaliate. The mystery labeler is still unknown.

On one occasion, while I was in uniform, observing two foot patrol officers having a conversation with a business owner, I was approached by an off duty officer. $\mathrm{He}$ introduced himself and explained that he was also a graduate of the same Metro Academy class as the officers assigned to the walking beat. It quickly became clear that this officer wanted to know how he could get an assignment to this pilot program. He had heard good things and his fellow graduates were raving about the benefits of the unit. I explained to him that I had no idea if the department had any intentions of continuing after the summer, but if they did, I would let the commanding officers know that he was interested. As the conversation continued, he explained that there were several of his cohorts that were also interested and that they did not want to ask because of the stigma following the walking patrol. I asked him to elaborate. He leaned forward and said quietly, "I don't want to be considered lazy or incompetent." When I asked him what he thought about the walking patrol assignment, he said he "respected" it and "wanted to make a difference." He continued, describing vehicle patrol as "putting out fires, but never getting to help with rebuilding." The conversation ended with, "that's not what I 
signed up to do," as the walking patrol officers approached us after they finished their conversation with the business owner.

I was in uniform trailing behind two female walking patrol officers on Bardstown Road when two civilians approached me on the sidewalk. They were in their mid-late twenties and had just exited their vehicle that they had parked on a side street. I had watched them get out of their car, purses thrown over their shoulders, conversing with each other. I could see the officers catch their eye. They continued walking, but their conversation paused. Then they both began to look around attentively and purposefully. The walking patrol officers had passed them long before the two had reached Bardstown Road from their parking spot, but when they saw me walking toward them on the sidewalk, they stopped and waited for me to reach them. They continued to look around, while asking me "is something going on?" I simply responded with, "no, not at all. Why would you think that?" They explained that they had just seen two male police officers walking around the intersection at Eastern Parkway when they were driving here and then saw two different officers walking here. They gestured to the two officers still walking away. They explained that they did not want to walk around and shop if there was something "dangerous" going on. I quickly assured them that nothing was going on and that the officers were assigned to walk in this area. "We just never see police unless something bad is going on," said one of the females as the other nodded in agreement. They laughed a little at the comment and began to walk away, while I waved, smiled, and started walking to catch up with the officers. When I caught up with them, I explained the conversation that had held me up, but they seemed less than surprised, expressing the regularity of the question "Is something going on?" during their shift. 
During an evening observation, as I was walking with the sergeant, we were approached on the sidewalk by a white, male civilian holding a large white paper bag. $\mathrm{He}$ shifted the bag from his right to left hand and reached out to us with his right. He gave us each a firm handshake and introduced himself as the district councilman. He expressed his excitement about the pilot program and that he needed to know whom he should call to make sure this continues in his district. The sergeant said that he was not sure, but that the police chief should know how he and possibly other district members feel. $\mathrm{He}$ recommended emailing letters and requests for continuation to the mayor and the chief, but he made it clear that several factors would have to be considered.

Environmental factors do affect the police and what their shifts might include. For example, when it rains, collision reports will increase due to the changing road conditions and decreased visibility. Although increasing temperatures will increase calls for service, police proactivity will decrease during a rise in heat. While observing, I found that the walking patrol continued working as normal, even as temperatures soared into the 90s and 100s. Although the contacts with citizens decreased due to the limited amount of people outside, their presence was still noticed and appreciated by the public. During several interactions with community members, the mention of the walking patrol officers still being out and visible was consistently a topic of conversation. One man even explained to me that he appreciated seeing them out there working because his job requires him to be out in the elements daily. He works for the state doing road construction, which means he works in the boiling hot or the freezing cold temperatures. He said it was nice to see and that he had a new respect for the law enforcement profession. 
While vehicle patrol had the option to sit in a climate-controlled patrol car, the walking patrol did not have that option as freely available during their shift. I walked in uniform with two of the foot patrol officers on a day the temperature reached 98 degrees. Not many people were out walking around on the sidewalks or enjoying the parks in the area, so we kept a brisk pace and stopped in several businesses just to gain a reprieve from the blazing sun. I had layered on the sunblock and tried to drink water at every stop we made. I found out that most of the restaurants would give the officer's free ice water and I was very thankful to the kind business owners. The concern of the citizens about the heat was evident throughout the day. One older man exited his business and told us to utilize his awning on the front of his business any time during the day and continued with, "Work smarter, not harder." We did not stop at that moment, but we thanked him for the offer. Later that day, we stood there for about twenty minutes. During the break, I reapplied sunblock. As we continued walking, I was noticing how extremely winded I was while I chatted with the two officers. They were sweating, but their ability to carry on a conversation without pausing between every fourth word was obvious. I appreciated some of the side streets since they at least offered some tree coverage. Even with all the water breaks, a short lunch break, and an arrest, I was physically tired. One of the officers had a watch that monitored distance, and he reported that we had "only" walked 8.2 miles.

I went home that evening and peeled my uniform off and removed my bulletresistant vest, I had two large spots on the right and left side of my lower back where the skin was chaffed and raw. I drank two more large glasses of water and collapsed into bed. I was hoping the next day would be a bit better, environmentally and physically. The next 
day I was dreading the thought of putting my vest back on, because the spots were now tender scabs. There was nothing I could do to make it more comfortable, except not wear my vest, and although it was tempting, I resisted. Instead, I just cringed my way out the door.

A local coffee shop was very supportive of the walking patrol and would offer free ice water and a place to cool off. I had many conversations with the employees. They explained that their problems with juveniles and vagrants had decreased tremendously since we started the pilot program. I asked if they had previously known any of the officers on their beat and the male gave a small chuckle and continued making a coffee concoction. He said they have had to file reports for damaged property or stolen property, but the officer would come in, write down information, hand out a report number, and then leave. He explained that "The officers that have come in to take reports are always professional and respectful, but just did not go out of their way to be helpful." The employee told me that the last two reports they made were done over the telephone using the crime reporting number. He assumed it had something to do with the type of report. He said he had worked at the coffee shop for approximately one year but has never seen officers on foot in the area of Bardstown Road. He laughed, "Well, not really anywhere in Louisville." I could tell he had several conversations with the walking patrol officers, because one entered the shop while I was there and instantly asked the employee how his trip to the lake last weekend went. The conversation continued with lots of laughter and talking. The other officer ordered a coffee and snagged the newspaper. The officer told me that this is their "tea-time." They come into this coffee shop every other day and enjoy the conversations that always end up happening while they sit there. The officer 
continued, "It just reenergizes me after the heat and all the walking. Ten hours is a long time, so this breaks up the day a bit. The great thing is that I get to do my job right here, right here [pointing down at the wooden chair he was sitting in] if I want to. I'm connecting with the public and getting to catch my breath. I definitely look less menacing sitting here sipping a latte [laughter]."

Not all the LMPD 8th District residents and business owners were on board with the new walking patrol. While I was in uniform and walking with the sergeant of the unit, we were approached by a grocery store employee. We had just been doing a stroll through the store and checking in with the manager. The sergeant says he normally just does a quick lap to show presence in the store and chats with the manager or store clerk, letting them know that the walking patrol is out in the Highlands. Today, the cake decorator for the store, who was 60-70 years old, wanted to share her opinion with us. She said she has seen the uniformed officers walking around the store and she "doesn't like it" and that she wants an officer to "get there fast." The sergeant tried to explain that the unit is just added support to this area and that there are still patrol officers in their vehicles. She continued, “Doesn't matter. You all should be able to get here fast, not just some of you."

A few weeks later, I was walking down Bardstown Road at Edgeland Avenue. I got a text from the sergeant to meet at the Mid-City Mall parking lot. When I arrived, four of the walking patrol officers had circled up outside the Heine Brothers coffee shop. The sergeant had also asked them to meet up. Once I stepped into the circle, he said that there had been a complaint called in to dispatch from a local bar on Bardstown Road that had requested that the unit not be in the business or on the patio talking to customers. The 
immediate response was similar among the four officers. They expressed that it was "bull shit" and seemed confused, explaining that they stop in at that location all the time. It was shared that the patrons sitting on the patio at the bar will yell for the walking patrol officers to come onto the property and talk to them. The four described them as "regulars" and that they always enjoy chatting with the group about things going on in the neighborhood or just general conversation. The sergeant continued, explaining that it was the bar owner that had called, not the manager that they had usually conversed with during the shift. The solution he gave was just to respect the owner's wishes, and "if the patrons of the business want to talk to you, then they will have to come to the sidewalk and meet you." I could tell immediately that the officers were disappointed and somewhat confused at the request. There were never any more calls concerning that business, so I am unsure if the officers continued entering the business property.

In the last month of the walking patrol, the days had become cooler, but the radio was not as busy with communication from the unit and the roll calls seemed to be quieter and less enthusiastic. There appeared to be a lull falling over the eight officers and even the sergeant. I watched from my car for most of the day and would observe the pairs from afar. Two of them just seemed to be walking north and south on Bardstown Road, rarely stopping in at any of the businesses. If they were approached, they would stop and chat with the citizen, but other than that, their interactions were minimal. Their pace was slower, and each step seemed to drag forward. Four of the others were eating at a local restaurant and all of them left walking together. They went straight to a Popsicle shop and hung out there for approximately 15 minutes. After exiting the store, they stood outside and chatted for the same amount of time. They greeted several people that were entering 
and exiting the business and would go back to chatting amongst themselves. My observations seemed to show a lower level of enthusiasm from the officers walking and what appeared to be boredom. The residents and employees in the area were more accustomed to seeing the officers regularly and fewer people were asking why they were out of their cars and walking around on foot. I later asked the walking patrol about their thoughts on their assignment during the focus groups. Several of them answered that they were very happy with the initiative, but they became "bored" with the areas of the assignment. The suggestions that followed were to rotate locations monthly or switch areas with other officers from the same assignment. Comments also were made by the officers that they had met all the business owners and addressed most, if not all, of their complaints and concerns. Although the crime rates and displacement (as shown in Chapter 5) did not increase as the walking patrol initiative progressed as seen in other research (Sorg, et al.), there was a change in the officer's motivation and their level of interest in the area of patrol.

I had been observing most of the day in my uniform and was just about to leave when $5^{\text {th }}$ Division officers were dispatched to an abandoned building in reference to a homeless person sleeping on the front porch. I was within one block of the location and started walking that way. Once the house was in my view, a vehicle patrol officer pulled onto the street. She walked up the front porch and I followed just a few moments behind. I could tell she was surprised to see me, but she continued to focus on the call for service. I got on the radio and cancelled the second car that had been dispatched, but as I did, another police car was parking in front of the building. I heard the officer say he was already on scene. He exited his car and also looked confused about who I was and what I 
was doing on this run. We had located the subject on the covered portion of the front porch, where he had established a small sleeping pad and a collection of items. The female officer collected his information and I talked to the contractors who had made the call when they arrived to do work on the building. They explained that they had never seen the male subject sleeping here before, but they did not want to just leave him there with all the demolition going on in and around the site. I explained that we would take care of it and if they had any more issues to contact dispatch again. As they headed back to their cars, I explained that I was working with the walking patrol officers. The two vehicle patrol officers then started telling me about their appreciation toward the initiative and that the walking patrol had handled several calls for service prior to their arrival. The female officer explained that one day she was eating her lunch at the division and was dispatched to a shoplifter at Mid-City Mall, but was quickly cancelled by two walking patrol officers. She said she was grateful to get to finish her meal and expressed her apologies for the way other LMPD officers were talking about the initiative. She was dispatched on another run, so our conversation was cut short, but she said it was nice to meet me and left.

Several hours later, I met up with the sergeant at a coffee shop. We walked right up to the counter to order. I asked for an iced coffee and pulled my wallet out of my back pocket, and before I could even get my card out, the young woman told me that it was "on the house." I thanked her and waited for my order to come up. The sergeant ordered next and I heard her tell him the same thing. I wondered if we had ordered something more complicated and expensive if it would have also been free. We sat down with our coffees and chatted about the day. I told him about my observations and added in my 
concerns. I discussed with him about addressing it at roll call with the entire unit and getting them all back on task. He asked me what we would be addressing. My concern was that their energy level had decreased and that they should be encouraged to remain diligent in their assignment. He had to remind me that they are still completing their jobs, even if they are not continuously interacting with the public. People are still seeing them in passing and they are still patrolling while they walk. I realized that I was carrying around an implicit bias of what law enforcement should entail and how it should be done based on my law enforcement experience and expectations. This perspective is something that is handed down by other officers, creating the culture of catching bad guys and enforcing laws. This conversation made me realize that just because they are not proactively policing, purposefully engaging the public, or responding to calls for service, the group is still policing, protecting, and serving the community.

We finished up our coffee and he asked if I wanted to walk around for a bit. I agreed to it and we started southbound on Bardstown Road. We walked toward Mid City Mall and went in the east entrance. We were flagged down by an employee from the discount store who had just confronted a shoplifter. She explained that the female suspect put several large items in her tote bag and just continued walking away when approached. After getting a brief description of the suspect, the sergeant and I started in the direction that the shoplifter was last seen. When we exited the mall, we saw the female approximately 50 yards away. She continued walking away from us, so I followed behind her, while the sergeant went straight to the cross street to head her off. We caught up with the suspect at the same time and asked her about being in the mall and stealing. She immediately admitted to having stolen property in her tote and was willing to hand it 
over. According to her, this was her second time getting caught shoplifting at that store. She emptied several bottles of cleaners and soaps on the sidewalk and sat down. The paperwork was completed and the property was returned to the store. There is no way to know if the shoplifter would have been caught if the store employee had called dispatch for a vehicle patrol officer to respond. This makes the ability to determine the impact of the walking patrol on response times and arrests difficult, because departments cannot recreate the exact circumstances involved in the incident. If the shoplifter had left with the property and not stopped by an officer, she later would have been charged (known suspect), but the returned property would likely be gone.

\section{Interviews and Focus Groups}

\section{Analytic Sample}

During the fall of 2019, I interviewed eight probationary officers, five had participated in the walking patrol initiative and the other three were vehicle patrol officers. The amount of time at each interview ranged from 35 minutes to 96 minutes. I completed them at different police Divisions based on their area of patrol and their convenience. Two were interrupted due to calls for service, but they were completed within the participant's same shift. I also conducted four focus groups; the first two were with the walking patrol officers during their last week at that assignment. All eight officers agreed to participate and gave me two separate times to complete the discussion. I allowed them to decide who would attend each one.

The other two focus groups were difficult to complete. I sent emails to the eligible officers two different times, with only one response. After several attempts via 
email, I reached out to the basic training sergeants, who send an email to the Metro Academy Class 42 probationary officers. He explained to them who I was, what I was doing, and asked them to participate. He essentially vouched for my credibility and trustworthiness. Within one day of that email, I received a return email from an officer asking to participate. That meant I was only up to two officers willing to participate in the study. An advanced training officer offered to reach out to some of the people on my list that I had not yet heard. He texted them directly and asked them to call him. When they did, I was standing with him in the training office. I listened to him explain that I was a new member of the training staff, but was also doing a research project surrounding the walking patrol. He jokingly told them that I didn't work for PSU (Professional Standards Unit) and was just wanting to talk to them about their experiences as an officer. He also told them that I would be providing food for them, which was a good selling point to these probationary officers working 12 hours shifts. I heard him share my phone number with each one on the phone. Within a few hours, five officers responded to me through text messages to express their interest.

I also texted the walking patrol officers and asked them to reach out to their peers and explain the process of the focus group and/or interviews. Two of them texted back and told me they would reach out in the next few days. Originally, my goal was to select participants that were in divisions similar in run volume, demographics, and crime statistics, but after such a low response rate, I could not be as selective in the process. Therefore, some of the vehicle patrol officers were working in the divisions with some major differences from the walking patrol area. Once I had established a group that was willing to do the focus group, it took several weeks to get a time that they all could meet. 
The second vehicle patrol focus group only had three officers due to one officer who got a call for service just prior to the start of the discussion.

The participants were all graduates from Metro Academy Class 42 and had completed the same Patrol Training requirements. Table 3 displays the participant and department distribution information, including gender, education level, and age.

\begin{tabular}{|c|c|c|c|c|}
\hline \multicolumn{5}{|c|}{ Demographic Information of the Study Participants and LMPD Sworn Personnel } \\
\hline & \multicolumn{2}{|c|}{ Participants $(n=18)$} & \multicolumn{2}{|c|}{ Department (n=1186) } \\
\hline & $\%$ & \# & $\%$ & $\#$ \\
\hline \multicolumn{5}{|l|}{ Gender } \\
\hline Male & 72.22 & 13 & 85.33 & 1012 \\
\hline Female & 27.78 & 5 & 14.67 & 174 \\
\hline \multicolumn{5}{|l|}{ Age } \\
\hline $21-25$ & 50 & 9 & 16.95 & 201 \\
\hline $26-30$ & 33.33 & 6 & 19.31 & 229 \\
\hline $31-35$ & 11.11 & 2 & 20.32 & 241 \\
\hline $36-40$ & 0 & 0 & 17.28 & 205 \\
\hline $41-45$ & 5.56 & 1 & 15.68 & 186 \\
\hline \multicolumn{5}{|l|}{ Race } \\
\hline Caucasian & 77.78 & 14 & 82.72 & 981 \\
\hline Black & 16.67 & 3 & 12.73 & 151 \\
\hline Hispanic & 5.56 & 1 & 2.28 & 27 \\
\hline \multicolumn{5}{|l|}{ Education } \\
\hline High School/GED & 44.44 & 8 & 36.34 & 431 \\
\hline Associate's Degree & 5.56 & 1 & 8.77 & 104 \\
\hline Bachelor Degree & 44.44 & 8 & 43 & 510 \\
\hline Master's Degree & 5.56 & 1 & 5.31 & 63 \\
\hline
\end{tabular}

Table 3. Demographic Information

On examining Table 3 , it is seen that the study consisted of 18 participants and the distribution of the sample is similar to the departmental frequency. It was a purposive sample, only including those officers that met specific criteria, which included being a graduate of Class 42 and currently on a walking patrol or vehicle patrol assignment. By meeting these criteria, I was able to ensure the data information collected would apply to the study. I did have several other officers (from different Metro Academy classes) ask if 
they could participate, and although their willingness was appreciated, it did not satisfy the requirements for this type of nonprobability sample.

During the analysis of the focus group and interview transcriptions, several themes developed. Some were shared between the walking patrol and vehicle patrol while others differed. First, the differences and similarities between the two groups will be presented within the overarching themes that emerged following the analysis of the focus group and interview transcriptions. The questions and topics during the focus groups and interviews developed the following themes: community concerns and engagement, officer view of the community and their perception of public treatment, job satisfaction, thoughts and opinions on the walking patrol, and integration into police culture. There were also additional themes that emerged from the data, including race and emotional labor. A discussion and interpretation of the results in relation to the theoretical frameworks will conclude the information found from the analytic sample.

When presenting these findings, I developed a composite narrative of the walking patrol and vehicle patrol officers by using the individual participant's responses and their descriptions of specific topics. Using a composite narrative method assists in maintaining the anonymity of each participant. I wanted to protect their identities due to the nature of their responses and the complications that could arise if the responses could be linked with the individual officer (Markham 2012). Also, the research did not focus on age, gender, or education. My aim with the research was not to distinguish between individual officers through their demographic categories and it did not seem critical to include an identifying pseudonym with each response. Willis (2019) explains that composite narratives "allow research to be presented in a way which acknowledges the 
complexities of individual motivations and outlooks, whilst drawing out more generalized learning and understanding." When creating the composite narratives, I followed four practices presented by Willis (2019). First, the composite narrative is based on similar experiences, reflections, and roles within the study. All participants had the same amount of time on the department as sworn officers and had completed the same training requirements. The walking patrol and vehicle patrol shared the same assignments following their training, and the overall reflections of the individuals were shared. Second, all of the quotes were directly taken from the focus group and/or the interview transcripts. Third, details mentioned regarding location of the interview, paraphrasing of the discussions, or how the conversation emerged are directly from the source of the interaction. And lastly, I do not make judgement or impose feelings motivations within the composite narrative. Any comments made in the finding are taken directly from the interview and focus group transcripts and are not ad libitum.

Using all of these processes together can provide an accurate interpretation of the interview and focus groups for the final composite narrative. The modification is only a change in the presentation of the actual data. Composite narratives combine all responses on a specific theme that emerged into one "fictional participant" and allows for a discussion of data in a way that protects the identity of a small group of respondents. The officers who participated in this study were from the same academy class, were from a small sample population, and distinguishing characteristics could lead to identification. Therefore, the assurance of anonymity becomes difficult and is more in-depth than assigning a pseudonym and not providing personal information (Tolich 2004). Using fictional participants as representatives with narratives based on actual data from focus 
groups and interviews protects officers from being easily identified and connected to their statements.

If my research focused on specific issues surrounding gender, race, ethnicity, or other demographics, a composite narrative may not be the solution to maintain anonymity. The characters developed can only portray one identity, therefore it would be impossible for me to represent several contrasting characteristics. If there were enough participants representative of each variable being studied, then each character could embody that specific one. This is a weakness of composite narratives, but since this research was not focused on a specific demographic it was an applicable solution. I listened to the narratives from the interviews and focus groups two times, once during the initial contacts and again during transcriptions. As I coded and developed themes, I read the narratives in addition to listening. I immersed myself and made notes throughout of thoughts, similarities, differences, and connections between all the interactions. Using Dedoose made it helpful in the analysis of each participant's responses and assisted in creating the character for the composite narrative based on accurate depictions of the core story that developed. I began braiding several stories and quotes together, creating the characters, Jay and Alyssa. In the following segments, Jay will represent the walking patrol officer's responses and Alyssa will represent the vehicle patrol officer's responses. I only included background information for the created character if necessary to relay the main point of the response, which was important to maintain the anonymity of each respondent. The comprehensive representation through a single character allows the research to convey a wholeness to the themes discussed. 


\section{Results}

\section{Community Engagement}

The first section of questions and/or prompts focused on community engagement and demonstrated how participants were interacting with the public and what types of contacts they were making unrelated to police calls for service. It also identified how they balanced law enforcement action with opportunities to engage the community. The walking patrol officers expressed that several of their interactions with the community led to sharing contact information, including social media accounts, email addresses, and cell phone numbers. This type of contact sharing continued throughout the assignment and assisted in addressing complaints, making arrests, receiving invitations to civilian events, and mentoring youth. During the vehicle patrol focus groups and interviews, a majority of the responses did not include a lot of contact information and the community engagement was generally occurring during police calls for service or in passing at gas stations during their shift.

\section{Jay - Foot Patrol}

I met several youth during my walking patrol assignment and gave my Snapchat account out to a few of them. Through that social media application, some of the kids would invite my partners and I to play basketball. We couldn't always meet up with them, but we would try. I don't always know what to say to the youth in our community, but I do spend quite a bit of my off-time playing video games, so that usually starts a nice introductory conversation.

There is a hair salon in our walking patrol area that we would always stop in and visit with the employees. One of the owners invited the walking patrol to a cookout at her personal residence. I attended with three others from our assignment and it was so nice to 
hang out with some of the people we met outside of work. She met us as cops and now she can say she is our friend. It has become mandatory for us to stop in her shop every shift [laughter]. One time, while visiting the hair salon, there was a teenager that came up to me and said he "did not like police officers." After conversing with him, he relaxed and seemed to enjoy our company. I gave him my phone number and told him to call me if he needed anything. There were a few times that the kid has gotten into trouble and he would call me. Sometimes the kid just wanted someone to talk to and needed someone to look out for him. He was getting bullied at school and would call me and ask for advice on how to handle it. I would tell him to reach out to a teacher or principal, but more importantly not to fight the bully. I'm not sure what that kid's future looks like, but I hope that his opinion has changed about the police and that my advice helped keep him safe and in school.

Another business that I became close with the owner was a specialty shop and the owner preferred that we call him by his nickname, "BigM." He was an incredibly good guy that spend most of his time looking out for all the walking patrol officers. He even bought us dinner one night during our shift. He was always talking about how we were preventing so much crime around his business. "BigM" explained that he had seen fewer problems during the summer months and that he had "no doubt" that it was due to the work of the walking patrol initiative. I look at our relationship as more of a friendship than a contact.

There were several shoplifting arrests or citations that I completed as the result of contacts with local business that would call me on my cell phone for assistance along with calling 911. I would often cancel the "beat guys" (vehicle patrol) and handle the run 
for them, or if it was a "regular" that was making a disturbance, the business owners would simply call me and trust that I would take care of it for them or find someone that could if I was on the other end of the beat. Several business owners have my phone number. I just hand it out during shift so they would have another option besides calling 911 or waiting for dispatch to send officers to respond. Obviously, the walking patrol did not work every day, but if we were not working, I would still try to answer and do my best to help the business take care of the problem. We are so familiar with the area that nine out of ten times we knew exactly who it was causing the problem and whether the person had an active arrest or bench warrant. I think that this knowledge and these interactions helped us build rapport with the community and that it made the situation a lot easier for everyone, including the officers that were responding. It became safer, because the walking patrol knew the people and the specific areas where problems were occurring. One example that comes to mind was a call I got about a homeless guy. We knew which vagrants would get aggressive, what drugs or alcohol they would partake in, and how to get them to say "guess I better go." So when we are dispatched or when we received a phone call, we generally knew who it was and what to expect when we showed up. There were a few times that I never had to say a single word to some of the regulars, because they knew if they did not leave or stop causing problems, I would arrest them. Also, during our roll calls, the walking patrol would share with each other the information about different incidents or people that we were having problems with. This was helpful, since any of the walking officers may be confronted with or addressing the same problem during their shift. 
When I returned to vehicle patrol following the end of the walking patrol initiative, the balance between engagement and enforcement greatly differed from walking patrol. It's mostly one-sided toward community engagement on foot and I felt that I was way friendlier and more open conversation. I also think I was more approachable. I'll use Jason and Sara as an example. There was this homeless couple that would panhandle in several different areas within the walking patrol and I would chat with them both when I saw them. One day, the male was very upset and I took the time to reassure him and let him release some frustration with the lay-offs. The homeless couple did not want to be homeless and felt that asking for money was their only option. Anytime I would see applications out or "we're hiring" signs, I would track down the couple and relay information about local businesses hiring. My assignment now would be much more cut and dry due to run volume and the differing opinions on what patrol officers priorities should be. On the walking patrol, the priority was making contacts and making an impact. I was still doing police work, still talking to people, but now I've taken one of those components away. Now, I'm strictly doing police work. I've isolated myself inside a vehicle. My new vehicle patrol partners get irritated with me when I speak with the person that called in the run. After the call for service has been cleared, I will go and talk with the caller. For example, we were dispatched to the White Castle parking lot where the manager was having some problems with disorderly kids on the lot in the middle of the night. After showing up in the lot, the juveniles had left and we cleared ourselves on the radio, which makes us available for another call for service. I like to make contact with the caller, so I met with the manager and told her to call dispatch if they come back and wrote down the description of each person. My partners 
are already moving on to the next run, which limits their contact with community members. A lot of these people call multiple times during the week, sometimes even within a shift, and I have found that when I take this approach on a run, the next time I shows up the people calling recognize me. If I stay and talk to the caller after the run, the person is much more receptive the next time I am called there. One of our calls for service involved a woman being kicked out of church housing on Christmas Eve. She and her two young daughters had their hands full with all that they could carry out. They were not able to enter back into the residence and the mom had stored all their Christmas presents in the storage room. I dug through my trunk and found two stuffed animals for each of the kids. Their mother just broke down in tears. Hell, I almost cried.

I just think that it's sad that we just stay so busy and we are undermanned that community policing isn't a thing. It is obvious to me that some officers don't care that it's not a thing. They are like, "let's go to this run and catch bad guys," which is great but the satisfaction like I got on Christmas Eve with these two little girls makes you feel like you are doing something good. At the end of the day, those girls are going to remember that when they had nothing for Christmas, an officer gave them plush unicorns. I'm not sure how many of the officer's in my Division, or on the department, will take the extra time on a run to engage the community. You can see it in some officers, they are just bitter. They just say let's do this stupid run and be done. I know that now I am way busier with dispatched runs, but I still try to do my part.

\section{Alyssa - Vehicle Patrol}

I have minimal information about contacts that I have made. I recognize the people, like the Thornton's clerk and loss prevention employees at Meijer, but that's 
about it. I don't know them by name. Our community engagement is generally occurring during calls for service or in passing at gas stations during our shift. I am horrible with names [laughter]! I am not a huge fan of officers giving out their phone numbers and I rarely do. Although I did just download a new application on my phone, which allows me to make calls through that without people getting my actual phone number. I think that will help me a lot when I'm out there in the community.

When I respond to a call for service, get gas, or grab some food, I will meet employees, especially the ones working security or loss prevention. During my shift, most of the local businesses are closed, so it does make it harder to connect with and meet people. I can see how the hatred of police can go hand-in-hand with engagement. We go to a run on the worst day of their lives and that's the only time they talk to us. They just think we are always locking people up. I attempt to make their day a little bit better. When I get a call for service, I can still be supportive and helpful to the community. The division I work in has an extremely high run volume, but that does not mean I can't be proactive on the actual call. For example, if I am responding to a traffic collision, the caller may be crying because they have never been in an accident and you just hold their hand or someone that's suicidal and you just talk to them and try to make them feel better. We [officer's] still need to try to make an impact when we have time. Contacts with the public are beneficial, but also can be annoying at times. "Karen's" [a term that is slang for white, nagging female] are a regular call we get. They are usually calling about very important things [said sarcastically] that they would report to the police. "Karen's" will call us over and over about things that really aren't important at all and are nowhere near the big fish we are looking for. We still try to help though. There is 
a retired firefighter that lives on my beat and his neighbor's kid sells drugs to junkies in the area. My beat partners and I will sit out on the house and watch. We will make traffic stops or do field interviews in an attempt to decrease the drug activity in the neighborhood. Another example is an elderly woman that would consistently call the police on her juvenile grandson for acting out, participating in criminal activity, or getting into domestic disputes with his siblings. I will do what I can, but I can't fix what she [caller] has managed to screw up in 15 years, but I will solve it for the night and know I will be back there my next shift.

I consider community engagement and enforcement actions unbalanced on vehicle patrol, with enforcement being a priority. I try to do more enforcement, especially when citizens tell me about issues they are having. I consider it my outreach. What I mean is that community engagement can be used to aid in enforcement. If I gain the trust of the locals, it will lead to increased information on crime and enforcement will follow. We can't be there all the time like they [callers] are. We are only there 12 hours a night and they are going to a see a lot more than us. We get called and that engagement will reach some type of enforcement action.

\section{Community Concerns}

When participants were asked what the people in their patrol area were concerned about, responses varied based on the Division to which they were assigned. The specifics of the concern were not as important to the research as determining by what means the officer gained this knowledge and perception of the community concerns. The response that people would just "walk up and tell us these things" and "ask us to do extra patrols" was expressed during the walking patrol focus groups and the individual 
interviews. Most of the vehicle patrol officers gave detailed descriptions of the concerns of the community, but their awareness of the issues revolved around calls for service, victims of crimes already completed, and "heat maps" that were given out at roll call. These are areas developed by police analyst based on the crime statistics for the week/month and are generated in a pictorial representation of a geographic area.

\section{Jay - Foot Patrol}

It seemed like anytime I would get my coffee, which I like to refer to as "tea time," I would have someone come up while I'm there and ask me if the Highlands are safe or tell me about their biggest concerns in their neighborhood. Safety was their biggest topic of conversation and getting the opportunity to talk to me about it seemed to help them. Some of it I couldn't even do anything about legally, like panhandling, but most of the time it would give me and my partner some direction. We would at least know what the citizens in the area wanted us to be doing.

\section{Alyssa - Vehicle Patrol}

I would say that in my Division one of the biggest issues would be theft from auto and auto theft. That's what they're concerned about. So because of that, we do a lot of patrolling to see if anyone's out there checking car door handles and sadly most of that is from drug habits or juveniles. It's meth heads or juveniles just doing it because they don't have anything better to do. We can't really do anything about juveniles and we can't

really do anything about meth either [laughter]. I really get to know the issues on my beat from taking the reports; that's how we hear the community's voice about it. I'm also always referring to our Major's emails that show us a heat map where those crimes are 
specifically occurring. I'm just kind of guessing, based on what the Major is pushing on us.

\section{View of Community}

When vehicle patrol officers were asked about positive things that occur in the community that they patrol, silence would fill the room briefly and sometimes laughter after another participant would say that "Nothing positive happens". Most of them eventually came up with a response, but it would be somewhat ephemeral and uncommitted, such as, "The churches in the area do good things for the area" or "Wyandotte Park hosts activities sometimes." The lack of detail and ability to provide additional information gave the impression that details were unknown or they were uncertain of the specifics. The walking patrol officers were more detailed in their responses which also revolved around their positive impact in the community.

\section{Jay - Foot patrol}

We had some kids that challenged us, saying that the police hurt people. I would take the time out of my shift to get to know these kids, answer their questions, and talk to them. My partner and I would be out on the street and an adult would come up and say my kid talks about you at home. You're the officer that comes to the school. I feel like we don't do that enough as a department and I have even talked to other officers that say, "Why are you going into the school? You're not being a very good officer if you're doing that." To me, it makes a bigger difference when you get to know the kids on your beat because parents are coming up to us, they know our names, we're building rapport through the youth. We started with the kids and we're ending with the parents. For example, my partner and I were approached by a black female with her young son, 
maybe five. He looked terrified of us. She was asking, 'Can my son say hi to you?' We said absolutely. So, we go over there, and we talked to them and we asked if he wanted to take a picture. The mom said "absolutely." She told her son not to worry, that we were not going to hurt him. It was kind of sad. It was great that she was saying, "I want you to like the police", but just that he has this perception at such a young age that we might try to hurt him. We took a picture with him and he hugged us. We let him in the car. It took 10 minutes of our time, if even that. There are other officers out there that won't take that time. The mom was extremely appreciative of it and hopefully that changes her sons mind set. Honestly, when I hit the street I was like, “Oh yeah, bad guys, runs, lock people up." I didn't really think about the community part. It's just a great feeling to be a positive piece of that.

I would always get stopped and asked, "What is going on?" People were not used to seeing officers just walking and not responding to an incident. I began building rapport and trust with the people in the area we walked around. Black, White, Hispanic, young kids, older people, we started building bonds. A lot of times people would say, "If it wasn't for you guys, we wouldn't even talk to the police." Now it's more than just wearing the badge, we're human. Our job consists of being the police, but they would get to see the human side of us, instead of just putting a label on us.

Like I said, we would spend some time in the schools, but my partner and I used to go down to an after-school program where we were invited to just come hang out by the sponsors. It was for middle school age kids. One day, I came out and was just standing there and several people kept asking each other what we were doing there and wouldn't even speak to me. I remember this one kid he expressed his hatred toward law 
enforcement. You could see it all over his face, his body language, and even what he would express at times. And I told myself, "Man, the youth is our future, I have to give them different perspective of what police officers are about." Everything they see on the news isn't what actually happens. So, it took my partner and me a while to win them over, but what we did left an impression on those kids. Now, maybe they have a different perspective on law enforcement. After that, our overall relationship with the youth changed; at first they were real standoffish, then maybe a month or two later, I would see them while I'm working overtime and they would actually acknowledge me in a positive way.

One time, I was working the dirt bowl [basketball tournament] and the kids from the community center came and greeted me. They made sure that they came over and spoke to me. Then the same thing happened at Forecastle, two kids from the Highlands came up to me and started chatting. They would have never done that at first. It makes you feel good. They see that I am just a person too and that I can be their friend.

One afternoon, during my shift, I was walking past one of the little bars on Bardstown with my partner. There were two young ladies with two young guys drinking. Right away, the guys got defensive and started saying all this bullshit like "Fuck the police!" You could tell that he was being disorderly, but he wasn't really pushing it, so we couldn't really do anything. So, it was a moment for us. I said, "I have a question for you. Can I ask you something?" He was being very loud, and he lowered his voice and said, "Sure." I asked him his name and he became belligerent and said he didn't have to give me his name. I put my hand out and told him my name is Jay and he shook my hand. I asked him what he does for a living, he again began cursing and defended that he was 
not giving me that information. I asked again and he said finally told me that he installed windows for a living. I asked him “does everyone install windows as well as you?" He paused for a minute and he knew why I was asking him and his response after a few seconds was, "If everybody was as good as I was, I would be going home every day at 12:30. I know why you are asking me." He said that not everyone is the same. I told him that I didn't know what happened during his last interaction, whether it was good, bad, or whatever the case might be. I just explained to him that you cannot put a label on everyone and asked him to give us a chance to show you that we are not all the same. We chatted a little and at the end of that conversation he said that I changed his perception of the police and said thank you for talking to him. And that's all I did! I took five minutes of my time to sit down and educate him about not all of us being robots.

\section{Alyssa - Vehicle Patrol}

Vehicle patrol being present in the community is the positive part of what goes on in our division, specifically my proactivity with enforcement actions. For example, when I stop cars, I don't cite every single person that I stop, I don't letter-of-the-law police. I feel like that impact on the community is greater than anything else that can go on. My partners and I know who the persistent problems are and handle that accordingly. Our discretion allows us to make an impact in a positive way for the people we are policing and protecting. Often our run volume only allows us to see people at their worst and I rarely have time to do a 10-54 [investigation] for something just to do it, especially since it's the middle of the night. My partners and I are always hunting proactively to serve the community, we are very young and motivated. 


\section{Public Treatment}

When the officers were asked about how the public treats them during their shift and how they perceive that the community sees them, it was similar between the vehicle and walking patrol. Both groups discussed how the treatment was much better than they had expected it to be following their graduation from the Academy. Both the groups mentioned that the treatment received seemed to depend on the area of the city they were patrolling, but that it also had to do with the officer's previous interaction with the subject and the attitude of the officer during the call for service. The vehicle patrol officers seemed to relay that they thought that most people in the city had a positive perception of law enforcement, but they were interacting mostly with people involved in negative situations and were not just casually conversing with the community.

\section{Jay - Foot Patrol}

Prior to becoming an officer, I had paid a lot of attention to police issues and knew that tensions were rising between the community and law enforcement. There seems to be an "anti-cop" lean to everything you read in mass media. In the Academy, I had some experiences where we would just be running down the road and people would be yelling out the window as they drove by "'Fuck the police!" The instructors would say that those are the people that are going to kill you the first chance they get. That's when I realized it really is that bad. And then we got out on the street and I realized it's not like that. The ones yelling were just being assholes because there wasn't anything we could do about it. It was mostly because of the Academy and the social media stuff that made me think people hated the police all day, every day. So, it is definitely better than I expected. I didn't think when I came into work every day I would be thanked for my service. The 
picture I had was kind of like a fishbowl, where they see you and you see them, but they don't communicate or talk to you. The walking beat it is obviously better than I had perceived. No matter where you go, people will thank you for what you're doing. It's an everyday occurrence, from young to old, people generally have liked us and what we are doing.

I would get several invitations to personal events and parties. One day, I attended a backyard barbeque in the west end of Louisville. The west-end is typically portrayed as high crime and anti-police, but everyone was happy to see us. They weren't worried about dope or drug crimes. They were worried about speed bumps [laughter]. Everybody was really friendly and welcoming.

\section{Alyssa - Vehicle Patrol}

Sometimes it can be a mixed bag when we respond to incidents and it does not matter the reason we are there. It could be an arrest or just a general interaction and the person is just going to be mean and it has nothing to do with the actual call for service. When I graduated and rode with my PTO, he loved to just chill out during the shift and was not very proactive. Seemed like everyone was thanking us for our service and I wasn't really even doing much then. Now, being in my assigned division, it is so busy, especially in the summer, and you don't hear many people say thank you". Most of the people don't like you. You will show up on a shooting and people that you know were out there all day, will tell you, "I don't have anything to say." So, there's a pregnant lady shot and you don't have anything to say? I guess that's the difference I noticed between the neighborhoods I started in versus my patrol area now. 
It's often a pleasant surprise when I would show up on a call for service and someone was nice and respectful. I would say 50 percent of my beat doesn't hate the police, but 90 percent of the people that I come in contact with on a daily basis do. That is the problem. I'm showing up on these runs and there's a reason why I am there. There seems to be an overall disconnect in trust between the community and the patrol officers. It is the trend right now within the U.S. There seems to be a silent majority that supports law enforcement. Police supporters might drop off cookies at the Division, but they're not going to do much more. When the news stories come out chastising us for doing everything that the Supreme Court and policy tell us that we can do to get our job done and we do it, somebody will cry about it. The supporters will not speak out against it, because they don't want to get threats or negative comments. For example, some people on Facebook who try to say a little nice comment about LMPD or the police in general are attacked by groups of people who disagree. It's just not worth it to them. They do support, they are just doing it in ways that they can remain anonymous.

The community's lack of understanding and knowledge of what law enforcement personnel can legally do in specific situations also causes difficulties in communication. Several citizens have a nuanced reality and will say “the police wouldn't evict my neighbors for me, so the police don't do anything around here." Well we can't solve that problem, but I don't think the community members that we actually do get to help are broadcasting that. Think of the domestic violence victim or the person who gets their stolen car back because of us; they are safe and got the property back, but I doubt they are getting on social media and thanking an officer for it. No one wants to post "Thank you to the officers that arrested my husband after he brutally assaulted me" or "I'm an 
idiot and left my car running at the gas station and it was stolen, but don't worry, LMPD rocks and returned it today."

\section{Job Difference}

Vehicle patrol and walking patrol officers responded similarly when asked how the job was different than expected following graduation from the basic Academy and field training. The concepts being taught and reinforced through scenarios, discussions, and videos portrayed to the officers the intense and dangerous components of their jobs. It bolstered the dangers of law enforcement and the vulnerabilities that could be exposed by the officer based on their response to a call for service.

\section{Jay - Foot Patrol}

The Academy is always intense. Every scenario and every video, the risk is so high that we will be injured or killed. It changes the way you talk to people and the way you look at them. The way I talk to people is firm, but I don't yell at people. I don't try to get them to fight me. I have seen other officers try to do that. They try to get some kind of violence out of the situation and are just really confrontational. There's no need for that, that's not how I do it. That's how they trained us in the Academy, to be aggressive, and I feel like that is really counterproductive. There's a time and a place for that, but my partner and I got a guy out of the car that had a digital scale on his lap and cash on him, so he had every reason to fight us or run. I just said, "Hey, hand it over," and he did. There was no need to rough him up or yell at him. That's the difference between training and doing it in real life; it's much more low-key and controlled.

During the training scenarios, they are trying to rough you up no matter what. It kind of seemed like part of the end game during the Academy was to end the run in a 
violent or negative way. When I got out on the street, I was intense, stand-offish, and basically avoided small talk. I mean, if I think you are going to kill me, I'm not going to go out of my way to be nice. I totally understand why we train like that, but there should be a balance. They want to prepare you for the worst. The idea is if you can perform during a worst-case scenario, then you can do well at the basic stuff. I don't feel like that's always the case. I went on a loud music complaint and the college students immediately complied, turned the music down, and apologized for the nuisance. I didn't know how to wrap up that call, because they did what I asked [laughter]. I did know what to do if they turned the music up louder or it someone ran at me with a knife, but respectfully turning the music down, I had no idea. My partner and I have volunteered several times with new recruits and act as role-players. We will be compliant and make it realistic. We're not just going to fight them and then not get the recruit any training out of it. A lot of them just can't talk to people and it's a huge problem, because when you get on the street, it's not always guns out and people trying to kill you. You have to know how to talk to people and some of the new officers can't. Honestly, I was one of those officers before the walking patrol. So honestly you are preparing them for the worst, but what about just talking to people. You have to be able to do the basics of policing before you can be a successful officer out on the street.

\section{Alyssa - Vehicle Patrol}

The Academy mostly trained us in critical incidents, which is the worst of the worst. Time constraints and staffing can limit the amount of repetitions with someone who just wants to talk to you. Instead, recruits are given the impression that every incident will develop into an adverse situation, where some type of confrontational 
behavior will occur. I was constantly anticipating something bad, like my first traffic stop, I thought the guy was going to have a gun and 16 people were going to hop out of the trunk. It is hard to change your mindset going on the street that every time this person is not going to throw a hay-maker and "granny" is not going to get out of the car and smack you with her cane. I get why they do it, you have to be prepared for the worst, but it's hard to break yourself of some of those habits that they teach you in the Academy [laughter]. After I started patrolling as a sworn officer, I really did have to take a step back several times and ask myself, "How do I need to handle this?" It's just so much different on the street, so much different. I wish there was some training in the Academy where I just pull up and you get the information, everyone is cooperative, and you don't have to fight anyone. They prepare you for a lot, but I wish some of the scenarios were a little more relaxed and just showed me how to go in and handle a basic run. Not everything on the street is as intense as it is in the Academy. Somebody that is acting weird, nine times out of ten they're just acting weird and they are not plotting a murderous ambush on you. Most of the Academy scenarios are like that.

\section{Job Satisfaction}

During the focus groups and interviews, all the officers expressed high satisfaction with the job itself and shared why a job in law enforcement was more satisfying than other jobs. They all also had similar responses when the discussion around what they were less satisfied with, such as the pay, politics, policy, and command staff.

\section{Jay - Foot Patrol}

This is the best way I can put it, every job I've ever had I have always called in sick as many times as I could. I would redline my vacation days, but this job I look 
forward to coming to work every day. Even on my days off, I look forward to when I can come back. That's because I enjoy what I do, who I work with, and I just love my job as a whole. It's that simple for me. I left the military and went to college and started working someplace. I hated my job. Even the stuff that I don't enjoy on patrol, like taking a traffic collision report, I still like it better than what I was doing before. There's a Gandhi quote and he says if you're not helping anyone then you're wasting your time. I wasn't helping anyone do reverse engineering, so I got on the police department and I have gotten drug traffickers, I have recovered kidnapped children, I took an accident report from a 16 year old that was crying and I got to calm her, and the list goes on. It's all so validating and fulfilling. I am very satisfied with my job.

\section{Alyssa - Vehicle Patrol}

This is my first career that I've stayed with. I've had a lot of random jobs, like I did food delivery for a year. Before that, I was in the military and at the job, sometimes aren't doing the job you signed up for, which can get frustrating. Sometimes it was hard to keep going to work, but there isn't a day as a police officer that I haven't wanted to come to work. There were jobs that I had that if I sneezed once I would call in sick. I was a bank teller one time in college, and it sucked. You're not doing anything. Here though, if I can talk, I can run, and I can breathe. Our benefits and pay aren't the greatest, but if I focus on those things like the old crusty officers that are so jaded, it just makes me angry and does not solve a thing. My job as a whole and what I do every day, well I love it.

Even if every run I made on a night is bad and everybody is just telling me that they hate me, helping that one person that genuinely needed me makes it all worthwhile. It totally makes the night worth it. Every night I come to work, I love being here, because 
I have fun. You get to see a lot of crazy stuff and interact with lots of different people. Even if I turn on the computer and there's an entire screen of runs holding, I still know it's going to be a great night. Sometimes there are things that we complain about, but overall it's still an awesome job and I like being a part of it. I think that the variety we get with this job is one of the things that makes me the most satisfied. I like the slow times we have where we just chill in a park and the exciting times when the emergency tones are going on the radio and $9^{\text {th }}$ mobile is on our beat asking for an entire Division to surround a building. Every night is a little different.

\section{Thoughts on Walking Patrol}

The walking patrol officers were extremely supportive and gave positive feedback about the initiative, including their satisfaction with the assignment and the amount of contacts they were able to collect. First, participants discussed the benefits of the walking patrol for themselves and the community, including increased communication skills, community interaction, crime intelligence, and tactical advantages. The responses from the vehicle patrol officers regarding the benefits of a walking patrol were minimal; some of them said they did not know enough about it, but most of their responses focused on the disadvantages. The participants would recognize that it was a good community policing effort, but disagreed with the logistics of the project. Manpower and lack of training were both popular concerns that resonated from the focus groups.

Jay - Foot Patrol

People are more likely to come up to officers who are walking than driving, because they see we're out there for a reason. When we're in the car, they don't know 
what we're doing. We could be responding to a call or be taking a report. Now, they might see us eating lunch and sit down and talk to us for a few minutes, which actually happens to us all the time. These conversations give me opportunities to build rapport, but also has the potential to provide valuable information regarding the neighborhood and problems that are important to the residents. We established rapport with business owners, bars, stores, and learned about the community perspectives about law enforcement.

I know the walking patrol has made me police differently. I would have been looking for my trouble areas, rather than going everywhere. I had the time to meet people that I never would have had the time to meet when I'm going from run to run. If I was on a beat and in a car, I would just be looking for the problem areas and crime the entire time. I would probably only know the Thornton's lady and the junkies that are up all night [laughter].

I was able to gain intelligence about crime occurring in the patrol area, which allowed me to police problems that community members had provided valuable information about. Issues that would otherwise be unknown to law enforcement. It seemed to me that if we did just a little bit of community policing, like asking people what was bothering them or what they needed us to take care of, would generally lead to some good intelligence about drugs or guns. They would give us a problem or something for us to address, then we would go take care of it and the person would come up and give us information a few days later that may involve some serious crimes. Sometimes the person would not even know the information was relevant to other crimes. I can remember one interaction, a woman sitting on the stoop flagged us down in an area that 
we had some drug complaints. I can remember thinking this is it, I'm going to get kilos [laughter]! And she said, "These old guys are coming up to our teenage daughters when they're getting off the bus. I think they're drunk. Can you do something about it?" I was a little let down, but explained that we would watch out for it tomorrow during our shift. The next day we're standing out there in front of Joe's shop and I see a guy walk over to this girl and grab her forearm and start talking to her. I go over and talk to this guy who is on a bicycle and I asked him “Do you know this girl?' He tells me no and I asked him if it was his cousin or granddaughter? He again responds with "no." I told him to get out of there or I was going to have to get involved and explained that I would be there every day. I guess he believed me, because I never heard about him harassing those girls again. I guess word got around that we did something about the complaint and so the mom pointed us to where there was some drug dealing going on at a location down the street. It wasn't kilos, but we took care of two problems with that one community engagement. My communication skills also flourished after the walking patrol assignment. I don't think I could really talk to people until I did the walking beat. When I was fresh out of the Academy and completing my midterm evaluation, eight weeks in with a PTO, and was finding myself just going through the motions. I'm doing reports and getting what I need, but not actually talking to people and figuring things out on my own. My PTO could see it and would write about my lack of communication skills in my evaluation and the community members were not responding well to me. My PTO would ask me what I would be doing on a call and I would be getting the information for the report, so I remember being confused as to what I was doing wrong. I knew what kind of report I had 
to do, the property value, when it happened, what time it occurred, the caller's information and their phone number, and that was all I needed.

Once I started the walking beat I realized that I was lacking the ability to converse with people. I was a robot, a quiet robot, getting the report information and moving on. When I started walking, I just started saying "hi" to people passing, the barista, the store clerk, and the dog-walkers. That's how I started developing relationships and communicating with people. Now I feel more comfortable approaching someone and starting up a conversation. I feel like I could talk to anyone now and that's a good feeling. In the Academy, they always say that we need to use the "gift of gab" and that it would make policing easier and safer, but they make it seem like you either have it or you don't. I didn't feel like I had it until I was assigned to the walking beat. Who knows how long it would have taken me to realize I could actually talk to people and that the skill of communication can be learned. Policing as a job is a lot of just talking to people. This assignment helps officers, like myself, talk to people, gain experience, and become better officers. I became human, not robotic, and now can have a thirty minute conversation with someone I met two minutes ago. I would not have gotten this opportunity if I was just out there making runs and traffic stops.

There are also a lot of tactical advantages when you are walking that assist in policing and crime control. On foot patrol, we are hiding in plain sight and I can see things that we might miss in a vehicle. My partner and I have walked up and looked at people doing illegal activity five feet away from us. I almost felt bad for a guy, because we were walking out of a restaurant and this kid had a joint in his hand. I looked at him and said hello, in turn he put his hand behind his back real slowly attempting to hide the 
marijuana. Of course, I told him it was no use, we had already seen it. The whole time he had been looking for a police car, but did not consider one might walk right up beside him.

My overall respect for the community increased while I gained experience. In terms of community policing, we are actually growing and building relationships with the community. It's almost like a marriage. You have to have a relationship with the community when you are trying to police, just like you have to have a relationship with your spouse in your marriage. A lot of these officers just ride around in their cars like it's their very own spaceship and everyone else is in outer space. When they do get out and don't know how to interact with people, it's can seem really alienating for officers and the community. If you didn't talk to your husband or wife, you would get divorced, right? It's kind of a similar relationship when we are discussing community policing. For example, there are cops that will slow roll runs. They will be at the Division and will be dispatched to a disorderly person and they will finish their lunch and say they will "get it later and maybe they'll leave." I feel like the walking beat changed my perception on that, now I take it personally. I know these people and I know who is most likely at the residence or business and I want that disorderly gone as bad as the caller does. This relationship I have built with the community makes me more eager to go on that run.

My partners and I knew that the department really didn't support us. Other officers, even ones from our class, would challenge us on social media and even in our yearly in-service training. We had to constantly defend ourselves, our work, and validate our identity as officers. There was a post from a commanding officer on the employee Facebook page after we started the walking patrol. He tried to make it sound like he 
wasn't trying to start anything, but it was very obvious that he was attempting it. The post was asking what other employees thought about the new initiative. The officer posting said that the walking patrol would hinder new officers and put them behind. I hesitated about even responding, but I wrote this huge paragraph about the pros and cons and explained that the walking officers can do as much or as little as they want. Discretion could allow an officer to spend four months not doing anything, but if the officer stays active, he/she can learn a lot. I also brought up community policing. There were people commenting that it was stupid and that community policing is senseless. If anything was discouraging or frustrating, it was reading that. Even though I'm patrolling on foot, I do the same thing they do, and I take time for people. If I hadn't done this, I would just be like all those other officers, going to the call, getting the facts, and then saying goodbye. Now I'm going to take the time to actually listen, communicate, and act like I give a shit. The only thing different, is that I actually will. I think what's going to hurt us when we go back to the Division.

There will be officers that say, "You're from the walking beat, then you aren't a real cop." And some of us, depending on where we go, might experience retaliation for that. Just because they do not like the idea of the walking beat. There's been a couple of times that we walked into roll call and my partners and I would find notes on the body camera station that say we are lazy and all we do is text on the phone and eat ice cream. I find it funny, but it does get exhausting. I did not think that I would have to defend myself at work from other officers. When coworkers would ask what we are doing, I would respond by saying, "You really have to be doing what we're doing to know exactly what it is and what it means to the community." If you sit in a car all day, every day for 
12 hours at a time for 10 plus years, your mind is warped. You don't get a different perspective of people on your beat. You see the worst of the worst every day. I guess I can understand the resistance to change and the lack of approval, because in their mind, it truly isn't making a difference.

\section{Alyssa - Vehicle Patrol}

I had a positive interaction with the walking patrol officers when I was off-duty one day. I had watched them interact with people when I just happened to be out and about in the Highlands. One day at a local ice cream shop, they saw me and a few of them came over. We were all hanging out and they were catching me up on their lives. Someone walked by and said, "Hey, you're still good to come by tomorrow, right?" Jay responded and conversed with her briefly, then came back to our group. I asked him what that had been about. He explained that the woman was the principal of such-and-such school and they wanted a few of the walking patrol to come over and make an appearance at an event. That was something that I thought was really promising, you get to know people and interact with them.

Overall though, I think it looks pretty on a brochure and in theory. It sounds like it would be nice for our community to have officers just walking about, but I don't think that it's as effective as vehicle patrol, especially with our manpower problem. Is it worth putting our resources out there? Vehicle patrol officers still interact with the community and we still know our businesses. You can get to know your beat just as well without walking around it all day. I cannot say for sure because I wasn't assigned to it, but based on the walking patrol officers Snap Chat stories, it appeared that all they did was play 
basketball and sit in coffee shops. I guess it's nice to do and helps bridge the gap with the community and the police, but I'm not sure the walking patrol is the solution.

I personally didn't want to do it out of the Academy, because I thought it was a bad idea for my career. You go 16 weeks with a PTO, you barely know anything as far as taking reports or responding to calls for service. Then to go straight into a walking patrol for an entire summer, I thought that I would lose all those skills. When you are walking around, you are not taking five reports a day, you're not doing police stuff that you just learned, so you're going to forget it. I just felt that my skills would diminish and I want to be the police, drive around in my car, and fight crime. I feel like I would have a hard time doing that on a walking patrol. Seriously, how do you travel to different areas on your beat when another officer is screaming 10-30 [officer in trouble]? One day, we had a report taker screaming for help on the radio and we didn't know what was going on. The 2nd Division shows up, the 1st Division shows up, but if you are walking, what would you do? If anything happens on another beat, we will be there and it doesn't matter where you work, we're all the police and want to be able to get there. I hate not being a part of something. If I see kids playing basketball, I can get out of my car and shoot hoops with them. If I see someone standing on the corner, I can get out of my car and talk to them. I can do the same things as a vehicle patrol officer and still have the mobility to get to emergencies. I can be just as involved in the community without being a designated walking patrol officer.

Once the walking patrol officers returned to vehicle patrol, they were not as prepared as I was. They were on the walking beat for over four months, and in that time, I had done hundreds of domestic violence calls in my Division. When Jay got here, he was 
very unsure of how to handle the first domestic call we went on together, because he had not done it in so long. His main issue was with the paperwork, which forms to fill out, and how to write the citation. It was not something he had to deal with a lot.

\section{Police Culture}

All participants were asked to define police culture and detail what it means to them. While defining the subject, vehicle patrol officers used words like "family" and "brotherhood" within the description and the walking patrol used the words "drama" and "exhausting". The two groups varied greatly in their definitions of police culture and their level of inclusion in the police culture.

\section{Jay - Foot Patrol}

I see a lot of cattiness within our department. It's not professional and I think it looks bad for the department. I don't have a lot of patience for that kind of thing. I think the only argument that this group of officers on the walking patrol has had were about the job, not personal stuff. From my experience on other platoons during my PTO phases, there seemed to be a lot of dissent between coworkers.

I thought I would have connections with everyone and have a huge network of people. We come and do a job and we're not sure we are going to go home. Not everyone is trying to kill you, but it could be that one run and you don't go home. Some people I don't think take that seriously and they're too busy talking about who is seeing who and who is screwing who. I don't feel like I am part of the overall police culture and I'm not sure I want to be. I wish there was more of our group, the walking patrol. We are so close to one another. Every now and then we have our spats, but we work through them because we are a family. I see them more than I see my own son. I trust them, we get 
along, and there's no drama. I feel like we are what policing should be or what the policing culture should be. We have the greatest time, but when it's time to get to work, everyone has a different skill set and we use that to our advantage and I'm going to miss that. We truly are a team.

I had one PTO, there were no breaks. You get cited or you go to jail. Being with a PTO for so long, you're not really forming the way you want a police. You are seeing things the way they do, you start to mimic their responses, and that mindset just catches on. This realization occurred when I rode with a different PTO and we responded to a lady who called 911 saying she had been beaten up, but she had a warrant. The reason she called was to get away from her spouse and she was so scared she was willing to go to jail just to be safe. The first thing I was going to do when I got on scene was run her information and check her for the warrant. My PTO stopped me and told me, "That's not why she called us, she called for help." Riding with my first PTO made me lose my focus on why I became a police officer. I rode with him so long, I lost myself. The new PTO snapped me back. I lost what I was here to do and that happens to so many officers. What if my second PTO had been the same as the first? Looking at other officers, I can see that the repetition in response, action, and attitude is a reflection of the officers surrounding them. Obviously that is not always a bad thing, but you just have to be strong and remember the reason why you became an officer. You don't have to be a part of the culture that is doing it wrong and to me that seems to be the majority right now.

I guess I could describe it as two police cultures. There is an external one that is shaped by public response, perception, and attitude toward law enforcement. That culture affects how officers respond to the public and behave when making calls for service. The 
internal one is developed through repetitive, trained behavior that develops our philosophy as a department and becomes a sort of support system for those within the group. Both of the internal and external cultures create a divide between the public and the department, an "us versus them" mentality. So in reality, it's us as police officers against everyone. I understand that we are different and held to a higher standard, but is it really so disconnected? Is this 10 -year old girl that I talk to at a school, is it me against her, because she's a civilian? I hope not. I'm there for her and when it comes to bad guys so to speak, it's nothing personal, it's not me against them. I have a job to do. They messed up, they broke the law, they did whatever they did and I have to do what I have to do. It's nothing more than that or anything that continues into the next encounter. The panhandler that I talked about earlier that cleaned his life up is a great example. Is it us against him or did we help him by not having the 'us against them' mentality? That is part of the police culture that seems to be persistent and taught to the next generation of officers. If you get too deep into it, it's going to take away from being human and to be a police officer, in my opinion, you still have to be a human.

\section{Alyssa - Vehicle Patrol}

Police culture is definitely like a family. No matter what agency you're from, what title you have, or what state you represent, that officer is your brother or your sister. We are very deeply connected because we took this job. Camaraderie is a huge part of it, whether you know the person or not, there's just an understanding that I have your back and you have mine.

I have a very disconnected family and so now to have a police family, these are my people. We send each other group messages, and if I don't show up to work, they will 
be asking where I'm at. Although that doesn't happen that often because I usually show up for work about three hours before roll call [laughter]. I just like to be here, be around other officers, so yeah, I give this department a lot of free time. It's very fulfilling for me and it's just good to be around it and to be a part of it all. I feel like the military is the only thing that is even close to similar. I haven't seen another job that's quite like it, as far as the concept of being connected just by what we do for a living. I feel like I am definitely a part of it, but I also felt like I had to earn it. After I got on the beat as a solo officer, I spent so much time getting to know my partners and making runs with them. They have become my family.

There is a separation between civilians and law enforcement, but I don't think that it is necessarily because officers distrust civilians, or the even the adverse news coverage that is often trending. It is often a lack of understanding between the two groups. For example, the perception that people have is so distorted and misguided. This dude almost ran us over on a traffic stop. We were going to get the guy from the car. $\mathrm{He}$ was six foot five, just a huge guy. We're trying everything we can to get him under control. We end up smashing him into a Dodge Charger full of people, my partner disengages and goes to tase him. At that point the guy lays down on his stomach with his arms out to the side. We never had to tase him, just saying it made him comply. The guy in the charger yells out the window at us "thank you so much for tasing him and not shooting him." That was never even a thought in my mind, it was just a fight. If the big guy tried to kill me, obviously that would change the situation, but it was just a fight and him being an ass hole. The occupants of the charger didn't even see what really happened. This suspect had been in a restaurant trying to assault and rob someone. I guess I just 
thought we did a great job of catching a really bad guy and was surprised that the assumption from the public was that I would shoot him. I don't think the public means to, but they definitely make officers feel isolated.

\section{Additional Results (Emotional Labor, Race)}

The research revealed some additional themes that were not considered prior to the collection of data through qualitative approaches. Through constant comparison methods developed around a grounded theoretical approach, the data analysis developed further themes that surround the walking patrol initiative. The qualitative data found that emotional labor was a common trend among the vehicle patrol group.

\section{Emotional Labor}

\section{Alyssa - Vehicle Patrol}

Sometimes it is hard for me to describe how our job is different. It's one of those things that you can kind of talk to each other after a difficult call, arrest, or shooting and you might feel a little better about it. There's not really anyone else you can chat with about it. Some of the information we know is private and some people just don't want to hear about it. Sometimes I might go home and I'm still in police mode and it takes a minute to get out of it. I think everybody in law enforcement can kind of relate to that in some form or fashion. And someone that works as a teacher or counselor, nothing against that, but they aren't going to understand it like the person standing next to you. I think from an outside perspective, it is very difficult to build regular friendships and relationships if you are in uniform. It's a lot of stress and it can be hard for some civilians to be a part of this lifestyle. I think it's easier for us because we all experience the same 
stuff and I can say, "Oh damn, I went to this 10-50 [injury accident] the other day and it was terrible, this kid was in 16 pieces, it was the worst thing ever," and we can talk about that, have our second, and it would be over. That other officer would have really understood that. It is absolutely not something I am going to talk to with my significant other. When asked how my day was, I usually just say that it was great and leave it at that. The only thing that I will do is share my location, because I don't generally answer my phone during my shift. That way he at least knows I'm out moving around. Now, my mom listens to the scanner app, and I have told her time and time again not to do that. Family members doing things like that is hard for us, because someone will ask "what does that number mean" or "why did you respond to that school?" It is hard to interact with non-police and explain things to them. And, if I get in a critical incident and I get rocked and my mom hears all of it, what does that do to her? I would rather her hear it from peer support and not over the scanner. I don't want to go out with my mom listening to it on an iPhone 11, so that has been really frustrating.

There is also a continuous swing in emotions throughout the patrol shift. This can affect interactions during and after the work day or night. It depends on what you're doing, but the decompression part of it is different. Sometimes it's hard to just go home and be. One night we had five cars and we did three shootings, all good 10-80 [dead person] shootings. So I went from seeing this kid shot, to this one, to this one. I had somebody the other day pull out an AR-15. It was just an overtime detail. All I kept thinking was I signed up for this [laughter]! In the Academy, you're well-rested. I would wake up, eat my Wheaties, stretched, and prepped for the day. In the real world though, I went to the DMV, then I went to the post office, and since there wasn't enough time to go 
to sleep, I just came straight to work. That's all after 8 hours of working and trying to deal with people with AR-15s. Not to mention the prosecutor has been calling me all day to get a Grand Jury packet together. You just can't simulate those kind of things in a training environment, so you are just thrown to the wolves when you get out here.

It seems that the public just does not truly understand what law enforcement officers can actually do and most of the time do not understand our legal capabilities. If I don't have enough to lock someone up, the public will ask me "why don't you just do your job?" They have no understanding of how we actually do our job or what we deal with during a shift. It's a lot more complicated than they realize. I know, because I go home and I'm exhausted. One run I'm climbing up on a semi-truck that just turned over to pull a passenger out, then I go arrest a bum. He's drunk and is defecating everywhere. The guy doesn't cooperate, so then I'm fighting him. I take him to jail and then go look for a missing kid. The randomness just wears on me. I go home and almost pass out in my tac vest.

\section{Racial Differences}

Differences in responses from the black officers were consistent in the interviews and focus groups. The racial differences during the data analysis were identified throughout the research. Some experiences were only mentioned by the black officers that participated. None of the white officers expressed anything in relation to race or conflict that emerged from their experiences on walking and vehicle patrol. There were no questions or prompts that specifically addressed race, but only the black participants mentioned any direct experiences with racial differences or conflict. This suggests that the white officers did not distinguish incidents or involvements in the same way as the 
black officers. Since this study did not focus on race or ethnicity, it is unknown exactly why there was a significant difference in the participant's experiences and/or understandings. It could lead to an interesting topic for future research and important to note when developing discussion questions for focus groups and interviews. As previously stated, the following information were all responses from black officers participating in the research study.

One respondent described that when he became an officer he was no longer black, "but blue." It became obvious that the other participants had experienced similar interactions during their short time as solo officers, as they nodded in agreement. He continued, saying, "There's been a few times when I've been off work and the only way a white person would interact with me, well they really didn't. But when I'm in uniform, white people interact with me all the time. It's almost like it's in reverse.” The conversation continued around this topic and another black officer shared, "The race thing is crazy, because you get it from both sides. You get it from black people, and you get it from white people. It just feels like you can't win. The only thing that really irritates me is if a minority kid wants to say hi to me and the parent tells them not to. That's the mindset that is going to keep this relationship how it is." The officers began discussing what it is like when they go home to their neighborhoods that they live in or visit in the west-end of Louisville. They shared similar interactions with family members, friends, and community members that would consistently end negatively because of their profession. One of the officers explained, “I don't know why they don't like us, or are mad at us. When we take our uniforms off we're right back there with them. This is just a 
job. You have to go to work. What if you are a garbage man and you hit my car, I don't dislike all garbage men."

Several of the officers mentioned that black community members would talk to and treat the white officers in their group differently. During one of the community center discussion panels, an officer shared where most of the youth's questions were directed. He said:

“To be honest, the questions from the black youth weren't really to me or my black partner, but instead directed at the two white officers with us. As we all know in the media you see white officers killing a black person, so they had a lot of anger toward them and a lot of questions. I can't remember in detail what they were, but they expressed it and didn't hold back. They were very honest about how they felt about law enforcement and it was all very negative."

Another example discussed was an interaction that occurred during a shift, "my

partner and I were eating, and we saw a guy sitting on top of our car. So, we walk up, and it's a black guy. As soon as he sees us walk up, he immediately jumps off and apologizes. He said, 'I thought it was a honkies car.' So not only do we get talked to negatively as black officers, but so do the white officers in our group as well."

\section{Other Considerations}

Several vehicle patrol officers discussed the difference in the shifts, with the night shift being less interactive due to fewer people being available to interact with. The participants also mentioned the time of year; winter generally has less pedestrian traffic due to the temperature and/or weather conditions. Alyssa described, "It's cold. Most people aren't out walking around, and I sure don't want to stand out in the cold and 
converse." Another point that made during the focus group involved the large volume of runs that several divisions deal with increases the difficulty in communicating with anyone other than the people that initiate a police call for service. This is due to the amount of time available to do proactive policing versus reactive. External factors, such as citizen interactions, training, calls for service, and weather changes, can contribute and should be considered when looking at the differences between the two groups.

\section{Discussion}

The shared stories, opinions, and overall views of the job gave insight into developing social identity, their views on police culture, and details on their community engagement. All of the participants are probationary officers that have had the same amount of policing and training experience. The level of skill may differ based on their previous employment (i.e. military, law enforcement) or by their PTO assignment. An officer assigned to a PTO in a division with a high run volume will possibly increase their skills and more quickly than those assigned to slower areas. Also, some training officers have specific skill sets (i.e., tactics, communication, paperwork) that may make the new officer more equipped to handle specific situations. Otherwise, the participants were equally trained for their assignments and received no additional direction or preparation. These officers also knew one another from their academy training, which could have been a contributing factor to the longer and more in-depth responses that were collected during the focus groups. The familiarity with one another and their similar experiences made the discussions smooth and very interactive. The interviews produced less anecdotal stories and were generally more formal. Other than scheduling issues, the 
participants had more interest in the focus groups and requested those first. It was difficult to find participants initially, as discussed in Chapter 3, but by using peers and trusted officers to gain entrée, several volunteered. These methodological approaches and recruitment strategies are informative to future researchers and could help make law enforcement case studies more successful.

Eight categories were designated based on the questions, discussion prompts, and responses that followed. The data analysis led to six of those categories showing that the responses were significantly different between the walking patrol and vehicle patrol officers. Those six categories, community engagement, community concerns, view of the community, and treatment by the public, were classified within the category of 'perception of community.' The views of the walking patrol initiative and police culture were classified as 'perception of police.' Two of the categories, job difference and job satisfaction, received the same responses from both groups of officers. This can be seen in Figure 6 below.

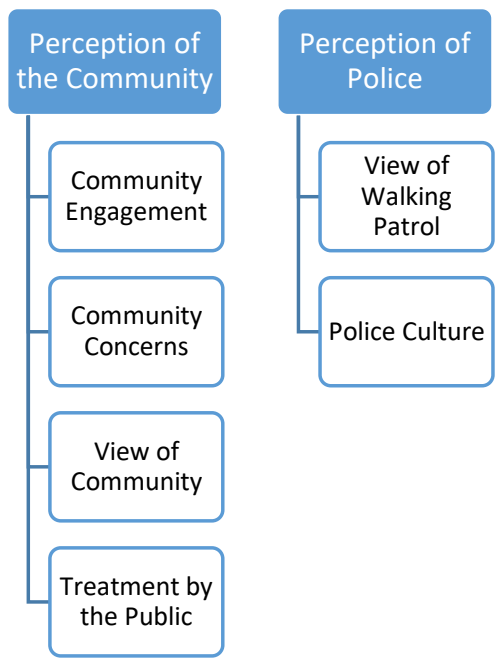

Figure 6. Qualitative Data Category Classification 
The topic of community engagement spurred conversation in relation to the number of contacts they had obtained during their time on patrol and how they balanced community engagement with enforcement. The walking patrol expressed several ways that they had successfully established contacts unrelated to calls for service. They also described an uneven balance between enforcement and community engagement, with the majority of their shift focusing on engagement. The walking patrol also shared that they had phone numbers, social media accounts, and emails for people they had met and spoke with them often through these means. Some even hung out with these contacts outside of work, attending picnics or events they were hosting. The vehicle patrol officers rarely told me about any specific contacts, other than gas station clerks or loss prevention officers. When asked specifically about those contacts they could not give me names, phone numbers, or any other detailed information regarding the people. The vehicle patrol also shared the uneven balance between enforcement and engagement. The majority of their shift consisted of enforcement actions. Some even described that the enforcement aspect of patrol was more important than community involvement. Social learning for a patrol officer seems to impact community engagement. Since neither group had any law enforcement experience other than their training phases, the ability to develop contacts was a learned behavior. Several of the vehicle patrol officers said they "never give a phone number out" and "I don't want 'these people' to know anything about me." To understand how these two groups differed so much can be explained through social learning theory and is reinforced by the overall culture that is considered acceptable by other officers. 
The topic of community concerns was another category that had dissimilar responses between the walking patrol and vehicle patrol. The walking patrol received their information about the concerns, problem areas, and issues that were occurring on their beat through conversations and details provided by the residents and employees in the area. Walking patrol officers shared stories of problems being taken care of prior to the community member even calling dispatch to report it. They also described becoming "invested" in the problem, because it was something that they wanted to ensure would not happen again. Several of them discussed that they had time to continuously monitor problem areas or individuals because they were not "slaves to the radio." These walking patrol officers informally took ownership of common issues in the area and were able to be proactive in these cases, which may have prevented additional calls for service or reported crimes. It is difficult to measure this in policing, as a crime that did not occur cannot be measured or tracked, and it is unknown how many of these events happened during the imitative. Still, it is important to note the unique capabilities of walking patrol officers to be invested in this way and to potentially prevent crime by their actions.

The vehicle patrol received their information about the community problems or concerns through crime statistics that were reported during roll call or via email. A few mentioned that community members would share problems or concerns with them, but it would be following a dispatched run to the location. This is an example of a rational myth that was previously introduced. Police departments are directing police action at high statistics without input from the community. This seems rational, but it is not addressing the true issue that is disturbing the public. A quote from Jay from the previous text said that the "west-end [of Louisville] is typically portrayed as high crime and anti- 
police, but everyone was happy to see us. They weren't worried about dope or drug crimes, they were worried about speed bumps..." If law enforcement is not addressing what is truly concerning the public, the ability to gain legitimacy becomes difficult and can decrease community relations (Bottoms and Tankebe 2012; Tankebe 2013).

The ways officers were treated by the public also varied between the walking patrol and vehicle patrol. Both groups expressed that the overall treatment was better than they had previously expected following the police training Academy. The walking patrol officers said that their treatment was generally positive, but the vehicle patrol expressed the overall treatment was negative. Although most of the participants did share stories of one or two instances of a negative interaction by the public, the overall consensus of the two groups was different. This category could potentially affect the officer's emotional labor that they must continuously manage during their shifts at work. The walking patrol told me about several contacts, interactions, and even arrests that ended positively. They also interacted more frequently with community members that were not calling for some type of police assistance. The vehicle patrol officer's shared responses consistently about negative experiences with the public and very few contacts throughout the shift that were unrelated to some type of law enforcement response.

Opposing views on the foot patrol initiative were shared by each group. The walking patrol was highly supportive and defended the work they did. They freely expressed the perceived positive effect on the community and their careers. The vehicle patrol group was concerned about the manpower issues, the walking patrol officers' deficiencies in basic police knowledge, and officer safety. Some expressed support for the initiative, but thought that more seasoned officers should be selected. Others did not 
see its relevance in policing today. They expressed that it is completely unrealistic to expect a walking patrol to be feasible in Louisville. Their logistical concerns regarded slow response times to calls for service, limited walkability in some Divisions, and the lack of tools that would otherwise be accessible in a vehicle, such as body armor, weapons, and laptops. Although these are reasonable concerns, they can have a negative impact on the already existing negative perception surrounding the initiative, and on officers' ability to adapt to change within the organization itself (Jaffee 2001). The work of Douglas (2000) explains how belief modification begins with the overcoming of unsubstantiated beliefs, which can make acceptance to change difficult. Social learning can also cause resistance to change (Savion 2009) and could partially explain the variance in responses between the groups. The major theme in the literature is that police misconduct is the result of police culture; that continuing (differential) association in the culture produces deviant behavior, and it instills resistance to change or to learning and accepting new police methods.

The responses to defining police culture were vastly different between the vehicle and walking patrols. Overall, the walking patrol did not express integration into the culture, with some even emphatically telling me they did not want to be a part of it. The general response was coated with negativity, with one even saying "the thin blue line...what thin blue line?" They expressed forms of isolation and uncertainty as the walking patrol was ending. Several said they were not sure they would "fit in" with vehicle patrol officers.

The vehicle patrol described police culture as "family" and "brotherhood." They were all fully integrated, with only one expressing they she "likes to be away from it" 
when she goes home. The data reflects the theory related to organizations and police culture. Both groups had completed the Academy at the same time and received the same field training. Yet, the walking patrol expressed complete separation from the police culture and the vehicle patrol officers were already embedded. Patrol methods, officer experience, and the amount of formal and informal law enforcement activities contribute to the cultural construction within policing. The mold that influences a police officer's attitude, decision-making and perceptions about public opinion is difficult to reform and creates a police culture that endures generationally. The walking patrol initiative and its focus on informal law enforcement activity and community engagement produced a change in the officer's connection to police culture. This will be discussed further in Chapter 6, but this change in the cultural construction within law enforcement allows for opportunity to improve or even develop a different culture.

\section{Methodological Strengths and Weaknesses}

\section{Strengths}

Sharing in the complexities of the policing experience with participants helped me establish rapport. If necessary, I would prompt the participant to provide more details (e.g., "What do you mean?" "Can you explain that more?" "Why do you think that?" "Give me an example."). This helped ensure that I was clear on what they were relaying and my perceptions of policing were not influencing the interpretation. The methodology used in this research provided the tools needed to acquire in-depth information surrounding the walking patrol initiative, including perceptions of law enforcement, perceptions of the community, and crime statistics. 


\section{Weaknesses}

My attachment to the group and my blurred participation became obvious during my research. I consistently had to remind myself to remain objective throughout the process when words of negativity about the walking patrol initiative were discussed by other officers. I found that I had become concerned with the participants of the walking patrol and their reputations within the agency. Due to the amount of time I spent walking, working, and interviewing participants, I began to get to know them personally. Boundaries began to blur, as I could tell the participants of the walking patrol considered me part of the group. I was no longer just a researcher or police officer to them, with many of them calling me with police questions and career advice. The stakeholders and my committee chair continuously encouraged me to critically assess the case study and report the findings in their entirety. This research project provided immeasurable experience and helped me gain skills in qualitative and quantitative research challenges. The support in navigating the unforeseen connection to the research gave me the confidence to do thorough and objective work.

I am also a white, female police officer and researcher; therefore, my lens to view the department, the public, and this research is influenced by my experiences based on my gender and skin color. During the qualitative portion of this research a race theme became apparent among the African American officers. They shared information about their personal experiences in training, with other officers, and with the public during informal and formal encounters. It came to my attention that I had not asked any questions in relation to race, either with the department or with the community. Although that was not the focus of the research, it is an essential variable to consider, especially in 
law enforcement. The white officers that were interviewed or participating in a focus group had no information surrounding their experiences with race issues and/or problems while at work. Their silence would have never been heard had the African American officers not mentioned some of their interactions concerning race. None of the topics or questions that I had posed had any mention regarding demographics. It was an educational moment for me, and I will remember this while conducting future studies, especially on topics surrounding law enforcement.

\section{Generalizability of Findings}

The qualitative data had a small sample size; therefore the potential for generalizability could be questioned. By looking at the themes that arose from the focus groups, interviews, and participant observations and comparing with the narratives brought forth from similar studies, I argue that the findings could be applicable to other groups of police beyond Louisville Metro Police Department. It also could expand the literature in areas that are less prominent in the literature, such as perceptions police have of the community and how that effects community relations. 


\section{CHAPTER V: QUANTITATIVE FINDINGS}

This chapter will address the following research questions:

1. Did crime statistics in the walking patrol area increase, decrease, or show signs of displacement?

2. Did the perception of the police, personal safety, and crime change for the community members within the walking patrol area?

\section{LMPD Crime Statistics}

RMS data also provided a five-year look at the reported crimes for several different categories, including murder, rape, robbery, property crime, burglary, larceny, and vehicle theft. The reports are labeled into separate categories based on definitions established by Kentucky Revised Statutes (KRS). These totals provide an overview of the crime fluctuations and give insight into the overall crime trend in the Louisville Metro area. The results are shown in Table 4.

\begin{tabular}{ccccccccc}
\hline \multicolumn{2}{l}{ Crime Rates for 2015-2019 } & & & & & \\
\hline Year & Murder & Rape & Robbery & $\begin{array}{c}\text { Property } \\
\text { crime }\end{array}$ & Burglary & Larceny & $\begin{array}{c}\text { Vehicle } \\
\text { Theft }\end{array}$ & Total \\
\hline 2015 & 80 & 262 & 1,538 & 28,056 & 6,227 & 18,753 & 3,076 & 57992 \\
\hline 2016 & 117 & 227 & 1,549 & 29,922 & 5,899 & 19,822 & 4,201 & 61737 \\
\hline 2017 & 102 & 214 & 1,333 & 28,107 & 5,531 & 18,785 & 3,791 & 57863 \\
\hline 2018 & 80 & 238 & 1,083 & 27,187 & 4,617 & 18,845 & 3,725 & 55775 \\
\hline 2019 & 119 & 234 & 1,208 & 29,114 & 5,166 & 16,687 & 4,697 & 57225 \\
\hline
\end{tabular}

Table 4. Louisville Metro 2015-2019 Crime Rates 


\section{Survey Results}

This research uses data from the Community Safety and Policing Survey (CSPS) that was developed specifically for this case study. The survey was distributed to District 8 in Louisville, Kentucky, between the dates of September 25 and October 31 of 2019 through an online survey database. It consisted of 35 questions with Likert-scale responses, which were divided into three categories (perception of crime, law enforcement, and safety) and 10 demographic related questions. The CSPS resulted in $106(42.57 \%)$ participants in the walking patrol area and $143(57.43 \%)$ within the control areas $(\mathrm{N}=249)$. Of those, $161(64.66 \%)$ were residents, 59 (23.69\%) were employees, and $29(11.65 \%)$ were both a resident and employee at the time of the survey. Appendix C provides the demographic distribution from the survey respondents and Appendix D details the demographics for the walking patrol area respondents.

This was a quasi-experimental design, due to the lack of randomization in the selection of participants in the control and experiment groups. The availability and the practicality were key factors in implementing this research design. I attempted to control for as many differences as possible by utilizing the same police division for both the control and the experimental group, which kept demographics, crime statistics, and policing techniques similar. I was not able to consider all factors that might affect certain phenomena within the case study, meaning there was no control over extraneous variables influencing the dependent variable. This design was more suitable for the real world setting and allowed for the evaluation of impacts under natural occurring conditions, providing a greater external validity. Even so, quasi-experimental designs deliver less reliable results for the establishment of a causal relationships between the 
independent and dependent variables, but it does allow for inferences regarding these relationships.

\section{Perception of Crime}

I used an ordinal logistic regression model to determine which of the independent variables had a statistically significant effect on my dependent variables. This model was used because I had an ordered categorical outcome. The CSPS has a small sample size $(\mathrm{N}=249)$ and the independent variables are categorical. I used ordinal logistic regression to provide robust results for the survey data available. The independent variable for this analysis was residential zone, which included the experimental group of residents within the walking patrol boundaries and the control group of residents who took the survey but resided outside the walking patrol areas. Dependent variables measured participant perceptions of crime in their area within the last four months, including break-ins/property thefts, violent crimes, homelessness, panhandling, drug crimes, and juvenile delinquency. Participants were ask to indicate on a scale of -2 to 2 if the various crime types listed reduced a lot, reduced a little, stayed about the same, increased a little, or increased a lot. 
Perception of Crime Variables

Dependent

\begin{tabular}{|c|c|c|}
\hline \multicolumn{2}{|c|}{ In the last four months... } & \multirow{7}{*}{$\begin{array}{l}-2 \text { - Reduced a lot } \\
-1 \text { - Reduced a little } \\
0 \text { - Stayed about the same } \\
1 \text { - Increased a little } \\
2 \text { - Increased a lot } \\
\text { Missing data-Don't know/No } \\
\text { opinion/Not lived/worked for } 4 \\
\text { months }\end{array}$} \\
\hline \multirow[t]{2}{*}{ your } & $\begin{array}{l}\text { The amount of break-ins/property thefts in } \\
\text { neighborhood have... }\end{array}$ & \\
\hline & $\begin{array}{l}\text { The amount of violent crimes in your } \\
\text { neighborhood have... }\end{array}$ & \\
\hline & $\begin{array}{l}\text { The amount of homelessness in your } \\
\text { neighborhood has... }\end{array}$ & \\
\hline & $\begin{array}{l}\text { The amount of panhandling in your } \\
\text { neighborhood has... }\end{array}$ & \\
\hline & $\begin{array}{l}\text { The amount of drug crimes in your } \\
\text { neighborhood have... }\end{array}$ & \\
\hline & The amount of juvenile delinquency has... & \\
\hline \multicolumn{3}{|c|}{ Independent } \\
\hline \multicolumn{2}{|c|}{ Walking patrol area (Purple) } & 1 \\
\hline \multicolumn{2}{|c|}{$\begin{array}{l}\text { Non-walking patrol area (Yellow, Purple, Orange, } \\
\text { Green, Red, Blue) }\end{array}$} & 0 \\
\hline
\end{tabular}

Table 5. Variable List for Perception of Crime

The variables used and the coding attached can be seen in Table 5. Prior to analysis, the non-walking patrol group was formed by recoding the residential/employment zones into a dummy variable. By changing the categorical variables into dichotomous I can use a single regression to represent multiple groups not included in the walking patrol area. The dependent variables were reverse coded to show the perception of crime reduction as a negative number and increased crime represented with a higher number in the data output. If the respondent answered "don't know/no opinion" or "not lived or worked here for 4 months" it was entered as missing data and not calculated in the regression analysis. 


\section{Results}

I completed an ordinal logistic regression to determine the correlation between the participants in the walking patrol area and their perception of crime in their neighborhood. I chose the dependent variables for this analysis because they are directly related to the respondent's current perception of crime in their neighborhood. The results for each dependent variable will be analyzed below, which includes perception of property crime, violent crime, homelessness, panhandling, drug crime, and juvenile delinquency.

Goodness of fit of the model was examined using chi-square and deviation statistics. This can be useful for models with categorical independent variables. Pearson chi-squared is a statistical test to evaluate how likely it is that any of the observed differences between the independent and dependent variables arose by chance. If the lines or planes are parallel, the significance level should be large, since the general model does not improve the fit very much. The results are reported and interpreted, but the Pseudo$\mathrm{R} 2$ value will be a better suited measurement. The test results for Pearson goodness of the fit are shown in the Table 6. For perception of property crime the chi-square value $\left(X^{2}=13.809, p=.003\right)$ and the deviation of chi-square value $\left(X^{2}=13.900, p=.003\right)$ were significant. This means that the $\mathrm{H}_{0}$ hypothesis was rejected and that suggests that the model does not fit the data well. For perception of violent crime the chi-square value $\left(\mathrm{X}^{2}=5.968, \mathrm{p}=.113\right)$ and the deviation of chi-square value $\left(\mathrm{X}^{2}=6.544, \mathrm{p}=.088\right)$ were not significant, therefore suggests that the model does fit the data well. For perception of homelessness the chi-square value $\left(\mathrm{X}^{2}=13.552, \mathrm{p}=.004\right)$ and the deviation of chi-square value $(\mathrm{X} 2=13.718, \mathrm{p}=.003)$ suggesting that the $\mathrm{H}_{0}$ is rejected and that the model does not 
fit well. For perception of panhandling the chi-square value $\left(X^{2}=14.122, p=.003\right)$ and the deviation of chi-square value $\left(\mathrm{X}^{2}=14.638, \mathrm{p}=.002\right)$ were significant. This suggests that the $\mathrm{H}_{0}$ is rejected and that the model does not fit well. For the perception of drug crime the chi-square value $\left(\mathrm{X}^{2}=14.746, \mathrm{p}=.002\right)$ and the deviation of chi-square value $\left(\mathrm{X}^{2}=14.936, \mathrm{p}=.002\right)$ are significant, suggesting that it is not a good model fit. For perception of juvenile delinquency the chi-square value $\left(\mathrm{X}^{2}=10.874, \mathrm{p}=.012\right)$ and the deviation of chi-square value $\left(\mathrm{X}^{2}=11.053, \mathrm{p}=.011\right)$. This suggests that the $\mathrm{H}_{0}$ is rejected and that the model does not fit well. In conclusion of the chi-square goodness of fit, only the perception of violent crimes shows to be a good fit for the model. Due to the previous issues discussed, this research will look at the Pseudo-R2 value.

\begin{tabular}{|c|c|c|c|}
\hline \multicolumn{4}{|c|}{ Results of the Goodness of Fit Test } \\
\hline & $\mathrm{X}^{2}$ & df & $p$ \\
\hline \multicolumn{4}{|c|}{ Perception of Property Crime } \\
\hline Pearson & 13.809 & 3 & .003 \\
\hline Deviation & 13.900 & 3 & .003 \\
\hline \multicolumn{4}{|c|}{ Perception of Violent Crimes } \\
\hline Pearson & 5.968 & 3 & .113 \\
\hline Deviation & 6.544 & 3 & .088 \\
\hline \multicolumn{4}{|c|}{ Perception of Homelessness } \\
\hline Pearson & 13.552 & 3 & .004 \\
\hline Deviation & 13.718 & 3 & .003 \\
\hline \multicolumn{4}{|c|}{ Perception of Panhandling } \\
\hline Pearson & 14.122 & 3 & .003 \\
\hline Deviation & 14.638 & 3 & .002 \\
\hline \multicolumn{4}{|c|}{ Perception of Drug Crime } \\
\hline Pearson & 14.746 & 3 & .002 \\
\hline Deviation & 14.936 & 3 & .002 \\
\hline \multicolumn{4}{|c|}{$\begin{array}{l}\text { Perception of Juvenile } \\
\text { Delinquency }\end{array}$} \\
\hline Pearson & 10.874 & 3 & .012 \\
\hline Deviation & 11.053 & 3 & .011 \\
\hline
\end{tabular}

Table 6. Pearson's Chi-Square Goodness of Fit Test Results 
The accuracy of the fit of the model was also tested by Pseudo-R2 value. The Pseudo-R2 aims to measure and assess the power of the relation between the dependent variables and the independent variables. Table 7 shows the statistics for each variable. According to the analysis, the level of explanation of the dependent variables by the independent variables are listed. Perception of property crime is $10.1 \%$, violent crimes is $14.2 \%$, homelessness is $9.2 \%$, panhandling is $8.5 \%$, drug crimes $12.5 \%$, and juvenile delinquency is $20.4 \%$ explained by the residency/employment of the respondent.

\begin{tabular}{lccc}
\hline \hline \multicolumn{2}{l}{ Results of Pseudo- $R^{2}$ Value } & & \\
\hline \multicolumn{1}{c}{ Variables } & Cox and Snell & Nagelkerke & McFadden \\
\hline Property Crimes & .095 & .101 & .035 \\
\hline Violent Crimes & .133 & .142 & .051 \\
\hline Homelessness & .092 & .096 & .032 \\
\hline Panhandling & .085 & .089 & .029 \\
\hline Drug Crimes & .118 & .125 & .043 \\
\hline Juvenile Delinquency & .192 & .204 & .075 \\
\hline \hline
\end{tabular}

Table 7. Pseudo- $R^{2}$ Values for the Dependent Variables

The Wald test was also conducted to see the significance or lack thereof with the independent variable used in this model. To interpret this, the Wald statistic is used to test the parallel lines assumption, which provides a comparison of the walking patrol and non-walking patrol areas. This gives the parameter significance based on the odds of perception changing based on the location of the respondent's residence and/or employment. Upon examination of the findings, all of the hypotheses $(\mathrm{H} 1, \mathrm{H} 2, \mathrm{H} 3, \mathrm{H} 4$, H5) were supported by the results. All had a significantly $(p<.05)$ higher chance of perceiving higher crime rates in their neighborhood than walking patrol respondents. The probability of the non-walking patrol respondents having a perception of higher property crime in their neighborhood was 1.193 more than the walking patrol respondents. Considering the odds ratio of the location variable, it shows that the non- 
walking patrol respondents odds of perceiving higher property crime rates was3.296 (95\% CI, 1.929 to 5.630) times larger than that of the other respondents. The model parameters showed that perception of property crime was statistically significant (Wald $\left.\mathrm{X}^{2}=19.060, \mathrm{p}<.001\right)$. See Table 8 for the results.

\begin{tabular}{lcccc}
\hline \multicolumn{6}{l}{ Significances of the Model Parameters of the Non-Walking Patrol Area } & \\
\hline Variables & $\beta$ & Wald & Odds Ratio $\left(\mathrm{e}^{\beta}\right)$ & $p$ \\
\hline Property Crimes & 1.193 & 19.060 & 3.296 & .001 \\
\hline Violent Crimes & 1.440 & 25.697 & 4.223 & .001 \\
\hline Homelessness & 1.146 & 19.487 & 3.145 & .001 \\
\hline Panhandling & 1.098 & 18.838 & 2.998 & .001 \\
\hline Drug Crimes & 1.332 & 19.788 & 3.789 & .001 \\
\hline Juvenile Delinquency & 1.778 & 38.006 & 5.917 & .001 \\
\hline \hline
\end{tabular}

Table 8. Perception of Crime Model Parameters

The probability of the non-walking patrol respondents having a perception of higher violent crime in their neighborhood was 1.440 more than the walking patrol respondents. Considering the odds ratio of the location variable, it shows that the nonwalking patrol respondents had 4.223 (95\% CI, 2.419 to 7.37 ) higher odds of perceiving higher violent crime rates than the other respondents. The model parameters showed that perception of property crime was statistically significant (Wald $X^{2}=25.697, p=.001$ ). Table 8 shows the results.

The probability of the non-walking patrol respondents having a perception of higher homelessness in their neighborhood was 1.146 more than the walking patrol respondents. Considering the odds ratio of the location variable, it shows that the nonwalking patrol respondents had 3.145 (95\% CI, 1.891 to 5.230) higher odds of perceiving 
higher homelessness rates than the other respondents. The model parameters showed that perception of property crime was statistically significant (Wald $X^{2}=19.487, p=.001$ ). Table 8 shows these results.

The probability of the non-walking patrol respondents having a perception of higher panhandling in their neighborhood was 1.098 more than the walking patrol respondents. Considering the odds ratio of the location variable, it shows that the nonwalking patrol respondents had 2.998 (95\% CI, 1.826 to 4.922) higher odds of perceiving higher panhandling rates than the other respondents. The model parameters showed that perception of property crime was statistically significant (Wald $\mathrm{X}^{2}=18.838, \mathrm{p}=.001$ ). Table 8 shows these results.

The probability of the non-walking patrol respondents having a perception of higher drug crime in their neighborhood was 1.332 more than the walking patrol respondents. Considering the odds ratio of the location variable, it shows that the nonwalking patrol respondents had the odds of perceiving higher drug crime rates was 3.789 (95\% CI, 2.107 to 6.815 ) higher than that of the other respondents. The model parameters showed that perception of property crime was statistically significant (Wald $\mathrm{X}^{2}=19.788$, $\mathrm{p}=.001)$. Table 8 shows these results.

The probability of the non-walking patrol respondents having a perception of higher juvenile delinquency in their neighborhood was 1.778 more than the walking patrol respondents. Considering the odds ratio of the location variable, it shows that the non-walking patrol respondents had 5.917 (95\% CI, 3.362 to 10.412) higher odds of perceiving higher juvenile delinquency rates than the other respondents. The model 
parameters showed that perception of property crime was statistically significant (Wald $\left.\mathrm{X}^{2}=38.006, \mathrm{p}=.001\right)$. Table 8 shows these results.

\section{Perception of Police}

An ordinary least squares (OLS) regression was completed to investigate the relationship between the walking patrol residents/employees and their perception of law enforcement in their neighborhood. I used two categories for the perception of police, with the first group of questions focusing on officer characteristics and the second group asking respondents about officer activities in their neighborhood. Perception of police characteristics (P1) consisted of seven dependent variables with Likert scale responses that were reverse coded with the higher number representing a more positive response (see Table 9). 
Perception of Police Characteristics Variables

Dependent

The police in my neighborhood supply information to the public on ways to reduce crime

1-Strongly Disagree

The police in my neighborhood are courteous.

The police in my neighborhood are approachable and easy to talk to.

The police in my neighborhood are visible.

The police in my neighborhood are professional.

The police in my neighborhood are fair.

2-Disagree

3 -Neutral

4-Agree

5-Strongly Agree

I am able to interact with police officers in my neighborhood on a daily or regular basis.

Independent

Residential/Employment Area

1-Walking Patrol Area

0-Non-Walking Patrol Area

Race

1-Black/African American

0-White, Hispanic, Asian, another race

In the last 4 months, your interaction with police when a crime has not occurred has...

1-Decreased a lot

2-Decreased a little

In the last 4 months, police officer presence in your neighborhood has...

3-Stayed the same

4-Increased a little

5-Increased a lot

In the last 4 months, police patrolling on foot in your neighborhood has...

6,7-Missing

Table 9. Variable List for Perception of Police Characteristics

Perception of police activity (P2) had five dependent variables with Likert scale responses that were also reverse coded prior to analysis. For the "don't know" response, 
it was recoded as missing data (see Table 10). For both P1 and P2, the non-walking patrol residential group was formed by recoding the residential/employment zones into a dummy variable.

\section{Perception of Police Activity Variables}

Dependent

How are the police at addressing the problems that are concerning people in your neighborhood?

How are the police in your neighborhood doing at keeping order on the streets and sidewalks?

How are the police doing at preventing crime in your neighborhood?

How would you rate the level of communication between you and the police patrolling your neighborhood?

Community policing involves police officers working with the community to address the causes of crime in an effort to reduce the problems themselves and the associated fear, through a wide range of activities. Based on this definition, how are the police doing at practicing community policing in your neighborhood?

\begin{tabular}{|c|c|}
\hline Independent & \\
\hline Residential/Employment Area & $\begin{array}{l}\text { 1-Walking Patrol Area } \\
\text { 0-Non-Walking Patrol Area }\end{array}$ \\
\hline Race & $\begin{array}{l}\text { 1-Black/African American } \\
\text { 0-White, Hispanic, Asian, } \\
\text { another race }\end{array}$ \\
\hline $\begin{array}{l}\text { In the last } 4 \text { months, your interaction with police } \\
\text { when a crime has not occurred has... }\end{array}$ & $\begin{array}{l}\text { 1-Decreased a lot } \\
\text { 2-Decreased a little }\end{array}$ \\
\hline $\begin{array}{l}\text { In the last } 4 \text { months, police officer presence in your } \\
\text { neighborhood has... }\end{array}$ & $\begin{array}{l}\text { 3-Stayed the same } \\
\text { 4-Increased a little }\end{array}$ \\
\hline $\begin{array}{l}\text { In the last } 4 \text { months, police patrolling on foot in } \\
\text { your neighborhood has... }\end{array}$ & $\begin{array}{l}\text { 5-Increased a lot } \\
\text { 6,7-Missing }\end{array}$ \\
\hline
\end{tabular}

1 -Very Poor

2-Somewhat Poor

3-Don’t know/no opinion

4-Somewhat Good

5-Very Good

Table 10. Variable List for Perception of Police Activity 
Results

For the preliminary analysis, a Cronbach Alpha test was conducted to ensure internal consistency between the dependent variables. This measure of reliability indicates if there is validity in the modified variables and provides support for their correlation (Taber 2017). The survey consisted of distinct categories of measurement with P1 and P2 using different Likert scales. The Cronbach Alpha for P1 was .899, which indicates a "good" internal consistency for the new seven item variable and the Alpha for P2 was .928, indicating an "excellent" correlation (Nunnally 1978).

See Table 11 and 12 for the zero order correlations and basic univariate statistics. Inter-item correlations examine the extent to which scores on one dependent variable relate to the other dependent variables. By providing an assessment of item redundancy it is possible to determine if there is enough unique variance (Cohen and Swerdlik 2005). If values are higher than .40 it shows isomorphic connections between the dependent variables. This supplements the decision to average the dependent variables as one variable for the regression analysis. 


\begin{tabular}{|c|c|c|c|c|c|c|c|c|}
\hline & \\
\hline & & & & \\
\hline \multicolumn{9}{|c|}{\begin{tabular}{ll|l}
1 & $\begin{array}{l}\text { The police in my } \\
\text { neighborhood supply } \\
\text { information }\end{array}$ & \\
\end{tabular}} \\
\hline 2 & $\begin{array}{l}\text { The police in my } \\
\text { neighborhood are } \\
\text { courteous }\end{array}$ & .481 & & & & & & \\
\hline 3 & $\begin{array}{l}\text { The police in my } \\
\text { neighborhood are } \\
\text { approachable }\end{array}$ & .567 & .675 & & & & & \\
\hline 4 & $\begin{array}{l}\text { The police in my } \\
\text { neighborhood are } \\
\text { visible }\end{array}$ & .447 & .446 & .560 & & & & \\
\hline 5 & $\begin{array}{l}\text { The police in my } \\
\text { neighborhood are } \\
\text { professional }\end{array}$ & .395 & .672 & .626 & .523 & & & \\
\hline 6 & $\begin{array}{l}\text { The police in my } \\
\text { neighborhood are fair }\end{array}$ & .459 & .680 & .672 & .531 & .793 & & \\
\hline 7 & $\begin{array}{l}\text { I am able to interact } \\
\text { with police officers in } \\
\text { my neighborhood }\end{array}$ & .505 & .517 & .691 & .705 & .589 & .643 & \\
\hline
\end{tabular}

Table 11. Perception of Police Characteristics Correlation Matrix

\begin{tabular}{|c|c|c|c|c|c|c|}
\hline \multicolumn{6}{|c|}{ Inter-Item Correlation Matrix for P2 } & \\
\hline & & 1 & 2 & 3 & 4 & 5 \\
\hline 1 & $\begin{array}{l}\text { How are the police doing at } \\
\text { addressing the problems that are } \\
\text { concerning people in your } \\
\text { neighborhood? }\end{array}$ & & & & & \\
\hline 2 & $\begin{array}{l}\text { How are the police in your } \\
\text { neighborhood doing at keeping order } \\
\text { on the streets and sidewalks? }\end{array}$ & .783 & & & & \\
\hline 3 & $\begin{array}{l}\text { How are the police doing at } \\
\text { preventing crime in your } \\
\text { neighborhood? }\end{array}$ & .767 & .742 & & & \\
\hline 4 & $\begin{array}{l}\text { How would you rate the level of } \\
\text { communication between you and the } \\
\text { police patrolling your neighborhood? }\end{array}$ & .726 & .709 & .645 & & \\
\hline 5 & $\begin{array}{l}\text { How are the police doing at practicing } \\
\text { community policing in your } \\
\text { neighborhood? }\end{array}$ & .778 & .750 & .733 & .806 & \\
\hline
\end{tabular}

Table 12. Perception of Police Activity Correlation Matrix

The $\mathrm{R}^{2}$ of the OLS model P1 was .087 which indicates that the regression model can describe $8.7 \%$ of the variation. A simple linear regression was calculated to predict the respondents' perception of the police based on their residency or employment within the walking patrol area. A significant regression equation was found for $\mathrm{P} 1(\mathrm{~F}(1,247)=$ 
23.416, $\mathrm{p}<.000$ ), with a summary of the model shown in Table 13 . This shows that respondents who live in the non-walking patrol area will have a negative unit change in relation to perception of police characteristics than the respondents within the walking patrol boundaries. The prediction of a respondent's perception of police is equal to 4.151 $(3.710+.441)$ if they are within the walking patrol area. This indicates that the respondent will have a $.441(95 \%$ CI, .261 to .620) unit change if they live or work in an area where a walking patrol is occurring. This is a significant change, representing slightly under a half unit improvement in perception based on the Likert scale used for this variable.

\begin{tabular}{|c|c|c|c|c|c|}
\hline \multicolumn{6}{|c|}{ Linear Regression Coefficients for P1 } \\
\hline $\begin{array}{l}\text { Independent } \\
\text { Variable }\end{array}$ & B & SE & t-Statistic & & ind \\
\hline $\begin{array}{l}\text { Walking Patrol } \\
\text { Area }\end{array}$ & .441 & .091 & 4.839 & .261 & .620 \\
\hline
\end{tabular}

Table 13. Linear Regression Coefficients for Perception of Police Characteristics

The $\mathrm{R}^{2}$ of the OLS model P2 was .082 which indicates that the regression model can describe $8.2 \%$ of the variation. A summary of the model is provided in Table 14 . The linear regression predicted the respondents' perception of the police based on their residency or employment within the walking patrol area. A significant regression equation was found for P2, which is shown in Table $14(\mathrm{~F}(1,247)=22.029, \mathrm{p}<.000)$. Therefore, respondents who live in the non-walking patrol area will have a negative unit change in relation to perception of police activity than the respondents within the walking patrol boundaries. The prediction of a respondent's perception of police is equal to 4.298 $(3.726+.572)$ if they are within the walking patrol area. This indicates that the respondent will have a $.572(95 \% \mathrm{CI}, .332$ to .812$)$ unit change if they live or work in an area where 
a walking patrol is occurring. This is a significant change, representing almost a one unit improvement in perception based on the Likert scale used for this variable.

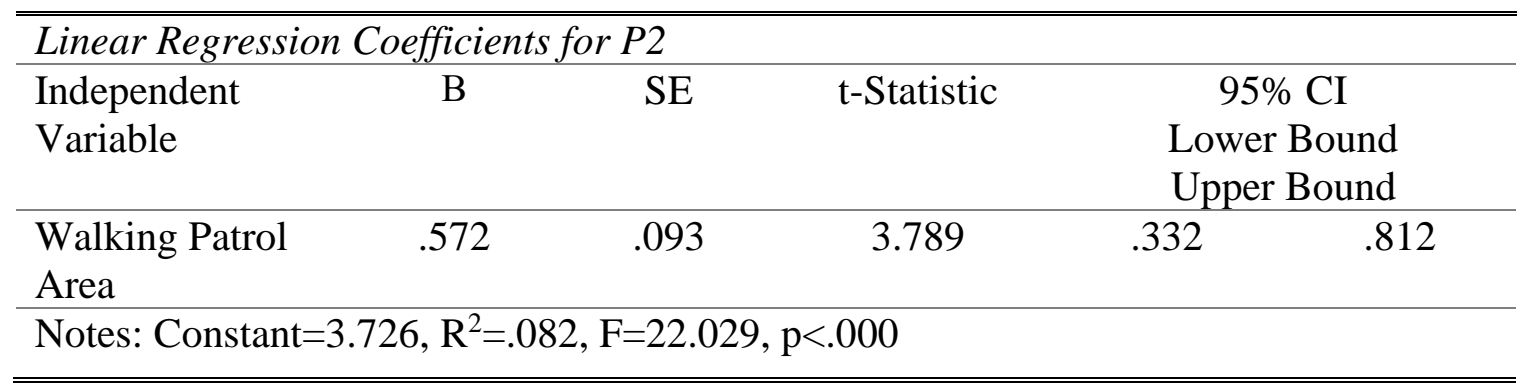

Table 14. Linear Regression Coefficients for Perception of Police Activity

After getting the above results, I felt that controlling for certain variables would provide a more thorough look at the data and what is affecting perception. Therefore, I also controlled for race and police interactions in the regression model to investigate if it was a factor in predicting a respondent's perception of police characteristics and activity.

A multinomial linear regression analysis was used to examine these relationships between the dependent variable and the independent variables shown in Tables 16 and 17. Table 15 presents a summary of descriptive statistics for the independent variables examined. The coefficient variation indicates that police visibility in neighborhoods has the highest variation regarding perception of police characteristics. An examination of the collinearity statistics, Tolerance and VIF, were all within accepted limits. The Mahalanobis distance scores indicated no multivariate outliers and the scatter plots indicated the assumptions of normality and linearity. 


\begin{tabular}{|c|c|c|c|c|c|c|}
\hline \multicolumn{7}{|c|}{ Descriptive Statistics for Independent Variables } \\
\hline Variables & $N$ & Minimum & Maximum & Mean & $S D$ & $\begin{array}{c}\text { Coefficient of } \\
\text { Variation }\end{array}$ \\
\hline Residential Area & 249 & 0 & 1 & .4257 & .4954 & .8593 \\
\hline Race & 236 & 0 & 1 & .1780 & .3833 & .4644 \\
\hline $\begin{array}{l}\text { Informal police } \\
\text { interaction }\end{array}$ & 249 & 0 & 5 & 3.257 & 1.570 & 2.075 \\
\hline Police in neighborhood & 249 & 0 & 5 & 3.799 & 1.307 & 2.907 \\
\hline Police patrolling on foot & 249 & 0 & 5 & 3.526 & 1.774 & 1.988 \\
\hline
\end{tabular}

Table 15. Descriptive Statistics for IVs

The models presented in Table 16 assess the influence of the independent variables controlling for selected conditions. Model 1 shows that the respondent's location of residence and/or employment changes the effect on perception of police characteristics, absent controls for other factors, $\mathrm{F}(1,234)=21.461, \mathrm{p}<.05)$. This model accounted for $8 \%$ of the variation in perception. Reported in Model 2, this effect remained significant when race is controlled, $\mathrm{F}(1,233)=10.686, \mathrm{p}<.05$, explaining $7.6 \%$ of the variation. Adding the police contact variables to the regression model (see Model 3) explained approximately $43 \%$ of the variation in perception and contributed significantly to the model, $\mathrm{F}(3,230)=36.281, \mathrm{p}<.05$. However, the effects of residential area disappear when the presence of informal police contacts, police presence in the neighborhood, and police patrolling on foot are introduced to the model. Informal police contacts and police presence in the neighborhood have a statistically significant positive effect on perception of police characteristics in Model 3 and were also positively significant by themselves $(\mathrm{p}<.05)$. Residential area, race, and police patrolling on foot were not statistically significant in the model. 


\begin{tabular}{lccc}
\hline \hline \multicolumn{2}{l}{ Multinomial Logistic Regression for P1 $(\mathrm{N}=236)$} & & \\
\hline & Model 1 & Model 2 & Model 3 \\
\hline Constant & 3.688 & 3.687 & 2.535 \\
& $(.061)$ & $(.063)$ & $(.115)$ \\
Residential Area & $.441 * * *$ & $.435 * * *$ & -.036 \\
& $(.094)$ & $(.095)$ & $(.087)$ \\
Race & & .006 & -.180 \\
& & $(.123)$ & $(.098)$ \\
Informal Police Contact & & & $.129 * * *$ \\
& & & $. .031)$ \\
Police in Neighborhood & & & $.214 * * *$ \\
& & & $.051)$ \\
Police on Foot & & .084 & .046 \\
& .084 & .076 & .441 \\
\hline R2 & .080 & .000 & .429 \\
Adjusted R2 & .084 & & .357 \\
R2 Change & & \\
$* \mathrm{p}<.05, * * \mathrm{p}<.01, * * * \mathrm{p}<.001$ & & \\
\hline \hline
\end{tabular}

Table 16. Logistic Regression for Perception of Police Characteristics

The same multinomial linear regression was completed for perception of police activity to determine if the inclusion of other factors would affect the level of significance of residential/employment area and examine the relationship between the dependent variable and independent variables. The models presented in Table 17 assess the influence of the independent variables controlling for selected conditions. Model 1 shows that the respondent's location of residence and/or employment has a statistically significant effect on perception of police activity, absent controls for other factors, $\mathrm{F}(1,234)=19.105, \mathrm{p}<.01$. This model explained $45 \%$ of the variation. Reported in Model 2 , race was included and the model was also significant, $F(1,233)=9.991, \mathrm{p}<.01$. The residential area variable remained significant when race was controlled, although race was not significant. Similar to the P1 regression effects, the significance of the residential area variable disappeared when the presence of informal police contacts, police presence in the neighborhood, and police patrolling on foot were introduced to the model (see 
Model 3). The difference is with the race variable, which was significant when controlling for the police contact variables $(\mathrm{p}<.01)$. Model 3 shows a statistically significant effect on perception, $\mathrm{F}(3,230)=37.271$, $\mathrm{p}<.01$, explaining $44 \%$ of the variation. Informal police contacts, police presence in the neighborhood, and race were statistically significant on perception of police characteristics in Model 3. Residential area and police patrolling on foot were not statistically significant in the model.

\begin{tabular}{|c|c|c|c|}
\hline \multicolumn{4}{|c|}{ Multinomial Logistic Regression for P2 $(N=236)$} \\
\hline & Model 1 & Model 2 & Model 3 \\
\hline \multirow[t]{2}{*}{ Constant } & 3.714 & 3.734 & 2.189 \\
\hline & $(.082)$ & $(.085)$ & $(.153)$ \\
\hline \multirow[t]{2}{*}{ Residential Area } & $.553 * * *$ & $.570 * * *$ & -.066 \\
\hline & $(.126)$ & $(.128)$ & $(.116)$ \\
\hline \multirow[t]{2}{*}{ Race } & & -.155 & $-.408 * *$ \\
\hline & & $(.165)$ & $(.130)$ \\
\hline Informal Police & & & $.187 * * *$ \\
\hline Contact & & & $(.042)$ \\
\hline Police in & & & $.267 * * *$ \\
\hline Neighborhood & & & $(.068)$ \\
\hline Police on Foot & & & $\begin{array}{c}.072 \\
(.047) \\
\end{array}$ \\
\hline $\mathrm{R} 2$ & .075 & .079 & .448 \\
\hline Adjusted R2 & .072 & .071 & .436 \\
\hline R2 Change & .075 & .004 & .369 \\
\hline
\end{tabular}

Table 17. Logistic Regression for Perception of Police Activity

\section{Perception of Fear}

An ordinary least squares (OLS) regression was completed to investigate the relationship between the walking patrol residents/employees and their fear of crime in their neighborhood. It consisted of three dependent variables with Likert responses that were changed to a scale measurement and reverse coded with the higher number representing a more positive response. Therefore, one of the variables, "I am fearful of 
crime in my neighborhood," remained the same to maintain analogous responses to the level of fear felt by the respondents. The non-walking patrol group was formed by recoding the residential/employment zones into a dummy variable. By changing the categorical variables into dichotomous, I can use a single regression to represent multiple groups not included in the walking patrol area. Table 18 references this information. 
Fear of Crime Variables

Dependent

\begin{tabular}{l|l}
\hline & $1-$ Strongly Agree \\
& $2-$ Agree \\
I am fearful of crime in my neighborhood. & - Neutral \\
$4-$ Disagree & $5-$ Strongly Disagree \\
\hline $\begin{array}{l}\text { I feel safe walking alone in my neighborhood during the } \\
\text { daytime. }\end{array}$ & $\begin{array}{l}1-\text { Strongly Disagree } \\
2-\text { Disagree } \\
3-\text { Neutral } \\
4-\text { Agree }\end{array}$ \\
\hline & $5-$ Strongly Agree \\
\hline
\end{tabular}

Independent

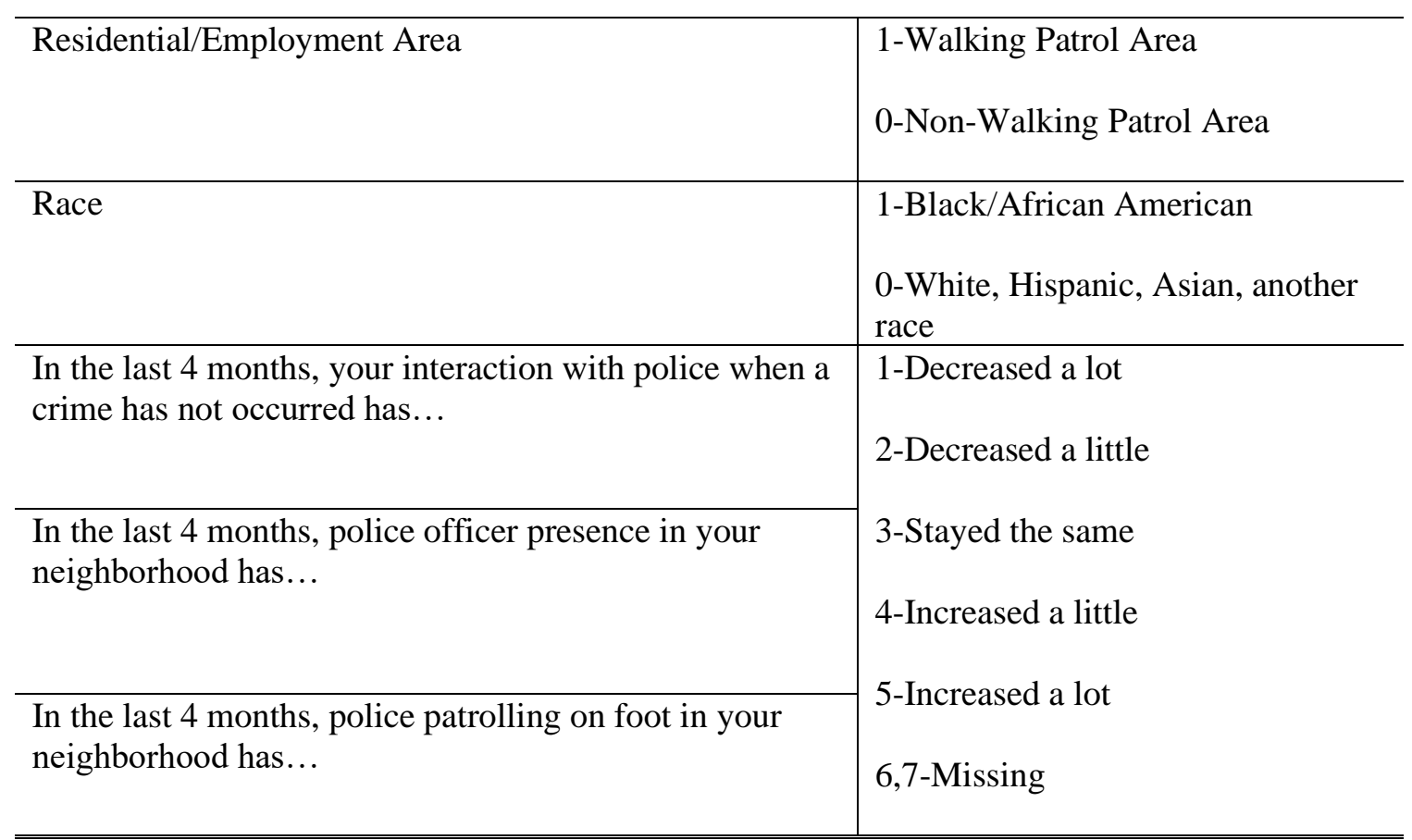

Table 18. Variable List for Perception of Police Characteristics

\section{Results}

For the preliminary analysis, a Cronbach Alpha test was conducted. This was done to look at the internal consistency between the dependent variables. The Cronbach Alpha for the variables related to "fear of crime" was .678, which is just below the 
acceptable internal consistency of .70 (Nunnally 1978). Due to the results, I continued the analysis using the three dependent variables to represent the level of fear residents/employees had in relation to crime in their neighborhood.

See Table 19 for the zero order correlations and basic univariate statistics. As stated before, the inter-item correlations examined the extent of the relationship between one dependent variable to another. The ideal correlation value is greater than .40 . This supplemented the decision to average the dependent variables, therefore I used the mean of the three variables for the OLS regression. If values are higher than .40 it shows isomorphic connections between the dependent variables. This supplements the decision to average the dependent variables as one variable for the regression analysis.

\begin{tabular}{l|lll}
\hline \multicolumn{3}{l}{ Inter-Item Correlation Matrix for Fear of Crime } \\
\hline \multicolumn{3}{l}{1} & \\
\hline 1 & $\begin{array}{l}\text { I am fearful of crime in my } \\
\text { neighborhood. }\end{array}$ & & \\
\hline 2 & $\begin{array}{l}\text { I feel safe walking alone in my } \\
\text { neighborhood during the } \\
\text { daytime. }\end{array}$ & .310 & .406 \\
\hline 3 & $\begin{array}{l}\text { I feel safe walking alone in my } \\
\text { neighborhood during after dark. }\end{array}$ & .576 & \\
\hline
\end{tabular}

Table 19. Fear of Crime Correlation Matrix

The $\mathrm{R}^{2}$ of the OLS model for fear of crime was .045 which indicates that the regression model can describe $4.5 \%$ of the variation. A simple linear regression was calculated to predict the respondents' fear of crime based on their residency or employment within the walking patrol area. A significant regression equation was found for the model $(\mathrm{F}(1,249)=12.227, \mathrm{p}<.001)$, with a summary of the model shown in Table 20. This shows that respondents who live in the walking patrol area have a negative unit change in relation to fear of crime, which differs from those respondents outside the 
walking patrol boundaries. The prediction of a respondent's fear of crime is equal to 3.415 (3.769 -.354) if they are within the walking patrol area. This indicates that the respondents in the walking patrol area had a .354 unit change on the fear of crime scale than respondents in the non-walking patrol area.

\begin{tabular}{|c|c|c|c|c|c|}
\hline \multicolumn{6}{|c|}{ Linear Regression Coefficients for Fear of Crime } \\
\hline \multirow{2}{*}{$\begin{array}{l}\text { Independent } \\
\text { Variable }\end{array}$} & \multirow[t]{2}{*}{$\mathrm{B}$} & \multirow{2}{*}{$\mathrm{SE}$} & \multirow{2}{*}{$\begin{array}{c}\mathrm{t}- \\
\text { Statistic }\end{array}$} & \multicolumn{2}{|c|}{$95 \% \mathrm{CI}$} \\
\hline & & & & Lower Bound & Upper Bound \\
\hline $\begin{array}{l}\text { Walking Patrol } \\
\text { Area }\end{array}$ & -.354 & .101 & -3.497 & -.554 & -.155 \\
\hline Notes: Constant $=$ & ${ }^{2}=.047$, & $27, \mathrm{p}<$ & & & \\
\hline
\end{tabular}

For further investigation, I completed a multiple linear regression to control for other variables in addition to residential/employment area. During the analysis, the variables of race, informal police contacts, police presence in the neighborhood, and police patrolling on foot were added to predict the level of fear of crime. An examination of the collinearity statistics, Tolerance and VIF, were all within accepted limits. The Mahalanobis distance scores indicated no multivariate outliers and the scatter plots indicated the assumptions of normality and linearity.

Table 21 shows the results of the multiple linear regression analysis. Both residential/employment area and informal police contacts were found to be significant predictors of a respondents fear of crime, $F(5,230)=3.550, \mathrm{p}<.05$. The analysis was found to suggest that a person's fear of crime will have negative unit change if they are living or working in the walking patrol area, which means an increase in fear of crime. It was also found that there was a positive unit change in relation to a respondents increase in numbers of informal police contacts. 


\begin{tabular}{|c|c|c|c|c|}
\hline \multicolumn{5}{|c|}{ Multiple Regression Results for Fear of Crime } \\
\hline & $\mathrm{B}$ & SE & t-statistic & p-value \\
\hline Residential Area & -.432 & .122 & -3.538 & $.000 * * *$ \\
\hline Race & .175 & .137 & 1.277 & .203 \\
\hline Informal Police Contacts & .110 & .044 & 2.493 & $.013 *$ \\
\hline Police Visibility in Neighborhood & .036 & .072 & .506 & .613 \\
\hline Police Patrolling on Foot & -.076 & .049 & -1.546 & .124 \\
\hline \multicolumn{5}{|c|}{$\begin{array}{l}\text { Notes: } \text { Constant }=3.550, \mathrm{R} 2=.100, \mathrm{~F}=5.112, \\
\mathrm{p}<.05\end{array}$} \\
\hline
\end{tabular}

Table 21. Multiple Linear Regression Results for Fear of Crime Variable

\section{Crime Statistics}

A method used often to evaluate new programs and their results is the difference in difference approach. The analysis uses the trend in the control group to help approximate what would have happened in the experiment group without the initiative. The difference found between the experiment group and the control group is the difference in difference estimate of the average effect of the initiative. Data for this was derived from the Record Management System (RMS) that is maintained by Louisville Metro Police Department based on reports and arrests made regarding criminal activity within the Louisville Metro area. The analysis only used the RMS data from the area of District 8 during the years of 2018 and 2019 between April $15^{\text {th }}$ and September $8^{\text {th }}$ and then separated the information into walking patrol and non-walking patrol locations. The data did not include calls for police service where a report or arrest did not result. This was decided based on the requests of the stakeholders, but also the usefulness of the data. Calls for service that do not have a form of physical documentation are often lacking details regarding the actual call and/or the results. Dispatch can also mischaracterize the information in the database, which can lead to inaccuracies in the reported amounts of 
specific problems in an area. Chart 2 visually shows the crime statistics between the locations and the years.

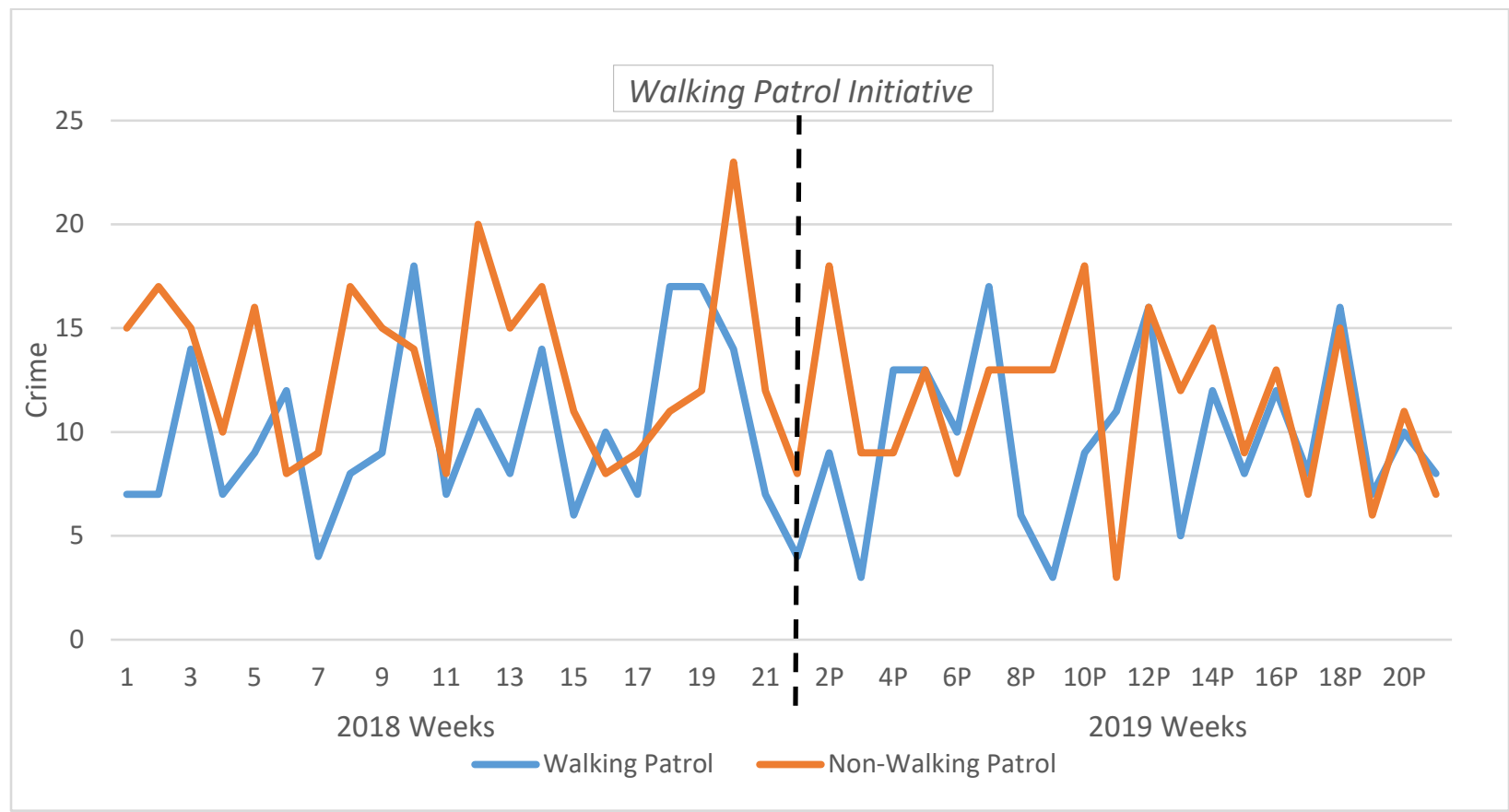

\section{Chart 2. Crime Statistics Pre and Post Walking Patrol Initiative}

A negative binomial regression model assessed the weekly effects on crime reports and arrests in the walking patrol area versus the non-walking patrol area. The results showed the $\mathrm{p}$-value is higher than $.05(\mathrm{p}>.999)$, which indicates the analysis is not statistically significant. Therefore, it indicates that there are not significant crime data changes between the walking patrol and non-walking patrol areas. I considered a Poisson Regression, but it showed over-dispersion (Deviance=1.319).

Displacement effects were assessed by comparing citizen reported incidents and self-initiated activity by police officers resulting in arrest and/or a police report(s) comparing the experiment and control locations. This is an important element to measure for any police initiative due to the unintended consequences following the direct effects of the treatment location. Using the same model, the findings from the negative binomial 
regression show that the crime statistics for the two areas to be similar following the initiative. This suggests that displacement was minimal in the surrounding, non-walking patrol areas.

\section{Summary of Findings}

The quantitative findings did reveal some information regarding the perception of crime, perception of police, and crime rate effects. Although the survey was a small sample, it provided important information relating to the initiative and data that can be utilized in future research. The initiative was completed over a small time frame and in an area with minimal reported criminal activity, but it is important to remember that this was not a specific effort by Louisville Metro Police Department to reduce crime. The research measured the perception of Louisville residents regarding perception of crime, perception of local law enforcement, and the fear of crime.

The research suggests that the perception of crimes, specifically property, violent, quality of life, and juvenile delinquency are perceived higher by those living in the non-walking patrol area. It also suggests that the perception of the police improves if the respondent is residing or employed within the walking patrol area. Respondents from this area also show decreased levels of fear regarding crime in their neighborhood.

Similar to the literature regarding fear of crime, this study suggests that the implementation of a walking patrol reduced fear due to the increase in informal police contacts, but did not change crime occurrences (Bowers and Hirsch 1987). This study also suggests from the quantitative findings that that the walking patrol officers were more approachable, similar to the literature, but the results additionally suggested that the 
officers were perceived as more courteous, fair, and professional (Simpson 2017). The literature referencing public perception of officer's job performance was also similar to the results found in the study that suggest that the respondent's opinion of law enforcement officers improved with increased visibility of police in their neighborhood (Maxson, et al. 2003). This contradicted the work of Kelling, et al. (1974), which found that fear of crime and community attitude did not change due to the amount or type of patrol initiated.

When controlling for race, being Black or African American did have significant results when looking at perception of police activity. This suggests that if a respondent is Black or African American they will have a more negative perception of police activity, including addressing problems, keeping order, preventing crime, level of communication, and community policing efforts. This control variable was not significant in the other regression analyses, which included fear of crime and perception of police characteristics. Within the models I also controlled for the amount of police contact that the respondent reported, i.e. amount of informal police interactions, police presence in the neighborhood, and police patrolling on foot. Informal police contact and presence in the respondent's neighborhood were found to be significant when measuring for perception of police characteristics and activity. This suggests that if the respondent had increased informal interactions and reported an increase in police presence in their neighborhood, they were more likely to have a more positive perception of police characteristics and activity. Informal police contacts were also showed significance when looking at fear of crime. This suggests that the respondent will be less fearful of crime in their neighborhood if they have an increase in informal police contacts. 
When controlling for the additional variables, the respondents residential and/or employment area was still significant when controlling for race. This variable was no longer significant when measuring for perception of police activity and characteristics when controlling for police contacts. Residential area remained significant when examining the respondent's fear of crime and using the police contacts as a control variable. These results show that the variable race did not impact the significance of the experiment group, but the amount of police contacts did affect the analyses. 


\section{CHAPTER VI: DISCUSSION AND CONCLUSION}

This study sought to explore the interconnectivity between the public perception of law enforcement and the police perception of the public's opinion and how that affects community policing efforts. More specifically the research analyzed: (1) how the perception of the police, personal safety, and crime changes for community members within the walking patrol area, (2) how foot patrol officers will perceive community opinions of law enforcement, and (3) how police officers job satisfaction changes with more informal law enforcement interactions. By using a mixed method approach, I was able to provide a more comprehensive investigation of the case study. The qualitative methodology gave in-depth descriptions of officer's personal experience for both walking patrol and vehicle patrol assignments, revealing trends that expand upon previous literature and introduce new considerations.

\section{Discussion}

\section{Perception of Police, Personal Safety, and Crime Changes for Community Members}

Police culture creates specific attitudes and perceptions for officers, as seen from the focus groups and interviews. Both the walking patrol and vehicle patrol built bonds with their cohorts and began sharing communal experiences toward the public and fellow

officers. These came from informal interactions, such as lunch breaks and roll calls, along with formal interactions at calls for service and proactive actions. As these connections 
intensify, the gap between the public and police begins to grow, creating the "us versus them" mentality. It also distorts communication and then often develops a misunderstanding about what the public needs or wants from their local law enforcement officers. A certain level of dissatisfaction begins to grow in a community (Fosam, et al. 1998). The walking patrol officers expressed discontent and lack of respect for police culture. It seemed to represent a divide between the community and law enforcement, which directly affects their ability to police in a community-focused way. The vehicle patrol officers felt part of the culture and described it as a "family" and that the divide between the community and law enforcement makes the officers feel isolated.

It is important to acknowledge that the walking patrol officers were not directed or taught how to perform their duties beyond their law enforcement responsibilities. The ability to gain intelligence on what was happening in the area that the officers patrolled proved to be different. The walking patrol officers were gaining information through communication via informal police interactions and the citizen conversations that followed. This led to what appeared to be a more clear understanding of public concerns and problem areas within the beat. The vehicle patrol often obtained intelligence about their patrol areas through statistics and communications at roll call. This not only limited their ability to fully understand the actual community concerns, but decreases legitimacy for the police department. It is the external public entities that sustain police departments, including residents and employees, and the more community involvement presents itself the higher the overall legitimacy of the agency (Crank 2003; Crank and Langworthy 1992). The skills to engage the public and determine the true concerns within the neighborhood were not taught by the academy. The qualitative research suggests that the 
ability to communicate and engage the public was learned through the process of the walking patrol assignment. As the literature shows, this increased level of communication can increase legitimacy for law enforcement. Vehicle patrol officers who are isolated in their car are limiting their interactions, unlike the walking patrol that consistently communicate, even when simply passing citizens on the sidewalk (Trojanowicz 1998).

Similar to Skogan's (1995) research, the walking patrol initiative did not have a significant change on the crime rates in the area, but did have significant findings in relation to citizen satisfaction, perception of disorder, and police legitimacy. The quantitative analysis of the survey data supported this, showing significant findings regarding these topics. Most of the literature shows that the fear of crime will decrease for residents when policing strategies involve direct contact between police and citizens (Bowers and Hirsch 1987; Weisburd and Eck 2004; Winkel 1986). The literature shows that even when higher crimes and disorder were perceived by the public, informal contacts impacted the approval of law enforcement. These informal contacts were also found to counter negative responses from formal contacts, and in turn have the potential to improve future formal contacts, such as citations and arrests (Maxson, et al. 2003). The quantitative results support this literature, suggesting a relationship between informal contacts and fear of crime. Respondents that reported an increase in informal contacts with law enforcement officers were less fearful of crime in their neighborhood.

As the literature discusses, organizational culture leads to learned behavior, which can affect biases, decisions, opinions, and attitudes. Conforming to the behavior is a differential association that nurtures an "us versus them" attitude within the group. The idea is that once officers are part of the culture, their ability to adapt to change and/or 
alter perceptions becomes difficult, if not impossible. Resistance, backlash, and lack of support can be results of police culture, which can bring challenges to an agency for generations (Cordner 2014; Burgess and Akers 1966). Organizational culture is an important part of growth and future success, but what that represents should be what is the priority and focus of the organization. Maskaly and Donner (2015) found that police culture is the most influential force in an officer's action, so it is important that the action is representative of the overall goals for the department. Since the analysis showed the walking patrol officers lacked a connection to the current police culture, is critical information for departments seeking ways to redevelop social learning in law enforcement.

These results substantiate institutional theory, showing that an officer's behavior and perceptions can change based on external exchanges and interactions. These changes offer potential breaks in the cycle of behavior and opinion regarding departmental goals and community relations. Walking patrol officers expressed discontent with the established police culture and denied involvement in the divide between the public and law enforcement. The vehicle patrol officers shared feelings of isolation and a disconnection with the public, with crime statistics directed their patrols and understanding of community concerns. These results suggest that community support and legitimacy could be reached through the implementation of a walking patrol. The preliminary findings show increased external connections from walking patrol officers, which coincides with the institutional theoretical perspective. External influences are foundational to law enforcement and maintaining legitimacy is essential. These findings 
suggest that walking patrols have the potential to increase community support through increased positive external interactions.

Social learning theory provides assumptions about the case study, specifically addressing police culture. The walking patrol officers expressed disrespect for current police culture, defining it through negative undertones. Vehicle patrol unanimously desired inclusion into the culture and defined it positively. Social learning theory explains how conforming behavior is a contributor to the creation and continuation of a strong police culture. This has a major influence on police behavior, attitude, decision-making, and external communication. The results of the research suggest that the walking patrol assignment can affect an officer's desire to be included in police culture. The implications of this substantiate social learning and provides a possible contributor to behavioral changes within an agency.

\section{Foot Patrol Officers Perception of Community Opinions on Law Enforcement}

Literature shows that often police officers feel less favorable in the public eye than other professions and this perception can change the attitude, communication, and decision-making during a call for service or other interaction during their shift. The vehicle patrol officers often felt a general level of negativity from the public. They discussed how that could accumulate with each call for service, which has the potential to affect the officer's perception of the entire community. Using the theoretical perspectives to frame these findings, this could partially explain the increased emotional labor discussed by the vehicle patrol officers. It could also potentially show their increased integration into the police culture. If an officer is continuously barraged with negativity and poor responses from the public, they will likely isolate themselves from the 
community and become more embedded in the culture that surrounds and supports them (Smith 1979; Yim and Schafer 2009). The organizational culture cultivates relationships based on shared feelings, experiences, and perceptions regarding community response and interaction.

The walking patrol officers shared higher incidents of positive interactions and perceived that the overall opinion of the public was positive. They also reported having consistent contacts with community members unrelated to calls for service. The opportunity to spend time with the community in relation to non-law enforcement activities was important for the officers to gain a better understanding of how the community perceives police and their role, but also what they are concerned about in their neighborhood. This communication increases law enforcement legitimacy and provides a bridge to the public, removing the officer from the isolation of the vehicle (Trojanowicz 1998). The officers patrolling in their cars are less likely to have random conversations with people walking down the sidewalk or soliciting a business in the area, which has the potential to limit them from gaining intelligence about community concerns or building rapport with citizens. Valuable information regarding crimes, quality of life issues, and safety concerns can be relayed through casual interactions between police officers and the public. Citizens are generally more knowledgeable about criminal activity and by using this resource, law enforcement is creating social cohesion (Brewer and Grabosky 2014; Groff, et al. 2013). The presence of co-production encourages involvement, cooperation, and joint community engagement. This can lead to safer neighborhoods, but more importantly, results in a community that feels heard and included in the process. 
The walking patrol officers reported knowing more people, gaining more information from the public, and having a higher amount of positive interactions than the vehicle patrol officers. Their perceptions of public opinion were more optimistic, suggesting that the more informal encounters the officers had, the more likely their perception of the community would be more positive. The walking patrol officers described interactions with empathy, understanding, and patience. In contrast, the vehicle patrol officers seemed annoyed by public encounters and most rarely took additional time to engage in an informal setting.

\section{Change in Job Satisfaction with more Informal Law Enforcement Interactions}

The literature shows that when officer's perception of community views was supportive, this positively affected their job performance and satisfaction, which is crucial to the success of any policing initiative (Skogan 1995; Yim and Schafer 2009). Job satisfaction can affect the attitude of the officer on formal and informal police actions, which can enhance community policing or hinder the engagement depending on the attitude portrayed during the interaction. This case study showed no significant differences between the walking patrol and vehicle patrol when evaluating job satisfaction. Both groups expressed high levels of satisfaction with their job assignment and the requirements of patrol. All the participants expressed eagerness for their shifts and were happy with their job duties. A few reported that the leadership and political matters could be "frustrating," but the overall consensus was positive regarding law enforcement activities.

This consistency between both groups and their level of job satisfaction, could be described by their amount of time on patrol and serving the public. These officers are all 
from the same academy class are new officers. Their satisfaction could be in relation to the amount of service time or lack of exposure to job-related stress or situations.

\section{Future Research}

While this case study is complete, there are several topics that I would like to pursue as future research projects. Doing studies based on law enforcement officers is difficult, especially when researching perception, because officers grow, change, and adapt to their surroundings. They are also human, so personal events related and unrelated to the job can change their perspectives and attitudes toward policing and the community. Emotional labor theory describes how years of policing experience can cause high levels of stress, anxiety, and introduce critical events, therefore an officers perception right now may change after a year, two, or five. Therefore, completing followup interviews and/or focus groups with the same participants throughout their career would provide valuable longitudinal data. Determining if these officers had the same perceptions, attitudes, and policing strategies consistently after several years of patrol would contribute to the literature surrounding police culture and institutional theory. The additional research would analyze the consistency of the officers' attitude toward police culture and how that does or does not affect their behavior, communication, and/or policing skills. It must be understood that walking patrol officers opinions pertaining to police culture are likely related to their assignment. Once they are reassigned their opinions could conform to the culture shared by the vehicle patrol. Determining how often the walking patrol initiative or something similar would have to be performed to 
maintain the community-oriented attitude could inform departments regarding future coproduction efforts.

I would also like to reevaluate the participant's level of job satisfaction throughout their employment to determine if the lack of significant findings for this case study was due to the amount of time in policing. The job is still new to them, but a follow-up interview could determine if the amount of time on the job has a significant effect on levels of satisfaction. Also, if previous experience with the walking patrol when controlling for time would have significant results would be a valuable contribution to the literature.

I would also like to complete pre- and post-interviews with recruits to determine if the officer's perception of the public and their opinion was changed during the academy and if so, if it was negatively or positively. Although not a goal of this study, several variables were introduced during the analysis that involved training. The perception that all encounters would involve some form of violence or negative response from the citizen(s) at a call for service was shared by all the participants. Several officers expressed that this training hindered their ability to communicate and engage the public due to the inherent belief that an adverse reaction was inevitable. The importance of community relations and the ability to engage the public is critical to the success of any department seeking to improve community policing efforts. Researching training curriculum and its inadvertent effects on the perception of new officers is valuable data that can inform structural changes with basic training. 


\section{Program Recommendations}

- Complete follow-up studies in relation to the current participants in relation to job satisfaction, community perception, and police culture.

- $\quad$ Probationary officers to do a walking patrol phase to enhance communication skills, teach community engagement, and allow time for more informal law enforcement interactions.

- During basic academy training, add an instructional block on the importance of patrolling on foot and connection with community leaders, business owners, and residents on the beat.

- $\quad$ During basic academy training have business owners and community leaders from the walking patrol areas present information and discuss the importance of community policing and what the walking patrol officers have accomplished in the neighborhood.

- Mandate monthly walking patrol rotations for officers to maintain informal law enforcement interaction and to promote officer wellness. It would also provide a decrease in calls for service, provide an opportunity for the officer to maintain community relationships and contacts, and potentially decrease citizen's fear of crime.

- $\quad$ Establish a monthly community forum for the walking patrol area to meet with the walking patrol officers to discuss issues, concerns, complaints, and/or updates on crime and quality of life issues.

- $\quad$ Prepare a handout for the walking patrol to have readily available with information about the area, contact numbers for law enforcement, crime deterrent tips, programs available for the public, and dates for community meetings. 


\section{Conclusion}

This case study provides significant contributions to the literature, including community policing and patrol techniques, while using established theoretical perspectives. Additionally, this research has provided valuable information regarding training, communication, and officer and community perceptions. Law enforcement initiatives in relation to community policing efforts can provide large amounts of qualitative and quantitative data, but it can be difficult to determine its direct effects. This is due to the complexities behind community engagement and the current societal narrative that is being portrayed. Large scale events, departmental policy, and organizational leadership can play a role in shaping the outcome of new policing strategies. Establishing goals for the officers, the department, and the community is challenging and they are often all very different. The current climate is volatile and has established that large organizational changes are wanted. Decisions made now will determine the direction and appearance of the next generation of police officers. Redeveloping legitimacy in law enforcement and identifying the effective methods for community engagement is essential.

The most important thing to establish from this research is that community policing and the efforts to gain positive public perception to increase legitimacy and professionalism will not be based on a solitary solution. If the research only considers one factor the results will be limited and an evaluation of its success or failure will be inadequate. Many contributing factors have to be considered when launching community policing efforts. Program evaluations of policing efforts are an important part of determining if the work was worth the departmental funds, officers efforts, and/or 
community support. To evaluate the success or failure of a program, policy modification, or organizational change, a critical examination of the role of law enforcement and the community members must be completed.

Police departments are consistently seeking out ways to encourage community relations and increase legitimacy, professionalism, and promote positive perceptions. This case study determined that the walking patrol initiative did have positive effects on community members' perception of crime and police activities and it also positively impacted the police officers' perception of public opinion. Although a walking patrol is not the singular response to solve community relations between law enforcement and citizens, it does influence community engagement, increases legitimacy, decreases the fear of crime, and changes the influence of police culture. 


\section{REFERENCES}

Adlam, R. 2010. “Government Rationalities in Police Leadership: An essay exploring some of the 'deep structure' in police leadership praxis.” Policing and Society: An International Journal of Research and Policy. Vol 12(1): 15-36.

Adler, P. and Adler, P. Membership Roles in Field Research. Sage Publications. Newbury, CA.

Agnew, R., Brezina, T. 2015. Juvenile Delinquency: Causes and Control. Oxford University Press. New York, NY.

Akers, R.L. 2012. Criminological Theories: Introduction and Evaluation (2 ${ }^{\text {nd }}$ Edition). New York, NY: Routledge.

Akers, R. L. 2011. Social Learning and Social Structure: A General Theory of Crime and Deviance. New Brunswick, NJ.

American Bar Association. 1972. Standards Relating to the Urban Police Function.

American Bar Association Project on Standards for Criminal Justice. Institute of Judicial Administration. New York.

Aronson, E.; Wilson, T. D.; Akert, R.M. 2010. Social Psychology, Seventh Edition. Upper Saddle River, NJ: Pearson Education, Inc. 83-115.

Ashcroft, J., Daniels, D. J., and Hart, S. V. 2003. "Factors that Influence the Public Opinion of the Police” Research for Practice, June 2003. National Institute of Justice, U.S. Department of Justice.

Attia, M., Edge, J. 2016. “Be(com)ing a Reflexive Researcher: A Developmental 
Approach to Research Methodology." Open Review of Educational Research. Vol 4(1): 33-45.

Bacon, M. 2014. Police Culture and the New Policing Context. The Future of Policing. Routledge. London.

Bakker, A. B., Heuven, E. 2006. "Emotional Dissonance, Burnout, and In-Role Performance among Nurses and Police Officers." International Journal of Stress Management. Vol 13: 423-440.

Beetham, D. 1991. The Legitimation of Power. Macmillan. London, U.K.

Berg, B. L., \& Lune, H. (2012). Qualitative Research Methods for the Social Sciences ( $8^{\text {th }}$ ed.). Boston: Pearson.

Bottoms, A., Tankebe, J. 2012. Beyond procedural justice: A dialogic approach to legitimacy in criminal justice. Journal of Criminal Law and Criminology Vol 102:119-70

Bowers, W. and Hirsch, J. 1987. "The Impact of Foot Patrol Staffing on Crime and Disorder in Boston: An unmet promise." American Journal of Policing. Vol 6(1): $17-44$.

Braga, A., Papachristos, A. Hureau, D. 2014. "The Effects of Hot Spot Policing on Crime: An updated systematic review and meta-analysis." Justice Quarterly. Vol 31: 633-663.

Brewer, R., Grabosky, P. 2014. "The Unraveling of Public Security in the United States: The Dark Side of Police-Community Co-Production." American Journal of Criminal Justice. Vol 39: 139-154.

Brown, M.K. 1981. Working the Street: Police Discretion and the Dilemmas of Reform. 
Russell Sage Foundation. New York, NY.

Burgess, R. L., \& Akers, R. L. 1966. “A Differential Association-Reinforcement Theory of Criminal Behavior.” Social Problems. Vol 14(2): 128-147.

Carter, D.L. 2002. The Police and the Community ( $7^{\text {th }}$ ed.). Prentice Hall, Englewood Cliffs, NJ.

Charmaz, K. 2009. Constructing Grounded Theory: A Practical Guide Through Qualitative Analysis. Thousand Oaks: Sage Publications.

Chappell, A.T., Piquero, A.R. 2004. “Applying Social Learning Theory to Police Misconduct." Deviant Behavior. Vol 25(2): 89-108.

Clarke, R. (ed.) (1997). Situational Crime Prevention: Successful Case Studies. Second Edition. New York: Harrow and Heston.

Clarke, R. and Weisburd, D. 1994. "Diffusion of Crime Control Benefits: Observations on the Reverse of Displacement." Crime Prevention Studies. 2:165-183.

Cockcroft, T. 2014. "Police Culture and Transformational Leadership: Outlining the Contours of a Troubled Relationship." Policing: A Journal of Policy and Practice. Vol $8(1)$

Cohen, R.V. and Marcus Felson. 1979. "Social Change and Crime Rate Trends: A Routine Activities Approach.” American Sociological Review. 71: 95-122.

Cordner, G. 2014. Community policing. In M. D. Reisig \& R. J. Kane (Eds.). The Oxford Handbook of Police and Policing (pp. 148-171).

Crank, J.P. 2003. Institutional theory of police: a review of the state of the art. Policing. Vol 26(2): 186-207.

Crank,J., Langworthy,R. 1992. '”An Institutional Perspective of Policing." Journal of 
Criminal Law and Criminology. Vol.83:338-63.

Crank,J., Rehm,L. 1994. "Reciprocity Between Organizations and Institutional Environments: A Study of Operation Valkyrie.” Journal of Criminal Justice. Vol 22(5): 393-406.

Dicker, Todd J. 1998. “Tension on the Thin Blue Line: Police Officer Resistance to Community Oriented Policing.” American Journal of Criminal Justice. Vol 23(1).

Donnelly, M., Kerr, N.J., Rimmer, R. and Shiu, E.M. 2006. “Assessing the Quality of Police Services Using SERVQUAL.” Policing: An International Journal of Police Strategies and Management. Vol 29(1): 92-105.

Donnermeyer, J.F., O'Block, R.L. 1991. Security and Crime Prevention. Elsevier. Etzioni, A. 1960. A Comparative Analysis of Organizations. Free Press. New York, NY.

Ferguson, K. and C. Mindel. 2007. "Modeling Fear of Crime in Dallas Neighborhoods: A Test of Social Capital Theory." Crime \& Delinquency. Vol 53(2): 322-49.

Fielden, S. 2009. The Mind of a Cop: What they do and why they do it. iUniverse Inc. New York, NY.

Friedmann, R. 1992. Community policing: Comparative perspectives and prospects. Hemel Hempstead.

Fosam, E.B., Grimsley, M.F., \& Wisher, S.J. 1998. “Exploring Models for Employee Satisfaction - With particular reference to a police force." Total Quality Management. Vol 9(2/3): 235-247.

Gill, C., Weisburd, D., Telep, C.W., Vitter, Z., Bennett, T. 2014. “Community-Oriented 
Policing to Reduce Crime, Disorder and Fear and Increase Satisfaction and Legitimacy among Citizens: A systematic review." Journal of Experimental Criminology. Vol 10: 399-428.

Glaser, B.G. and Anselm L. S. 1967. The Discovery of Grounded Theory: Strategies for Qualitative Research. 1st Edition. Aldine de Gruyter.

Goffman, E. 1959. The Presentation of Self in Everyday Life. Anchor Books.

Goldstein, H. 1990. Problem-Oriented Policing. McGraw Hill. New York, NY.

Grabosky, P. 1992. "Law Enforcement and the Citizen: Non-government participants in crime prevention and control." Policing and Society. Vol 2(4): 249-271.

Greene, J. 1989. "Police Officer Job Satisfaction and Community Perceptions: Implications for Community Oriented Policing." Journal of Research in Crime and Delinquency. Vol 26(2): 168-181.

Groff, E.R., Johnson, L., Ratcliffe, J.H., Wood, J. 2013. “Exploring the Relationship Between Foot and Car Patrol in Violent Crime Areas.” Police Strategies and Management. Vol 36, 1: 119-139.

Hauser, W. and Kleck, G. 2016. "The Impact of Police Strength and Arrest Productivity on Fear of Crime and Subjective Assessments of the Police.” American Journal of Criminal Justice. Vol 42: 86-111.

Hinkle, J.C. and Weisburd, D. 2008. “The Irony of Broken Windows Policing: A micro place study of the relationship between disorder, focused police crackdowns and fear of crime.” Journal of Criminal Justice. Vol 36: 503-512.

Innes, M. and Roberts, C. 2008. "Reassurance policing: community intelligence and the 
co-production of neighborhood order", in Williamson, T. (Ed.), The Handbook of Knowledge-based Policing: Current Conceptions and Future Directions. John Wiley and Sons. West Sussex. 241-62.

Jacobs, J. 2011. The Death and Life of Great American Cities. Modern Library. New York, NY.

Jaffee, D. 2001. Organization Theory: Tension and Change. McGraw Hill. New York, NY.

Kelling, G.L., Pate, T., Dieckman, D., Brown, C.E. 1974. The Kansas City Preventative Patrol Experiment. National Police Foundation. Washington, D.C.

Kelling, G. and Coles, C.M. 1996. Fixing Broken Windows. The Free Press. New York, NY.

Kraska, P. and Kappeler, V. 1997. "Militarizing American Police: The rise and normalization of paramilitary units." Social Problems. Vol 44: 1-18.

Langan, P.A., Greenfeld, L.A., Smith, S.K., Durose, M.R., Levin, D.J. 2001. Contact Between Police and the Public: Findings from the 1999 National Survey. Washington, DC: U.S. Department of Justice.

Lee, S., Choi, K., Choi, S., \& Englander, E. 2019. “A Test of Structural Model for Fear of Crime in Social Networking Sites." International Journal of Cybersecurity Intelligence \& Cybercrime. Vol 2(2), 5-22.

Lipsky, M. 2010. Street-Level Bureaucracy. Russell Sage Group. New York, NY. Louisville/Jefferson County Metro Government. 2013. Executive Order No. 1. 
Maguire, E. R. and Johnson, D. 2010. "Measuring Public Perceptions of the Police." Policing: An International Journal of Police Strategies \& Management. Vol 33(4): 703-730.

Maguire, E.R., Lowrey, B.V., Johnson, D. 2016. "Evaluating the relative impact of positive and negative encounters with police: a randomized experiment." Journal of Experimental Criminology. Vol 13(3): 367-391.

Markham, A. 2011. "Fabrication as Ethical Practice. Qualitative Inquiry in Ambiguous Internet Contexts." Information, Community, and Society. Vol 15(3): 334-353.

Martin, S.E. 1999. "Police Force or Police Service? Gender and Emotional Labor.” The Annals of the American Academy of Political and Social Science. Vol 561: 111126.

Maskaly, J., \& Donner, C. M. 2015. "A theoretical integration of social learning theory with terror management theory: Towards an explanation of police shootings of unarmed suspects." American Journal of Criminal Justice. Vol 40(2): 205-224.

Maslov, A. 2015. Measuring the Performance of the Police: The Perspective of the Public. Research Report. Public Safety Canada.

Maxson, C.L., Hennigan, K., Sloane, D.C. 2003. Factors That Influence Public Opinion of the Police. U.S. Department of Justice. Office of Justice Programs.

Meyer, J.W., Rowan. B. 1977. "Institutionalized Organizations: Formal Structure as Myth and Ceremony." American Journal of Sociology. Vol 83:340-363.

Modaff, D.P., DeWine, S., Butler, J. 2011. Organizational Communication: Foundations, Challenges, and Misunderstandings (2nd Ed.). Boston: Pearson Education. 
Nunnally, J. C. 1978. Assessment of Reliability. In: Psychometric Theory (2nd ed.). New York: McGraw-Hill. 245-246

Office of Community Oriented Policing Services. 2012. Community-Oriented Policing

Defined. Washington, DC: U.S. Department of Justice, Office of Community Oriented Policing Services.

Piza, E. 2018. “The Effect of Various Police Enforcement Actions on Violent Crime: Evidence from a Saturation Foot-Patrol Intervention.” Criminal Justice Policy Review. Vol 29(6-7): 611-629.

Paoline, E.A., Myers, S.M., Worden, R.E. 2000. "Police Culture, Individualism, and Community Policing: Evidence from Two Police Departments." Justice Quarterly. Vol 17(3): 575-605.

Peak, K. 2015. Policing America. Pearson. Boston, MA.

Police Foundation. 1981. The Newark foot patrol experiment. Washington, DC: Police Foundation.

Press, J.S. 1971. Some Effects of an Increase in Police Manpower in the $20^{\text {th }}$ Precinct of New York City. Rand Institute. Report R704. New York, NY.

Ravasi, D., Schultz, M. 2006. "Responding to Organizational Identity Threats: Exploring the role of organizational culture." Academy of Management Journal. Vol 49 (3): 433-458.

Reid, S.T. 2009. Crime and Criminology. 12th Ed. Oxford University Press, Inc. Oxford, NY.

Reiman, J. 2004. The Rich Get Richer and the Poor Get Prison. American University. New York, NY. 
Ross, L. 1977. The intuitive psychologist and his shortcomings: Distortions in the attribution process. Advances in Experimental Psychology. Vol 10: 174-214.

Rose, T., \& Unnithan, P. 2015. "In or out of the group? Police subculture and occupational stress.” Policing: An International Journal of Police Strategies \& Management. Vol 38(2): 279-294.

Rosenbaum, D.P. 2006. The limits of hot spots policing. In D. Weisburd and A.A. Braga (Eds.), Police Innovation: Contrasting perspectives. Cambridge, MA: Cambridge University Press.

Savion, L. 2009. “Clinging to Discredited Beliefs: The Larger Cognitive Story.” Journal of the Scholarship of Teaching and Learning. Vol 9(1): 81-92.

Schafer, J.A., Huebner, B.M., Bynum, T.S. 2003. “Citizen Perceptions of Police Services: Race, Neighborhood Context, and Community Policing.” Police Quarterly. Vol 6 (4): 440-468.

Schiable, L., Gecas, V. 2010. “The Impact of Emotional Labor and Value Dissonance on Burnout among Police Officers.” Police Quarterly. 13(3): 316-341.

Schnelle, J.F., Kirchner Jr., R.E., Casey, J.D., Uselton Jr., P.H., McNees, M.P. 1977. "Patrol Evaluation Research: A multiple-baseline analysis of saturation police patrolling during day and night hours." Journal of Applied Behavior Analysis. Vol 10, Issue 1: 33-40.

Shaw, C. and H. McKay. 1942. Juvenile Delinquency and Urban Areas. Chicago, United States: University of Chicago Press. 
Simpson, R. 2017. "The Police Officer Perception Project: An experimental evaluation of factors that impact perceptions of the police." Journal of Experimental Criminology. Vol 13: 393-415.

Skogan, W. G. 1990. Disorder and Decline: Crime and the Spiral Decay in American Neighborhoods. Los Angeles, United States: University of California Press.

Skogan, W.G. 1995. "Community policing in the United States". In Brodeur, J.-P. (Ed.), Comparisons in Policing: An International Perspective. Avebury Press, Aldershot. 86-111.

Skogan, W.G. 2011. "Community-Based Partnerships and Crime Prevention.” Criminology and Public Policy. 10(4):987-90.

Skolnick, J. 1994. Justice without Trial: Law Enforcement in Democratic Society. Macmillan. London.

Smith, D.C. 1979. Public attitudes to the police and their preventive roles. Collected Studies in Criminological Research. Vol 16: 37-68.

Steinberg, R., Figart, D. 1999. "Emotional Demands at Work: A Job Content Analysis." The Annals of the American Academy of Political and Social Science. Vol 561(1): 177-191.

Stoughton, S. 2014. "Policing Facts.” Tulane Law Review. Vol 88(5).

Taber, K. 2017. “The Use of Cronbach's Alpha When Developing and Reporting Research Instruments in Science Education." Research in Science Education. Vol 48: 1273-1296.

Tankebe, J. 2013. Viewing Things Differently: The Dimensions of Public Perceptions of 
Police Legitimacy. Criminology. Vol 51(1): 103-136

Taylor, R.B. 1999. Crime, Grime, Fear, and Decline: A Longitudinal Look. Washington, DC: National Institute of Justice.

Taylor, R.B. 2006. Incivilities Reduction Policing, Zero Tolerance, and the Retreat from Coproduction: Weak Foundations and Strong Pressures In Police Innovation: Contrasting Perspectives, eds. David L. Weisburd and Anthony A. Braga. Cambridge University Press. New York, NY.

Terrill, W., Paoline III, E. A., \& Gau, J. M. 2016. Three Pillars of Police Legitimacy: Procedural Justice, Use of Force, and Occupational Culture. In The Politics of Policing: Between Force and Legitimacy. Emerald Group Publishing Limited. pp. 59-76.

Thornton, P.H., Ocasio, W., Lounsbury, M. 2012. The Institutional Logics Perspective: A New Approach to Culture, Structure, and Process. Oxford University Press. Oxford, UK.

Trojanowicz, R.C., Kappeler, V.E., Gaines, L.K., and Bucqueroux, B. 1998. Community Policing: A Contemporary Perspective. Anderson. Cincinnati, OH.

Tyler, T.R. 1990. Why People Obey the Law: Procedural Justice, Legitimacy, and Compliance. Yale University Press. New Haven, CT.

Vilalta, C.J. 2013. Determinant Factors in the Perception of Crime-Related Insecurity in Mexico. Inter-American Development Bank.

Watson, E.M., Alfred R.S., and Stuart M.D. 1998. Strategies for Community Policing. Upper Saddle River: Prentice-Hall, Inc. 
Weisburd, D., Eck, J. 2004. "What Can Police Do to Reduce Crime, Disorder, and Fear?" The Annals of the American Academy. Vol 593: 42-66.

Willis, R. 2018. "The use of composite narrative to present interview findings."

Qualitative

Research. Vol 19(4): 471-480.

Wilson, J.Q. and Kelling, G.L. 1982. "Broken Windows: The Police and Neighborhood Safety. Atlantic Monthly. Vol 249(3): 29-38.

Wilson, O.W. 1953. Put the Cop Back on the Beat. Public Management.

Winkel, F.W. 1986. "Reducing Fear of Crime through Police Visibility: A Field Experiment." Criminal Justice Policy Review. Vol 1, No 4: 381-398.

Yang, S. 2007. Causal or merely co-existing: A longitudinal study of disorder and violence at places. University of Maryland.

Yim, Y., Schafer, B.D. 2009. "Police and their perceived image: how community influence officers' job satisfaction.” Police Practice and Research. Vol 10(1): 17-29. 


\section{APPENDIX A}

SURVEY QUESTIONS for District 8 residents:

Perception of safety: Strongly Agree, Agree, Neutral, Disagree, Strongly Disagree

1. I am fearful of crime in my neighborhood.

2. I feel safe walking alone in my neighborhood during the daytime?

3. I feel safe walking alone in my neighborhood after dark?

4. The police in my neighborhood supply information to the public on ways to reduce crime.

5. The police in my neighborhood are courteous.

6. The police in my neighborhood are approachable and easy to talk to.

7. The police in my neighborhood are visible.

8. The police in my neighborhood are professional.

9. The police in my neighborhood are fair.

10. I am able to interact with police officers in my neighborhood on a daily or regular basis.

Perception of Police: Very Poor, Somewhat Poor, Somewhat Good, Very Good, Don't Know

11. How are the police doing at addressing the problems that are concerning people in your neighborhood?

12. How are the police in your neighborhood doing at keeping order on the streets and sidewalks?

13. How are the police doing at preventing crime in your neighborhood?

14. How would you rate the level of communication between you and the police patrolling your neighborhood?

15. Community policing involves police officers working with the community to address the causes of crime in an effort to reduce the problems themselves and the associated fear, through a wide range of activities. Based on this definition, how are the police doing at practicing community policing in your neighborhood?

Perception of LMPD: Strongly Agree, Agree, Neutral, Disagree, Strongly Disagree

16. LMPD has a good working relationship with the community.

17. LMPD is making an effort to become more involved with the community.

18. LMPD officers respond in a fair way when dealing with racial and ethnic groups.

19. LMPD officers respond in a fair way when dealing with religious groups. 
20. LMPD officers respond in a fair way when dealing with LGBTQ.

21. LMPD officers respond in a fair way when dealing with persons with a disability or mental health condition.

22. LMPD officers respond in a fair way when dealing with persons of various social classes.

23. LMPD is a professional law enforcement agency.

Level of Satisfaction: Very Satisfied, Somewhat Satisfied, Somewhat Dissatisfied, Very Dissatisfied, Don't know

24. Overall, how satisfied are you with the police visibility or presence in your community?

25. Overall, how satisfied are you with the services provided by LMPD officers?

26. Thinking about your most recent contact, how satisfied were you with the way the police handled the matter?

Perceptions of crime: Increased a lot, Increased a little, Stayed about the same, Reduced a little, Reduced a lot, Don't know, Haven't lived here for 3 months In the last four months:

27. The amount of break-ins/property thefts in your neighborhood have...

28. The amount of violent crimes in your neighborhood have...

29. The amount of homelessness in your neighborhood has...

30. The amount of panhandling in your neighborhood have...

31. The amount of drug crimes in your neighborhood have...

32. The amount of juvenile delinquency has...

33. My interaction with police when a crime has not occurred has...

34. Police officer presence in your neighborhood has...

35. Police patrolling on foot in your neighborhood has...

\section{DEMOGRAPHIC INFORMATION:}

1. What zone do you reside in?

2. How long have you lived in the neighborhood? Less than a year; 1-3 years; 4-6 years; $7-9$ years; $10+$

3. Age: $18-20 ; 21-24 ; 25-29 ; 30-34 ; 35-39 ; 40-44 ; 45-49 ; 50$ and older

4. What gender group do you most identify with? Male, Female, Other

5. What racial or ethnic group do you most identify with? White/Caucasian;

Hispanic/Latino; Black/African-American; Native American; Asian/Pacific Islander; Other

6. What is your highest level of education? High school; Less than two years of college; Associate's Degree; Professional Degree; Bachelor's Degree; Graduate Degree 7. What is your marital status? Single; Married; Domestic Partnership; Widowed, Divorced; Separated; Prefer not to say.

8. Do you have any children under 18 years of age living in your home? Yes/No 
9. Total household income: Less than $\$ 10,000 ; \$ 10,000$ to $\$ 19,999 ; \$ 20,000$ to $\$ 29,999$; $\$ 30,000$ to $\$ 39,999 ; \$ 40,000$ to $\$ 49,999 ; \$ 50,000$ to $\$ 59,999 ; \$ 60,000$ to $\$ 69,999 ; \$ 70,000$ to $\$ 79,999 ; \$ 80,000$ to $\$ 89,999 ; \$ 90,000$ to $\$ 99,999 ; \$ 100,000$ to $\$ 149,999 ; \$ 150,000$ or more 


\section{APPENDIX B}

\section{FOCUS GROUP QUESTIONS}

How is the job different from what you thought it would be following your graduation from the Academy?

Describe something positive for the community that occurs in the area you patrol.

Describe what you think the people in the area you patrol are most concerned with/about. Prompt: Why do you think this?

Describe ways you are interacting with and/or engaging the community?

Tell me about an event/run/interaction during patrol that was important to you.

Prompt: Can you think of 1-2 highlights from your time on patrol?

Tell me your thoughts and/or views about foot patrol?

Prompt: What are the benefits or advantages of foot patrol?

Prompt: What are the disadvantages?

Prompt: Do you think foot patrol makes a difference with regard to crime or community relations, and why do you think that

You have interactions with civilians throughout your entire shift. How are you treated by the public?

Prompt: Is the treatment what you had expected?

Prompt: Describe the community's perception of law enforcement.

Describe your level of satisfaction with your job in policing. 


\section{APPENDIX C}

\section{INTERVIEW QUESTIONS:}

\section{Goals/missions/philosophy}

- What are your personal goals for your current assignment?

- What do you perceive as the departments goals for you at your current assignment?

- What do you perceive as the most problematic area you patrol?

$\circ \quad$ In your opinion, what is a problem that is negatively impacting the area you patrol?

$\circ$ In your opinion, what is something positive for the community that occurs in the area you patrol?

- What do you think the people in the area you patrol are most concerned with/about?

○ Describe the community's perception of law enforcement.

\section{Deployment/tactics}

○ How do you greet people during your shift?

$-\quad H o w$ many contacts have you made with the public unrelated to calls for service?

$\circ \quad$ How are you balancing enforcement with community engagement?

- $\quad$ (Prompt) Do you focus more on enforcement, community engagement, or some combination of both? 2. Do you conduct frequent pedestrian stops? 3. How do you deal with people loitering, panhandling, or creating other disturbances?

$\circ \quad$ How are you interacting with and/or engaging the community?

- Scenario based questions:

- $\quad$ shoplifter, loitering, graffiti, DV

$\circ \quad$ How are you interacting with and engaging the community? 1. What types of things are you doing to get to know people in your walking beat?

\section{Personal performance/feedback}

- Think about last shift_- describe some of the interactions you had with the public. (Exclude calls for service) What were the interactions about?

- Tell me about an event/run/interaction during patrol that was important to you.

- What are the disadvantages or challenges you have experience in your patrol area? 
- Has your assignment changed some of your views about foot patrol or police work in general? How?

$\circ \quad$ How has your patrol area changed your job satisfaction, if at all?

- Can you think of 1-2 highlights from your time on patrol?

O Tell me how foot patrol is viewed by other patrol officers in the department - is it generally seen as a good assignment or a bad one?

$\circ \quad$ What are your thoughts and views about foot patrol?

- What do you like about it? 2. What don't you like about it?

What would you change?

$\circ \quad$ Do you think foot patrol makes a difference with regard to crime or community relations, and why do you think that?

- What are the benefits or advantages of foot patrol?

Areas to highlight in interview questions:

$>\quad$ Job satisfaction for officers.

$>\quad$ Better equipped at recognizing problems

$>\quad$ Interpersonal communication skills

$>\quad$ Problem and incident solving skills alternate to enforcement to enhance quality of life problems.

$>\quad$ Identifying issues/problem solving.

$>\quad$ Alternative methods to arrests/citations if applicable. 
APPENDIX D

\begin{tabular}{|c|c|c|}
\hline \multicolumn{3}{|c|}{ Demographic Information from Community Survey } \\
\hline & \multicolumn{2}{|c|}{ Participants $(n=249)$} \\
\hline & $\%$ & \# \\
\hline \multicolumn{3}{|l|}{ Residential Zone } \\
\hline $1($ Yellow $)$ & 6.02 & 15 \\
\hline 2 (Purple) & 42.57 & 106 \\
\hline 3 (Orange) & 20.88 & 52 \\
\hline 4 (Green) & 21.69 & 54 \\
\hline $5(\operatorname{Red})$ & 5.62 & 14 \\
\hline 6 (Blue) & 3.21 & 8 \\
\hline \multicolumn{3}{|l|}{ Neighborhood Status } \\
\hline Resident & 64.66 & 161 \\
\hline Employee & 23.69 & 59 \\
\hline Both & 11.65 & 29 \\
\hline \multicolumn{3}{|l|}{ Time in Neighborhood } \\
\hline$<1$ year & 6.02 & 15 \\
\hline $1-3$ years & 23.29 & 58 \\
\hline 4-6 years & 24.10 & 60 \\
\hline $7-9$ years & 12.45 & 31 \\
\hline 10 or more & 34.14 & 85 \\
\hline \multicolumn{3}{|l|}{ Age } \\
\hline $18-24$ & 11.65 & 29 \\
\hline $25-34$ & 18.47 & 46 \\
\hline $35-44$ & 23.69 & 59 \\
\hline $45-54$ & 21.29 & 53 \\
\hline $55-64$ & 14.06 & 35 \\
\hline $65+$ & 10.84 & 27 \\
\hline \multicolumn{3}{|l|}{ Gender } \\
\hline Male & 37.35 & 93 \\
\hline Female & 58.63 & 146 \\
\hline Other & 2.01 & 5 \\
\hline Prefer Not to Say & 2.01 & 5 \\
\hline \multicolumn{3}{|l|}{ Race/Ethnicity } \\
\hline White/Caucasion & 67.47 & 168 \\
\hline Black/African American & 16.87 & 42 \\
\hline Hispanic/Latino & 3.21 & 8 \\
\hline Asian/Asian American & 6.02 & 15 \\
\hline
\end{tabular}




\begin{tabular}{|c|c|c|}
\hline American Indian/Alaska Native & 0 & 0 \\
\hline Native Hawaiian/Pacific Islander & 0 & 0 \\
\hline Another Race & 1.2 & 3 \\
\hline Prefer Not to Say & 5.22 & 13 \\
\hline \multicolumn{3}{|l|}{ Education Level } \\
\hline High School & 13.25 & 33 \\
\hline Some College & 19.68 & 49 \\
\hline Associate's Degree & 6.08 & 15 \\
\hline Professional Degree & 8.43 & 21 \\
\hline Bachelor's Degree & 32.93 & 82 \\
\hline Graduate Degree & 19.68 & 49 \\
\hline \multicolumn{3}{|l|}{ Marital Status } \\
\hline Single & 31.33 & 78 \\
\hline Married & 50.60 & 126 \\
\hline Domestic Partnership & 5.22 & 13 \\
\hline Widow & 4.02 & 10 \\
\hline Divorced & 6.02 & 15 \\
\hline Separated & 0.80 & 2 \\
\hline Prefer Not to Say & 2.01 & 5 \\
\hline \multicolumn{3}{|l|}{ Child(ren) Under 18 yo } \\
\hline Yes & 34.94 & 87 \\
\hline No & 65.06 & 162 \\
\hline \multicolumn{3}{|l|}{ Total Household Income } \\
\hline$<\$ 15,000$ & 1.61 & 4 \\
\hline Between 15,000-29,999 & 11.65 & 29 \\
\hline Between 30,000-49,999 & 13.65 & 34 \\
\hline Between 50,000-74,999 & 20.88 & 52 \\
\hline Between 75,000-99,999 & 233.69 & 59 \\
\hline Between 100,000-150,000 & 15.66 & 39 \\
\hline Over 150,000 & 12.85 & 32 \\
\hline
\end{tabular}




\section{APPENDIX E}

\begin{tabular}{|c|c|c|}
\hline \multicolumn{3}{|c|}{ Demographic Information for Walking Patrol Area from Community Survey } \\
\hline & \multicolumn{2}{|c|}{ Participants $(\mathrm{n}=249)$} \\
\hline & $\%$ & \# \\
\hline \multicolumn{3}{|l|}{ Neighborhood Status } \\
\hline Resident & 41.51 & 44 \\
\hline Employee & 44.34 & 47 \\
\hline Both & 14.15 & 15 \\
\hline \multicolumn{3}{|l|}{ Time in Neighborhood } \\
\hline$<1$ year & 8.49 & 9 \\
\hline $1-3$ years & 32.08 & 34 \\
\hline 4-6 years & 19.81 & 21 \\
\hline $7-9$ years & 14.15 & 15 \\
\hline 10 or more & 25.47 & 27 \\
\hline \multicolumn{3}{|l|}{ Age } \\
\hline $18-24$ & 24.53 & 26 \\
\hline $25-34$ & 16.98 & 18 \\
\hline $35-44$ & 22.64 & 24 \\
\hline $45-54$ & 20.75 & 22 \\
\hline $55-64$ & 11.32 & 12 \\
\hline $65+$ & 3.77 & 4 \\
\hline \multicolumn{3}{|l|}{ Gender } \\
\hline Male & 41.51 & 44 \\
\hline Female & 56.60 & 60 \\
\hline Other & 0 & 0 \\
\hline Prefer Not to Say & 1.89 & 2 \\
\hline \multicolumn{3}{|l|}{ Race/Ethnicity } \\
\hline White/Caucasian & 58.49 & 62 \\
\hline Black/African American & 22.64 & 24 \\
\hline Hispanic/Latino & 4.72 & 5 \\
\hline Asian/Asian American & 7.55 & 8 \\
\hline American Indian/Alaska Native & 0 & 0 \\
\hline Native Hawaiian/Pacific Islander & 0 & 0 \\
\hline Another Race & 0 & 0 \\
\hline Prefer Not to Say & 6.6 & 7 \\
\hline \multicolumn{3}{|l|}{ Education Level } \\
\hline $\begin{array}{r}\text { High School } \\
\end{array}$ & 16.98 & 18 \\
\hline Some College & 32.08 & 34 \\
\hline
\end{tabular}




\begin{tabular}{|c|c|c|}
\hline Associate's Degree & 7.55 & 8 \\
\hline Professional Degree & 10.38 & 11 \\
\hline Bachelor's Degree & 28.30 & 30 \\
\hline Graduate Degree & 4.72 & 5 \\
\hline Single & & 49 \\
\hline Married & 46.23 & 38 \\
\hline Domestic Partnership & 35.85 & 9 \\
\hline Widow & 8.49 & 4 \\
\hline Divorced & 3.77 & 3 \\
\hline Separated & 2.83 & 0 \\
\hline Prefer Not to Say & 0 & 3 \\
\hline Yes & 2.83 & 30 \\
\hline No & & 76 \\
\hline Child(ren) Under 18 yo & 28.30 & 3 \\
\hline Total Household Income & 71.70 & 24 \\
\hline Between 15,000-29,999 & & 16 \\
\hline Between 30,000-49,999 & 2.83 & 19 \\
\hline Between 50,000-74,999 & 22.64 & 22 \\
\hline Between 75,000-99,999 & 15.09 & 16 \\
\hline Between 100,000-150,000 & 17.92 & 6 \\
\hline Over 150,000 & 20.75 & 15.09 \\
\hline
\end{tabular}




\section{CURRICULUM VITA}

Jennifer Lee Hall

\section{Education}

2015-present

2011-2015

2001-2005

University of Louisville, PhD student, Department of Sociology-expected

University of Louisville, M.S. Sociology

Eastern Kentucky University, B.S. Criminal Justice, A.S. Emergency

Medical Care

\section{Professional Experience}

2019 to present

2019 to 2020

2016-2019

2011-2015

2006-2010
Louisville Metro Police Department

Training Division/Special Projects

Train sworn and non-sworn personnel, coordinate field training, prepare in-service training curriculum

University of Louisville

Research Assistant

Scheduling and completing interviews, maintaining documents, coding transcripts

Louisville Metro Police Department

Crimes Against Children Detective

Criminal investigations in relation to sexual and physical abuse of children, case file preparation, interviews, interrogations, crime scene processing, and courtroom presentations

Louisville Metro Police Department

Division Detective

Criminal investigations in relation to felony and misdemeanor cases, case file preparation, interviews, interrogations, crime scene procession, and courtroom presentations

Louisville Metro Police Department Patrol Officer 
Respond to calls for service, complete reports, evidence collection, and courtroom presentations

2003-2006

King's Daughters' Hospital

Paramedic

Patient care and treatment, drug administration, documentation, communication to hospital staff, long distance transports

\section{Achievements and Awards}

2020

2015

2011

2010

2009
Two Letters of Commendation, LMPD

Outstanding Research Award, University of Louisville

Community Letter of Commendation, LMPD

Meritorious Unit Citation, LMPD

Lifesaving Award, LMPD

\section{Research Experience}

Master's Thesis, University of Louisville

Food Safety: Analyzing the Connection between Government and Industrial Influence

\section{Presentations}

Mid-South Sociological Association Annual Conference 2017

Indiana Academy of the Social Sciences Annual Meeting 2018 